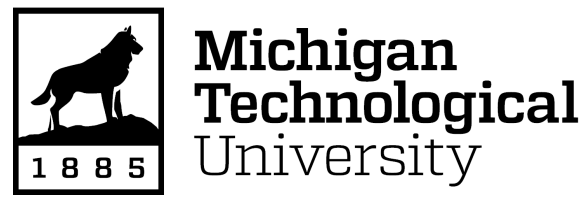

Michigan Technological University Digital Commons @ Michigan Tech

\title{
THE EFFECTS OF MOLYBDENUM, CHROMIUM, AND NIOBIUM ON GRAY IRON FOR BRAKE ROTOR APPLICATIONS
}

Matthew Hasbrouck

Michigan Technological University, mshasbro@mtu.edu

Copyright 2021 Matthew Hasbrouck

\section{Recommended Citation}

Hasbrouck, Matthew, "THE EFFECTS OF MOLYBDENUM, CHROMIUM, AND NIOBIUM ON GRAY IRON FOR BRAKE ROTOR APPLICATIONS", Open Access Master's Thesis, Michigan Technological University, 2021.

https://doi.org/10.37099/mtu.dc.etdr/1292

Follow this and additional works at: https://digitalcommons.mtu.edu/etdr

Part of the Automotive Engineering Commons, and the Metallurgy Commons 
THE EFFECTS OF MOLYBDENUM, CHROMIUM, AND NIOBIUM ON GRAY IRON FOR BRAKE ROTOR APPLICATIONS

\author{
By
}

Matthew Hasbrouck

\begin{abstract}
A THESIS
Submitted in partial fulfillment of the requirements for the degree of MASTER OF SCIENCE

In Materials Science and Engineering
\end{abstract}

MICHIGAN TECHNOLOGICAL UNIVERSITY

2021

C 2021 Matthew Hasbrouck 
This thesis has been approved in partial fulfillment of the requirements for the Degree of MASTER OF SCIENCE in Materials Science and Engineering.

Department of Materials Science and Engineering

Thesis Advisor: $\quad$ Dr. Paul Sanders

Committee Member: Dr. Douglas Swenson

Committee Member: Dr. Stephen Kampe

Department Chair: Dr. Walter Milligan 


\section{Table of Contents}

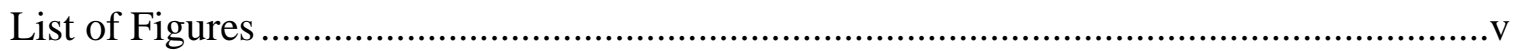

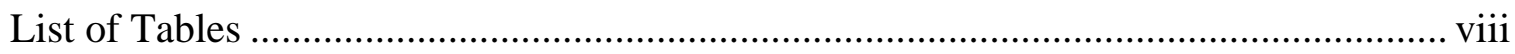

Acknowledgements .......................................................................................... ix

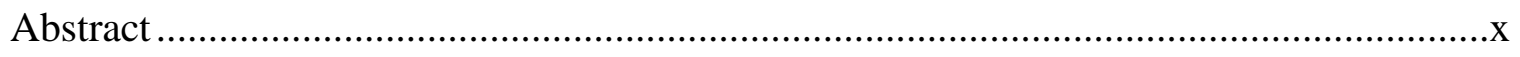

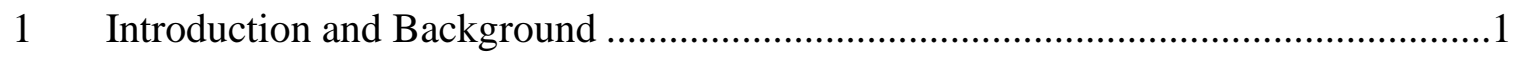

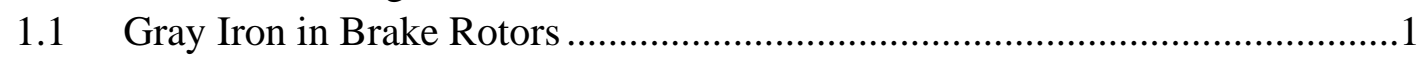

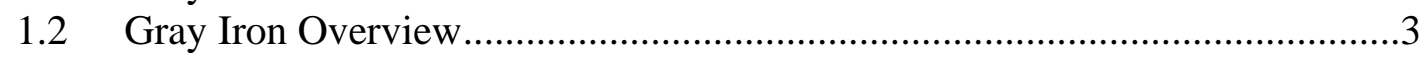

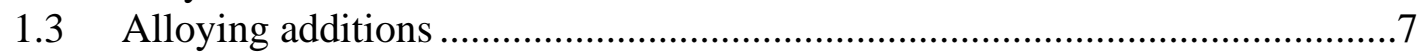

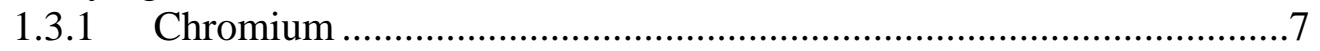

1.3.2 Molybdenum ..................................................................................

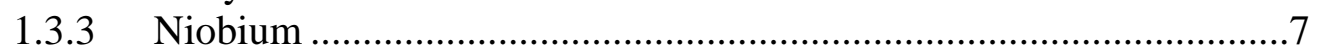

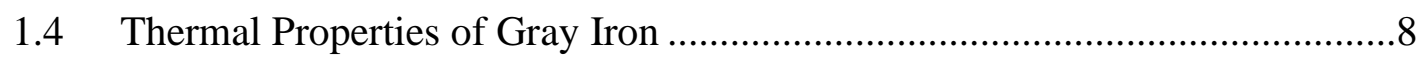

1.4.1 Hypothesis..................................................................................

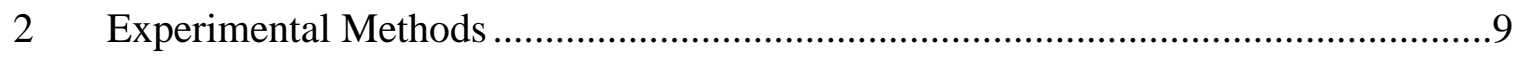

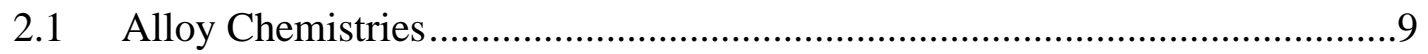

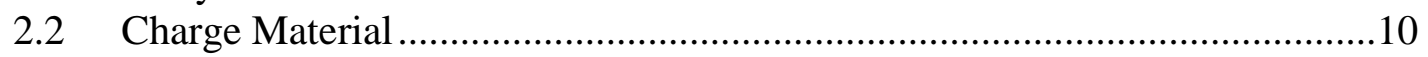

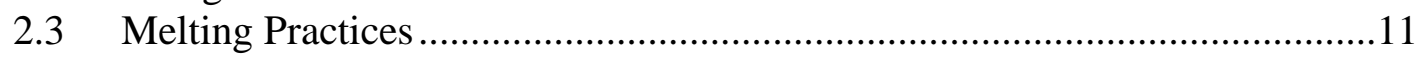

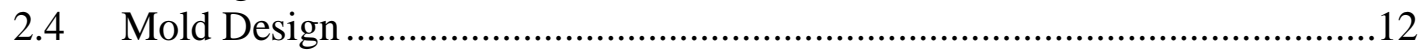

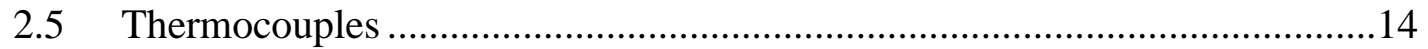

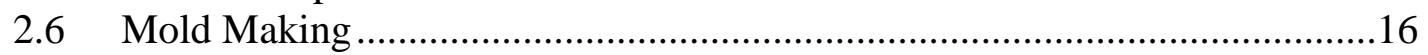

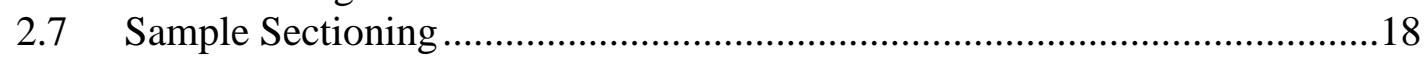

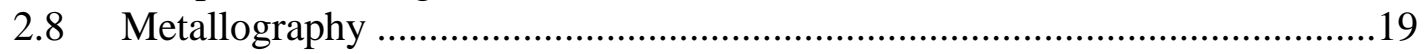

2.9 Graphite Analysis ...........................................................................19

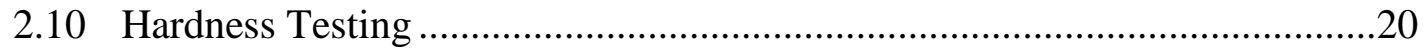

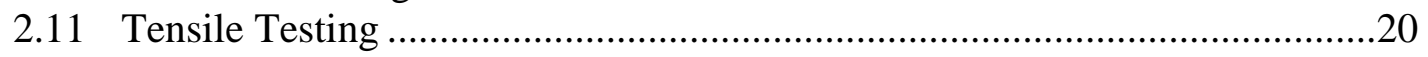

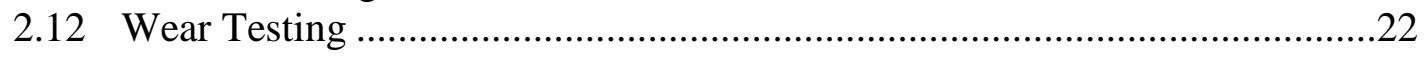

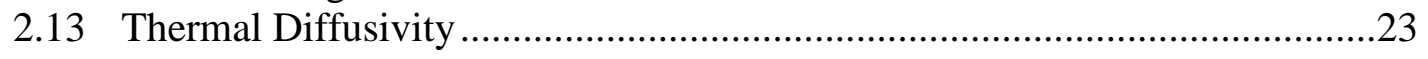

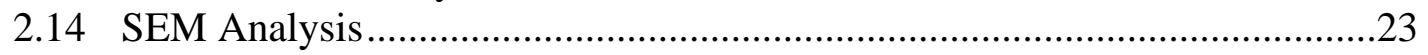

2.15 Electrical Resistivity ...........................................................................25

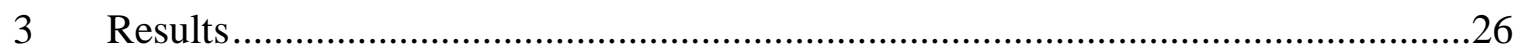

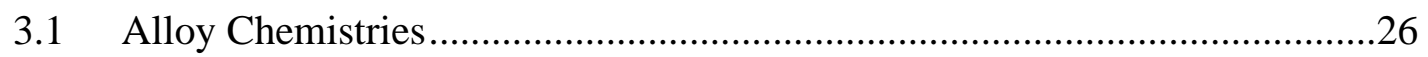

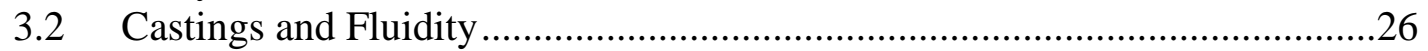

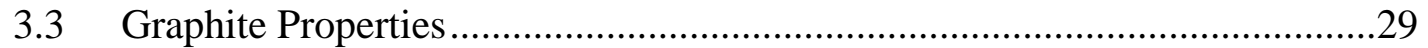

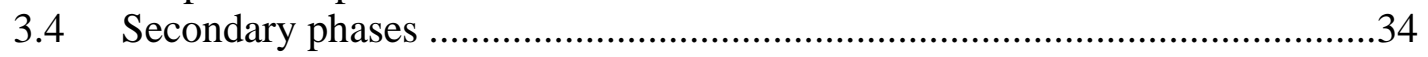

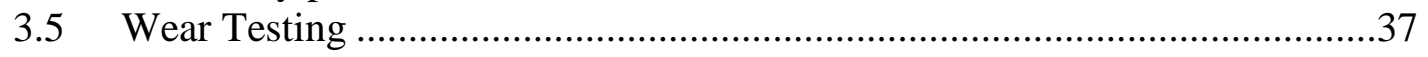

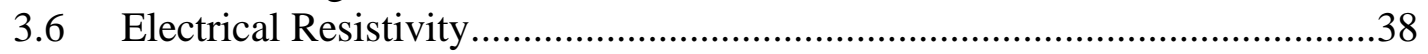

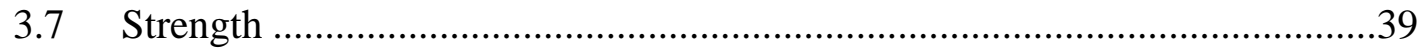




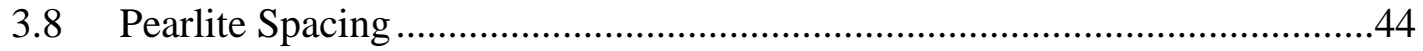

3.9 Thermal Diffusivity ..............................................................................45

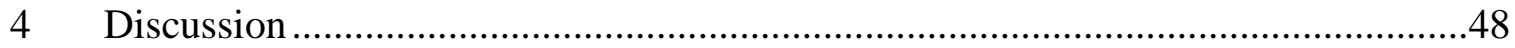

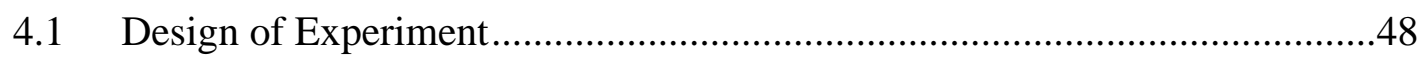

4.2 Graphite Flake Properties .......................................................................49

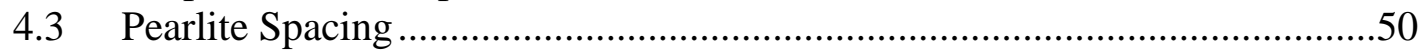

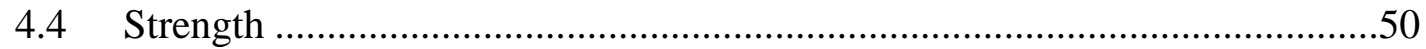

4.5 Resistivity and Strength........................................................................52

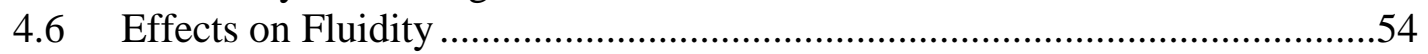

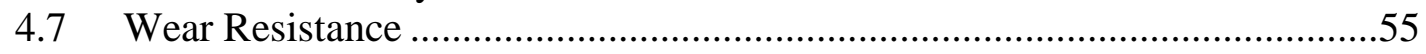

4.8 Thermal diffusivity ..............................................................................56

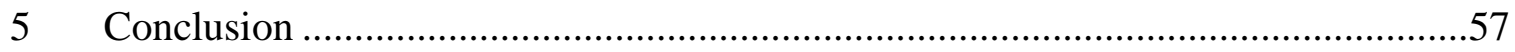

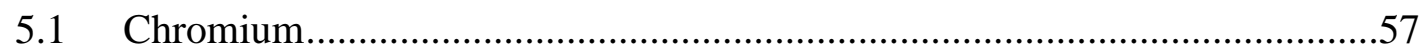

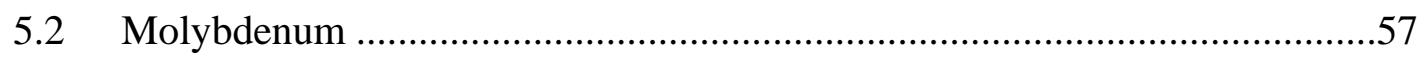

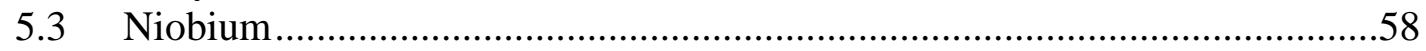

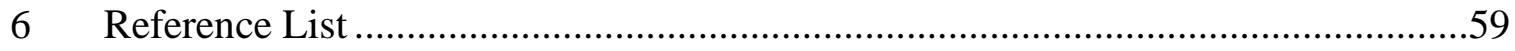

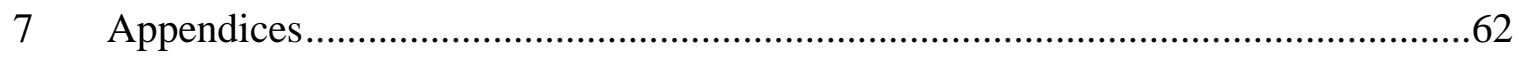

7.1 Appendix A: Charge Chemistries.............................................................62

7.2 Appendix B: Cooling Curves ............................................................63

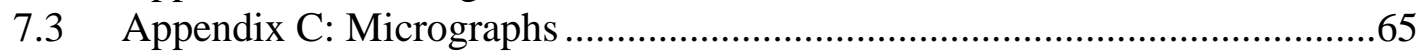

7.4 Appendix D: High Temperature Tensile Strength .......................................72 


\section{List of Figures}

Figure 1.1.1. The mechanism causing thermal-mechanical cracking [4]. ........................1

Figure 1.1.2. Surface cracks on rotor after intense use [5]. .........................................

Figure 1.2.1. Iron carbon phase diagram including the metastable iron-cementite diagram (dotted line) [14].

Figure 1.2.2. Left: unetched micrograph clearly showing graphite flakes in gray iron.

Right: etched micrograph revealing a mixed pearlitic-ferritic matrix [17].............5

Figure 1.2.3. Graphite flake morphology classification based on ASTM A247 [19].........6

Figure 2.2.1. Alloying additions used to meet individual chemistries specs...................11

Figure 2.4.1. Illustration of the two different bar castings produced for each alloy and

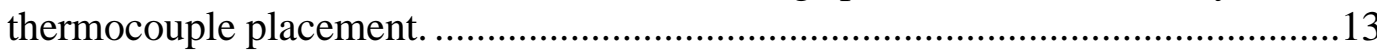

Figure 2.4.2. Fluidity casting geometry poured at the end of each casting run...............14

Figure 2.5.1. Quartz encapsulated thermocouples used to measure casting temperature..14

Figure 2.5.2. Illustration of how thermocouples were placed in the mold. 15

Figure 2.5.3. The extrapolated portion of the NIST type-K thermocouple table used to

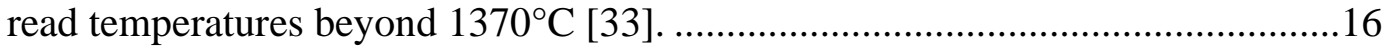

Figure 2.6.1. Bar mold prep with ceramic filters, venting, and a bead of CoreWeld........17

Figure 2.6.2. Mold prep for fluidity mold with CoreWeld used to seal around

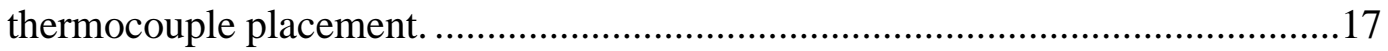

Figure 2.7.1. Illustration of how castings were sectioned to create various test specimens...18

Figure 2.11.1. Grips made to speed up the tensile testing process. ...............................21

Figure 2.11.2. Left: thermocouple placement in tensile bar. Right: 13 bars with zirconia

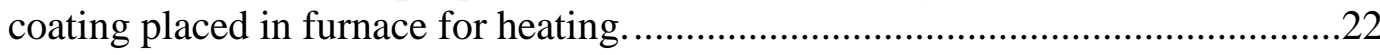

Figure 2.14.1. Example process image from a custom MATLAB program used to measure pearlite spacing.. .24

Figure 3.2.1. Example of castings produced from each heat after sandblasting..............27

Figure 3.2.2. Fluidity castings produced for each alloy...............................................28

Figure 3.3.1. Mean flake spacing measured from the $30 \mathrm{~mm}$ bar using the circular grid

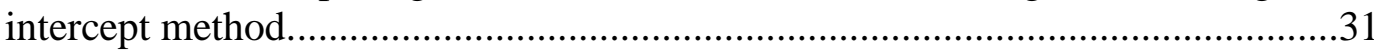

Figure 3.3.2. Percent graphite measured as a function of section size. ...........................31

Figure 3.3.3. Mean flake length measured for each section size...................................32

Figure 3.3.4. Max flake length for each section. .........................................................33

Figure 3.3.5. Graphite flake aspect ratio (length/width) for each section size. .................33 
Figure 3.4.1. Backscatter electron images of the $30 \mathrm{~mm}$ bar for alloy 8 (left) and alloy 10 (right)....

Figure 3.4.2. Backscatter electron images of the $30 \mathrm{~mm}$ bar for alloy 11 (left) and alloy 13 (right). 35

Figure 3.4.3. Example of phase appearance under optical microscopy at 500X. .36

Figure 3.4.4. FE-SEM secondary electron image of cementite and eutectic niobium carbides $(\mathrm{NbC})$.. .36

Figure 3.5.1. ASTM G65 sand abrasion wear testing on the $30 \mathrm{~mm}$ bar for each alloy....37

Figure 3.5.2. Coefficient of friction measured during sand abrasion wear testing on the 30 $\mathrm{mm}$ bar from each alloy. .38

Figure 3.6.1. Electrical resistivity of the $30 \mathrm{~mm}$ bar sections measured using the 4-point probe technique. .39

Figure 3.7.1. Brinell hardness of the $30 \mathrm{~mm}$ bar.

Figure 3.7.2. Vickers hardness of the matrix microconstituent for the $30 \mathrm{~mm}$ section of each alloy....

Figure 3.7.3. Ultimate tensile strength vs temperature for ASTM E8 standard 0.5 in tensile rounds machined from the $22 \mathrm{~mm}$ bar sections of each alloy.

Figure 3.7.4. Room temperature ultimate tensile strength measured from ASTM E8 standard 0.5 in tensile rounds machined from the $22 \mathrm{~mm}$ bar sections of each alloy.

Figure 3.7.5. Modulus data for the high CE alloys calculated using the secant method...44

Figure 3.8.1. True mean pearlite spacing estimated from mean random spacing measurements of cementite using the circular grid intersection technique on FESEM images.

Figure 3.9.1. Thermal diffusivity measured from the $30 \mathrm{~mm}$ bars at temperatures from $100-500^{\circ} \mathrm{C}$

Figure 3.9.2. Thermal diffusivity at $100^{\circ} \mathrm{C}$ for all alloys measured from the $30 \mathrm{~mm}$ bars.....47

Figure 4.2.1. Main effects plots for mean graphite flake length.

Figure 4.3.1. Main effects plot for the true mean pearlite spacing measured from the 30 mm bars.

Figure 4.4.1. Main effects plots for Brinell hardness measured from the $30 \mathrm{~mm}$ bars......51

Figure 4.4.2. Main effects plots for Vickers microhardness conducted on the matrix microconstituent, pearlite, in the $30 \mathrm{~mm}$ bars.

Figure 4.4.3. Main effects plots for tensile strength of the $22 \mathrm{~mm}$ bars at room temperature. .52

Figure 4.5.1. Main effects plots for electrical resistivity measured from the $30 \mathrm{~mm}$ bars......53 
Figure 4.5.2. The power law correlation observed between tensile strength and electrical resistivity....

Figure 4.6.1. Main effects for the fluidity as measured using a custom 6-finger fluidity mold .55

Figure 4.7.1. Main effects plots for amount of wear experienced during sand abrasion wear testing on the $30 \mathrm{~mm}$ bars. .55

Figure 4.8.1. Main effects plots for thermal diffusivity at $100^{\circ} \mathrm{C}$ for the $30 \mathrm{~mm}$ bar........56

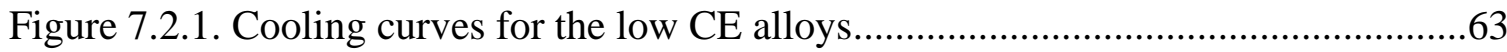

Figure 7.2.2. Cooling curves for the high CE alloys. ...............................................64

Figure 7.3.1. Representative micrographs of the different section sizes for alloy 1 .........65

Figure 7.3.2. Representative micrographs of the different section sizes for alloy 2 .........65

Figure 7.3.3. Representative micrographs of the different section sizes for alloy 3.........66

Figure 7.3.4. Representative micrographs of the different section sizes for alloy 4 .........66

Figure 7.3.5. Representative micrographs of the different section sizes for alloy 5.........67

Figure 7.3.6. Representative micrographs of the different section sizes for alloy $6 \ldots . . . . . .67$

Figure 7.3.7. Representative micrographs of the different section sizes for alloy 7.........68

Figure 7.3.8. Representative micrographs of the different section sizes for alloy 8.........68

Figure 7.3.9. Representative micrographs of the different section sizes for alloy $9 \ldots \ldots . . . .69$

Figure 7.3.10. Representative micrographs of the different section sizes for alloy $10 \ldots . . .69$

Figure 7.3.11. Representative micrographs of the different section sizes for alloy $11 \ldots . . .70$

Figure 7.3.12. Representative micrographs of the different section sizes for alloy $12 \ldots . . .70$

Figure 7.3.13. Representative micrographs of the different section sizes for alloy $13 \ldots . . .71$

Figure 7.4.1. High temperature ultimate tensile strength for all alloys measured using 0.5 in standard tensile rounds 


\section{List of Tables}

Table 1.2.1. A list of graphite promotors and carbide stabilizers normalized to the power of silicon [16].

Table 2.1.1. Target alloy chemistries for design of experiment. ........................................9

Table 2.1.2. Chemistry of the type standards used in OES analysis...................................

Table 2.2.1. Charge materials used as a base for each alloy..............................................10

Table 2.8.1. Polishing and etching steps for metallography...........................................19

Table 3.1.1. Final chemistries (wt $\%$ ) measured using type-standardized OES.................26

Table 3.2.1. Tapping temperatures, pouring temperatures, and finger fluidity

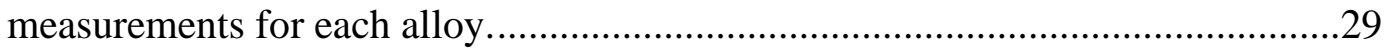

Table 3.3.1. Graphite properties measured for the $30 \mathrm{~mm}$ bar. ........................................30

Table 3.4.1. Precipitated phases found in the $30 \mathrm{~mm}$ bar of each alloy qualitatively evaluated using SEM-EDS. ..............................................................................

Table 4.1.1. Design of experiment analyzed in Minitab...................................................48

Table 7.1.1. Charge materials and chemistries as provided by vendor $\left(^{*}\right)$ or measured inhouse using OES...........................................................................................62 


\section{Acknowledgements}

I would like to thank Dr. Paul Sanders for his excellent advisership and leadership throughout this project. He has allowed me to work in a self-guided manner but has always been there with ideas and connections when needed.

This project would not have been possible without the financial support of CBMM and project foundation provided by Matthew Enloe and Gilberto Leal.

Thanks to my committee members, Dr. Stephen Kampe and Dr. Douglas Swenson, for their review work and material science knowledge which they are always eager to share.

Special thanks to Andrew Halonen (Mayflower Consulting) for his feedback and expertise on keeping up with current industry standards and practices.

I would like to thank Dr. Dale Dewald for his immense help in all foundry operations. He has always been very knowledgeable, helpful, and willing to pass that knowledge down. I especially appreciate his willingness to stay long evenings for a couple weeks straight to complete all the pours.

I would like to thank Jacob Longstreth for his machining expertise and always being available to make custom parts on the fly.

Thanks to Dr. Dan Seguin for being an excellent academic advisor and source of knowledge on polishing techniques.

Special thanks to Dr. Peter Moran for his consultation and many hours spent measuring thermal diffusivity and for setting up an effective way to measure electrical resistivity.

Thanks to Paul Fraley for his ideas on making tensile testing more efficient and for suggesting a grip design that worked quite well.

The long hours and late nights spent working on this project would not have been as bearable if it was not for the company of Brendan Treanore and Emily Tom. I would especially like to thank them for keeping us each in check and working through the grad school journey together. They have certainly made the experience more enjoyable and entertaining. 


\section{Abstract}

Brake rotor composition and microstructure must be optimized for thermal and mechanical performance to avoid thermal-mechanical cracking, excessive wear, and to reduce noise. Niobium is an element that increases the strength and wear resistance of gray iron; however, the interaction of niobium with other common alloying elements (chromium and molybdenum) is not well understood. Thirteen gray cast iron alloys were produced with varying levels of carbon equivalent $(\mathrm{CE}), \mathrm{Cr}$, Mo, and $\mathrm{Nb}$. Bars with four different diameters $(8,14,22$, and $30 \mathrm{~mm})$ were cast from each alloy and microstructural and physical properties such as graphite flake morphology, pearlite spacing, electrical resistivity, and thermal diffusivity were measured. Mechanical measurements included tensile testing from ambient up to $680^{\circ} \mathrm{C}$ and room temperature pearlite microhardness, macro Brinell hardness, and ASTM G65 sand abrasion wear testing. Fluidity was measured using a purpose-built finger mold. It was found that niobium refined the graphite morphology, reduced pearlite spacing, and precipitated eutectic $\mathrm{NbC}$. High CE rotors are attractive for their higher thermal and damping properties, but they have lower mechanical and wear properties than low CE iron. It was found that alloying high CE gray iron with small amounts of chromium and niobium can provide good mechanical and thermal properties while simultaneously increasing wear resistance. 


\section{Introduction and Background}

\subsection{Gray Iron in Brake Rotors}

Gray iron is the most widely cast material because of its useful properties and low cost. About 51 million metric tons of gray cast iron were produced globally in 2019 alone, accounting for $47 \%$ of all castings produced [1]. Gray iron is used to produce a wide variety of products ranging from cookware to vehicle components such as engine blocks, housing manifolds, cylinder heads, piston rings, hydraulic valve bodies, and brake rotors and drums. The properties of gray iron which are desirable for such applications are its excellent damping, thermal conductivity, and casting properties such as high fluidity and low shrink, dimensional stability, and machinability [2]. The main downsides of gray cast iron compared to its other highly produced counterpart, ductile iron, is its low tensile strength and lack of ductility due to an interconnected graphite flake morphology.

Gray cast iron is used for brake rotors primarily due its excellent thermal and damping properties which are required to prevent thermal-mechanical cracking (also known as heat check cracking) and minimized noise during brake operation. Cracks may develop after excessive braking from high speeds or quick deceleration. A compressive pressure of roughly $1.5 \mathrm{MPa}$ is exerted on the rotor from the pad during normal braking [3]. This leads to tremendous heat generation at the brake pad/rotor interface. During excessive braking, the temperature at the rotor surface can exceed $600^{\circ} \mathrm{C}$ with a thermal gradient of $330^{\circ} \mathrm{C}$ existing between the rotor surface and interior [4]. This thermal gradient can induce tensile stresses on the surface of the rotor when cooling due to uneven expansion and contraction of the surface and interior (Figure 1.1.1).

\section{Hypothetical compressive plastic deformation}

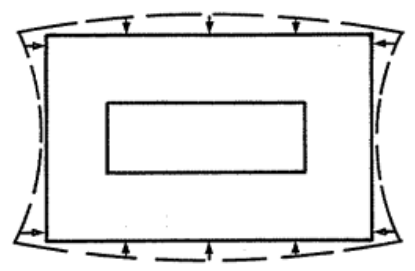

Early stage of braking
Tensile stress

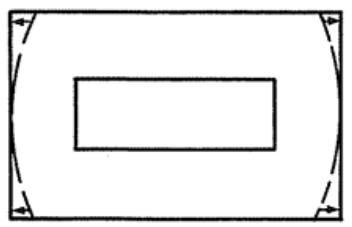

Cooling process
Crack formation

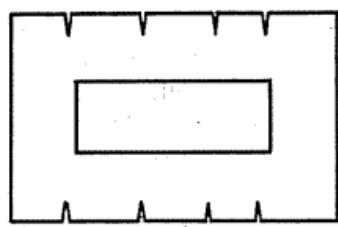

After braking

Figure 1.1.1 The mechanism causing thermal-mechanical cracking [4]. 
In some cases, these tensile forces exceed the strength of the material and cracks initiate at the surface and continue to grow with thermal-mechanical cycling (Figure 1.1.2).

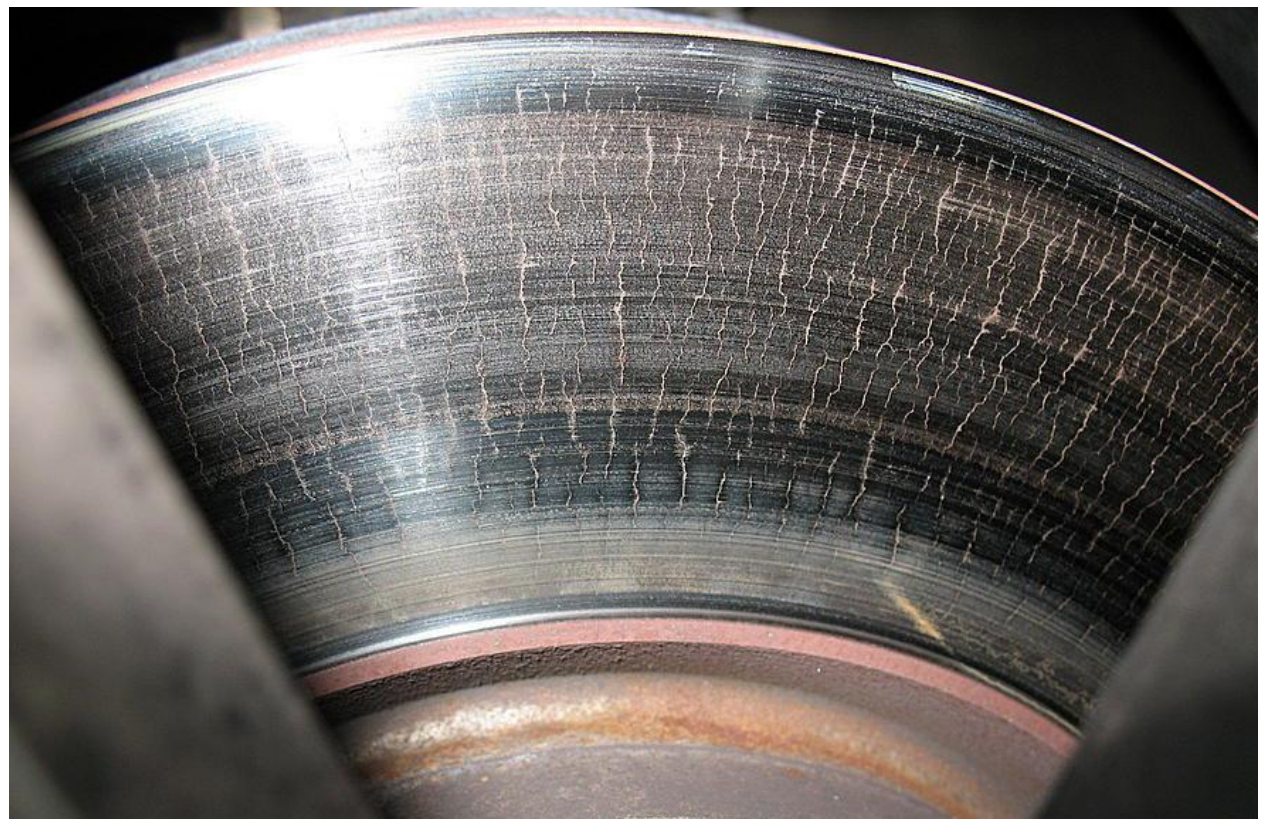

Figure 1.1.2 Surface cracks on rotor after intense use [5].

The easiest method to increase the thermal conductivity of gray iron is by increasing the carbon content or carbon equivalent (CE), which in turn increases the amount of graphite present in microstructure; however, this negatively effects mechanical properties such as strength and wear resistance. Niobium $(\mathrm{Nb})$ has the potential to negate the drawbacks of higher carbon and maintain strength and wear resistance. Niobium has been shown to increase strength by refining the microstructure and forming niobium carbides $(\mathrm{NbC})$ that also increase wear resistance [6]-[9]. Mercedes Benz AG was the first to patent $\mathrm{Nb}$ brake rotor technology in 1996 when searching for a gray iron brake rotor alloy that would last as long as drums on heavy duty vehicles [8]. The patent called for $0.38-0.45 \mathrm{wt} \%$ addition of $\mathrm{Nb}$ to buy back strength in high $\mathrm{CE}$ gray iron and this successfully reduced the formation of heat cracks while increasing wear resistance and mechanical properties.

Niobium has also been successfully incorporated into gray iron diesel engine cylinder heads to reduce cracking failures and improve mechanical properties [6]. A $0.2 \mathrm{wt} \%$ addition increased tensile strength by $18 \%$ and improved impact energy by $10 \%$. Niobium 
additions have also been proven to improve fatigue performance due to refinement of the microstructure [10].

In a more recent study in Brazil, nine busses were fit with drums alloyed with $0-0.33$ wt $\%$ $\mathrm{Nb}$ and driven for eight months for a combined total of 257,000 km (170,000 miles) with wear being evaluated at regular intervals [11]. A 5-15\% decrease in wear was observed at the end of each component's life for the 0.2 and $0.33 \mathrm{wt} \%$ alloyed drums. The same alloys were cast into rotors and tested on a dynamometer and a $40-50 \%$ reduction in wear was observed compared to $\mathrm{Nb}$-free rotors.

While niobium additions to gray iron have proven to be successful at increasing strength, hardness, and wear resistance, no study has been conducted to evaluate the interaction effects that may occur with other common alloying elements: chromium ( $\mathrm{Cr}$ ) and molybdenum (Mo). Furthermore, no study has been conducted to directly measure how these elements effect the thermal performance of gray iron. Chromium and molybdenum are strong carbide stabilizers and at higher concentrations can form carbides. Both have a refining effect on pearlite spacing which improves mechanical properties [12], [13]. Additions of molybdenum (Mo) produce higher strength at elevated temperature and have an improved resistance to heat crack formation [4].

In this study, 13 alloys with varying $\mathrm{CE}, \mathrm{Cr}, \mathrm{Mo}$, and $\mathrm{Nb}$ were produced and tested. Microstructural and physical properties such as graphite flake morphology, pearlite spacing, and electrical resistivity were measured. Hardness, high temperature tensile, and sand abrasion measurements were made to evaluate mechanical properties. Thermal diffusivity was measured to assess thermal performance.

\subsection{Gray Iron Overview}

The solidification of gray cast iron is visualized in the iron-carbon phase diagram (Figure 1.2.1). Some elements typically found in cast irons, namely silicon and phosphorus, have a large impact on the effective iron-carbon eutectic point. These effects are accounted for in the carbon equivalent calculation (CE) shown in equation 1.2.1. The $\mathrm{CE}$ for gray iron is 
typically in the range of 3.8-4.6. Irons with a CE below 4.3 are termed hypoeutectic while irons above 4.3 are termed hypereutectic.

$$
C E=C(w t \%)+\frac{1}{3} S i(w t \%)+\frac{1}{3} P(w t \%)
$$

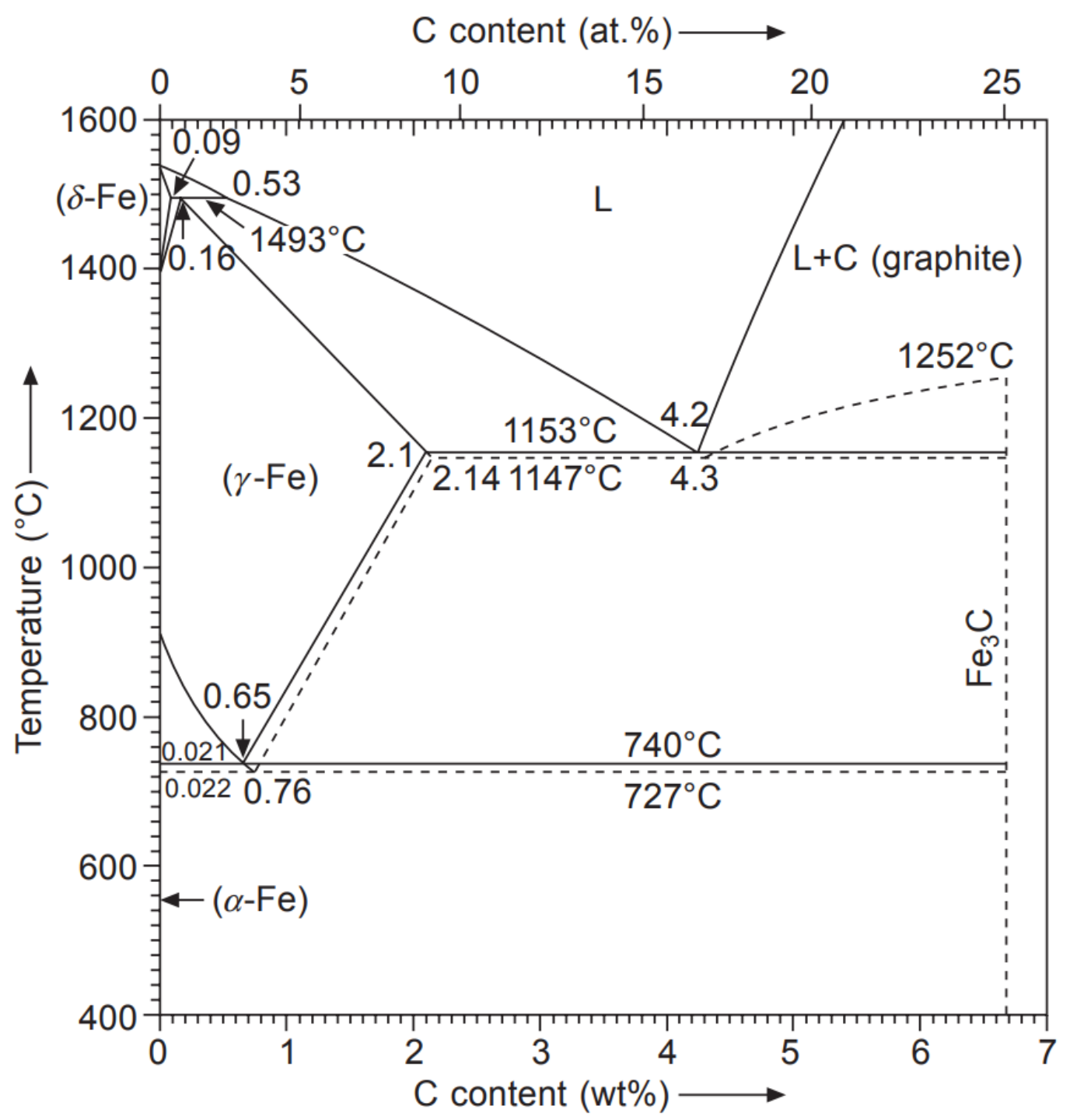

Figure 1.2.1 Iron carbon phase diagram including the metastable iron-cementite diagram (dotted line) [14].

Certain elements can shift the metastable portion of the iron-carbon phase diagram (see dotted line in Figure 1.2.1) making the gap between the iron-carbon eutectic temperature and iron-Fe ${ }_{3} \mathrm{C}$ eutectic larger or smaller. Elements that make this gap larger are 
characterized as graphitizers because they promote the formation of graphite. Elements that shrink the gap are considered carbide stabilizers and can lead to the formation of carbides during solidification [15]. A list of these elements can be found in Table 1.2.1 where their graphitizing power (+) or carbide stabilizing power (-) is ranked against silicon.

Table 1.2.1 A list of graphite promotors and carbide stabilizers normalized to the power of silicon [16].

\begin{tabular}{lcc}
\hline & Element & Graphitization value \\
\hline Graphitizes & $\mathrm{Si}$ & +1.00 \\
& $\mathrm{Al}$ & +0.50 \\
& $\mathrm{Ti}$ & +0.40 \\
& $\mathrm{Ni}$ & +0.35 \\
& $\mathrm{Cu}$ & +0.20 \\
Carbide stabilizers & $\mathrm{Mn}$ & -0.25 \\
& $\mathrm{Mo}$ & -0.30 \\
& $\mathrm{Cr}$ & -1.00 \\
& $\mathrm{~V}$ & -2.50 \\
\hline
\end{tabular}

Gray cast iron consists of graphite in the form of flakes (which are rosettes in 3D) dispersed throughout the matrix (Figure 1.2.2).
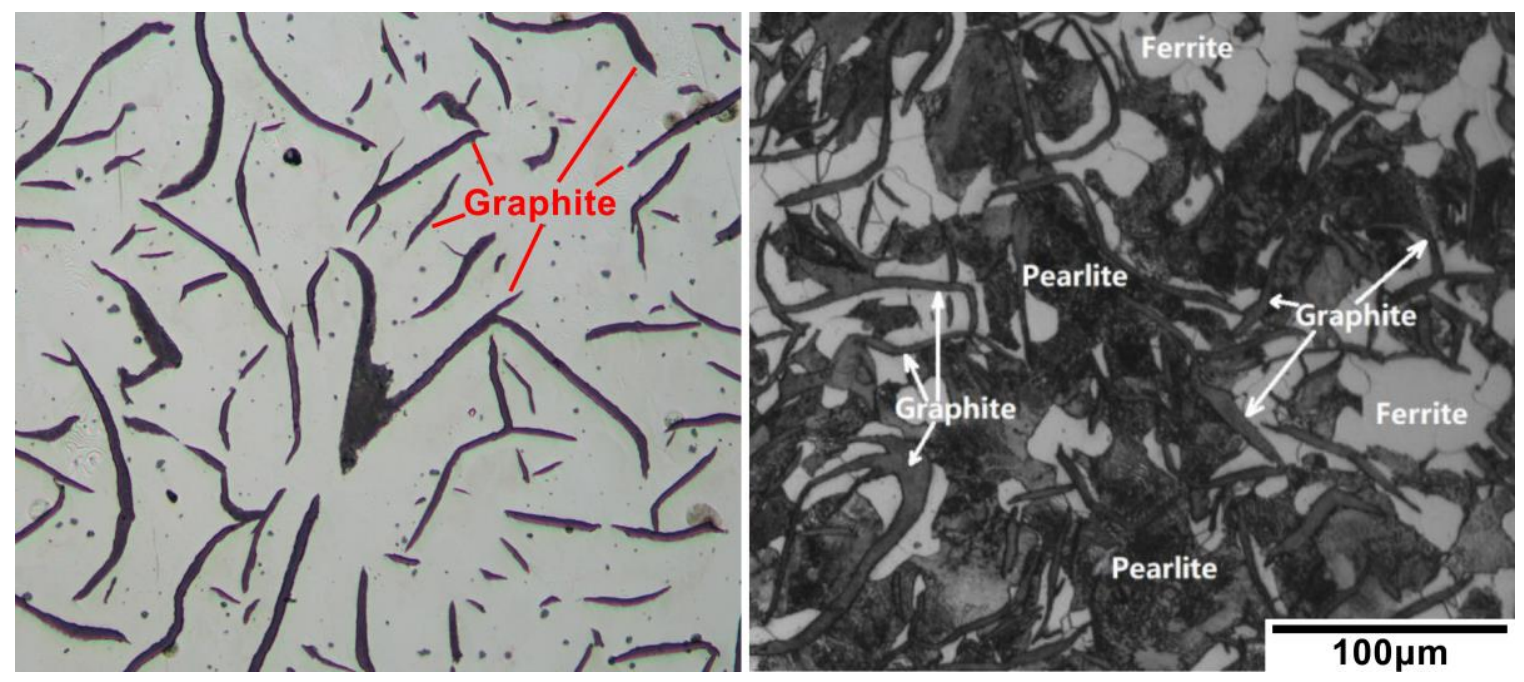

Figure 1.2.2 Left: unetched micrograph clearly showing graphite flakes in gray iron. Right: etched micrograph revealing a mixed pearlitic-ferritic matrix [17]. 
The graphite flake morphology can vary substantially based on cooling rate, inoculation, and constitutive elements. The American Society for Testing and Materials (ASTM) categorizes the different morphologies commonly observed in gray iron in ASTM A247 [18]. Evenly dispersed type A flakes are desirable because they promote thermal and mechanical properties. Faster cooling rates during solidification, as with small section sizes, can lead to degenerate interdendritic graphite flakes characterized as type $\mathrm{C}$ or type E (Figure 1.2.3).
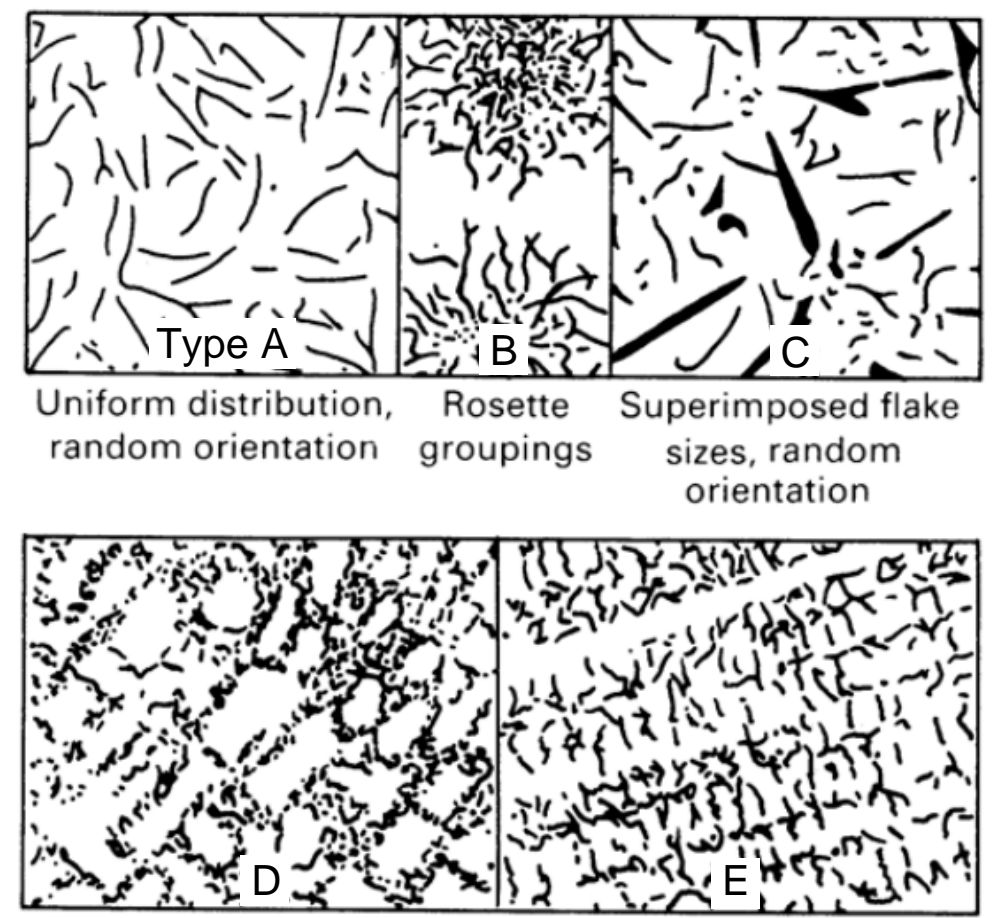

Interdendritic segregation, Interdendritic segregation, random orientation preferred orientation

Figure 1.2.3 Graphite flake morphology classification based on ASTM A247 [19].

The matrix of gray iron can be pearlitic, ferritic, or a mixture of the two (Figure 1.2.2). Ferrite ( $\alpha$ iron) is softer and more malleable than pearlite, leading to more ductility. Pearlite, which is alternating plates (lamellae) of ferrite and cementite $\left(\mathrm{Fe}_{3} \mathrm{C}\right)$ is much stronger, harder, and more wear resistant than ferrite but is also more brittle. 


\subsection{Alloying additions}

\subsubsection{Chromium}

Chromium can remain in solid solution with iron but is a strong carbide former and promotor. Chromium refines pearlite which in turn increases hardness, strength, and wear resistance. In high concentrations, $\mathrm{Cr}$ can increase creep resistance and high temperature stability and well as corrosion resistance [13], [20].

\subsubsection{Molybdenum}

Molybdenum hardens ferrite and strongly increases the hardenability of austenite. It is a carbide stabilizer (not as strong as chromium) and when in high enough concentrations, it can form carbides. Additions up to $0.5 \mathrm{wt} \%$ refine pearlite without effecting graphite morphology. Molybdenum also improves high temperature strength and creep resistance as well as thermal-mechanical fatigue life [12], [20], [21].

\subsubsection{Niobium}

Niobium has been shown to have several refining effects when alloyed with gray iron. Since the solubility of $\mathrm{Nb}$ is very small in austenite, $<0.1 \mathrm{wt} \%$ at $1200^{\circ} \mathrm{C}$, it has a propensity to form very hard (2400HV) niobium carbides of the MC type [7]. Additions above 0.1 wt\% can form primary carbides which act as nucleation sites for graphite [7]. This inoculating effect results in a refinement of the graphite structure with a decrease in flake length as well as an increase in eutectic cell count [6], [7], [9], [11]. Niobium interacts with carbon in the melt reducing the transformation temperature for pearlite and increasing eutectoid supercooling, resulting in finer pearlite. These combined effects improve strength, hardness, and wear resistance with the formation of $\mathrm{NbC}$ contributing significantly. Although the formation of primary niobium carbides is possible with $>0.1$ $\mathrm{wt} \% \mathrm{Nb}$, the temperature of formation is only $4^{\circ} \mathrm{C}$ above the eutectic at a concentration of $0.29 \mathrm{wt} \%$ [9]. This means blocky primary carbides are often rarely seen optically; rather, eutectic X-Y-shaped carbides are more likely to form in the last-to-solidify regions [6]. In higher concentrations such as $0.85 \mathrm{wt} \%$, the temperature of formation is much higher, exceeding $150^{\circ} \mathrm{C}$ above the eutectic temperature, allowing plenty of time for primary $\mathrm{NbC}$ to nucleate, combine, and grow before graphite begins to nucleate [9]. This tends to reverse 
the graphite refining effects since fewer, larger nuclei have limited graphite nucleation benefits. Furthermore, the increase in mechanical properties tends to plateau at $0.2 \mathrm{wt} \%$ $\mathrm{Nb}$, implying a sweet spot of approximately $0.2 \mathrm{wt} \%$ exists to achieve a balance between refining effects and mechanical property improvements [7].

\subsection{Thermal Properties of Gray Iron}

The susceptibility of gray iron to thermal-mechanical cracking is a function of its heat dissipation. Thermal performance can be characterized by thermal diffusivity $(\alpha)$, which quantifies how quickly the material absorbs and spreads heat via heat capacity $\left(C_{p}\right)$ and thermal conductivity $(k)(1.4 .1)$. Thermal conductivity and diffusivity have been measured at room temperature and elevated temperatures on various gray irons, and often can be used interchangeably to gauge thermal performance since changes in density $(\rho)$ and heat capacity generally offset each other [22]-[24].

$$
\alpha=\frac{k}{\rho C_{p}}
$$

Gray iron has a high thermal diffusivity when compared to steels and other forms of cast iron due to the flake graphite morphology. Graphite has high thermal conductivity of 293$419 \mathrm{~W} / \mathrm{mK}$ in the basal plane and $84 \mathrm{~W} / \mathrm{mK}$ along the c-axis. Ferrite and pearlite have thermal conductivities of 71-80 W/mK and $25 \mathrm{~W} / \mathrm{mK}$, respectively [25], [26]. Hence, the graphite flakes, which extend along the basal plane, act as heat conduits throughout the material and the spacing from flake to flake is largely what determines thermal diffusivity. Long, type A flakes, produced with good inoculation and slow cooling, are best at increasing thermal diffusivity [22], [23], [27], [28]. Increasing CE also reduces the flaketo-flake spacing because of the presence of more graphite; however, this can also lead to a reduction in mechanical properties.

\subsubsection{Hypothesis}

If $\mathrm{CE}$ is increased while alloying preferentially with $\mathrm{Nb}$, then the thermal properties of gray iron can be improved without sacrificing mechanical or wear properties, because of the microstructural refining effects of $\mathrm{Nb}$ and the formation of hard $\mathrm{NbC}$ precipitates. 


\section{Experimental Methods}

\subsection{Alloy Chemistries}

Twelve different alloy chemistries were proposed to evaluate the interaction effects of $\mathrm{Cr}$, Mo, and $\mathrm{Nb}$ (Table 2.1.1). Six of the 12 chemistries were classified as high $\mathrm{CE}$ while the other six were low $\mathrm{CE}$. Within these two groups, $\mathrm{Cr}, \mathrm{Mo}$, and $\mathrm{Nb}$ had two levels while all other elements were held constant.

Table 2.1.1 Target alloy chemistries for design of experiment. All compositions are given in weight percent.

\begin{tabular}{ccccccccccccc}
\hline Alloy & Classification & $\mathbf{C}$ & $\mathbf{S i}$ & $\mathbf{P}$ & $\mathbf{C u}$ & $\mathbf{M n}$ & $\mathbf{C r}$ & $\mathbf{S n}$ & $\mathbf{S}$ & $\mathbf{M o}$ & $\mathbf{N b}$ & $\mathbf{C E}$ \\
\hline 1 & Low CE & 3.36 & 1.8 & 0.03 & 0.25 & 0.70 & 0.25 & 0.00 & 0.085 & 0.00 & 0.00 & 3.97 \\
2 & Low CE & 3.36 & 1.8 & 0.03 & 0.25 & 0.70 & 0.25 & 0.00 & 0.085 & 0.00 & 0.12 & 3.97 \\
3 & Low CE & 3.36 & 1.8 & 0.03 & 0.25 & 0.70 & 0.45 & 0.00 & 0.085 & 0.00 & 0.12 & 3.97 \\
4 & Low CE & 3.36 & 1.8 & 0.03 & 0.25 & 0.70 & 0.25 & 0.00 & 0.085 & 0.35 & 0.00 & 3.97 \\
5 & Low CE & 3.36 & 1.8 & 0.03 & 0.25 & 0.70 & 0.25 & 0.00 & 0.085 & 0.35 & 0.12 & 3.97 \\
6 & Low CE & 3.36 & 1.8 & 0.03 & 0.25 & 0.70 & 0.45 & 0.00 & 0.085 & 0.35 & 0.12 & 3.97 \\
7 & High CE & 3.72 & 1.95 & 0.05 & 0.25 & 0.70 & 0.25 & 0.00 & 0.085 & 0.00 & 0.00 & 4.39 \\
8 & High CE & 3.72 & 1.95 & 0.05 & 0.25 & 0.70 & 0.25 & 0.00 & 0.085 & 0.00 & 0.22 & 4.39 \\
9 & High CE & 3.72 & 1.95 & 0.05 & 0.25 & 0.70 & 0.55 & 0.00 & 0.085 & 0.00 & 0.22 & 4.39 \\
10 & High CE & 3.72 & 1.95 & 0.05 & 0.25 & 0.70 & 0.25 & 0.00 & 0.085 & 0.43 & 0.00 & 4.39 \\
11 & High CE & 3.72 & 1.95 & 0.05 & 0.25 & 0.70 & 0.25 & 0.00 & 0.085 & 0.43 & 0.22 & 4.39 \\
12 & High CE & 3.72 & 1.95 & 0.05 & 0.25 & 0.70 & 0.55 & 0.00 & 0.085 & 0.43 & 0.22 & 4.39 \\
\hline
\end{tabular}

Melt chemistry was measured using optical emission spectroscopy (OES) using a Bruker Q4 TASMAN spectrometer. Two type standards were produced to calibrate the spectrometer to obtain more accurate results. The type standards were sent out to three independent labs (Lehigh Testing Laboratories, APL, and Element) for inductively coupled plasma OES and LECO carbon and sulfur analysis (Table 2.1.2).

Table 2.1.2 Chemistry of the type standards used in OES analysis. The values listed were carefully selected and averaged from the chemistries reported by three independent labs (wt\%).

\begin{tabular}{cccccccccccc}
\hline \multirow{2}{*}{ Classification } & $\begin{array}{c}\text { LECO } \\
\text { C }\end{array}$ & \multirow{2}{*}{ Si } & \multirow{2}{*}{$\mathbf{C u}$} & $\mathbf{M n}$ & $\mathbf{C r}$ & \multirow{2}{*}{ Sn } & $\begin{array}{c}\text { LECO } \\
\text { S }\end{array}$ & \multirow{2}{*}{ Mo } & Nb & CE \\
\hline Low CE & 3.31 & 1.72 & 0.035 & 0.27 & 0.80 & 0.22 & 0.004 & 0.052 & 0.03 & 0.072 & 3.89 \\
High CE & 3.71 & 1.89 & 0.035 & 0.26 & 0.83 & 0.22 & 0.005 & 0.052 & 0.40 & 0.250 & 4.35 \\
\hline
\end{tabular}




\subsection{Charge Material}

Approximately $23 \mathrm{~kg}(50 \mathrm{lbs}$ ) heats were produced for each alloy using the same base materials (Table 2.2.1) with varying alloy additions to meet each chemistry target. Approximately $60 \%$ of the charge was foundry returns with the remaining amount being scrape steel and pig iron to reflect common foundry charge practices.

Table 2.2.1 Charge materials used as a base for each alloy.

\begin{tabular}{lcc}
\hline Material & $\begin{array}{c}\text { Amount } \\
(\mathbf{k g})\end{array}$ & $\begin{array}{c}\text { Amount } \\
(\mathbf{l b s})\end{array}$ \\
\hline Gray Iron Bars (Neenah Foundry) & 13.27 & 29.25 \\
Pig Iron (Waupaca Foundry) & 4.08 & 9.00 \\
Steel Punchings (U-Metco) & 4.08 & 9.00 \\
Ductile Iron Risers (Waupaca Foundry) & 1.29 & 2.85 \\
Copper Scrap (scrap flange gaskets) & 0.001 & 0.003 \\
\hline
\end{tabular}

$\mathrm{FeCr}$, FeMo, FeMn, and $\mathrm{FeS}_{2}$ (Hickman, Williams \& Company) were used to tune $\mathrm{Cr}$, Mo, $\mathrm{Mn}$, and S levels, respectively. Silicon composition was met with the use of FeSi (Elkem) and FeNb fines (CBMM) were used to tune Nb levels (Figure 2.2.1). Desulco 9001 and 9018 (Hickman, Williams \& Company) were used to meet carbons levels. All additions were added to the base charge material (pig iron and returns) and blanketed with steel punchings. A near $100 \%$ recovery rate was obtained for the FeMo and FeNb additions when added in this way. Charge material chemistries and approximate granulometries can be found in Table 7.1.1 in Appendix A. 


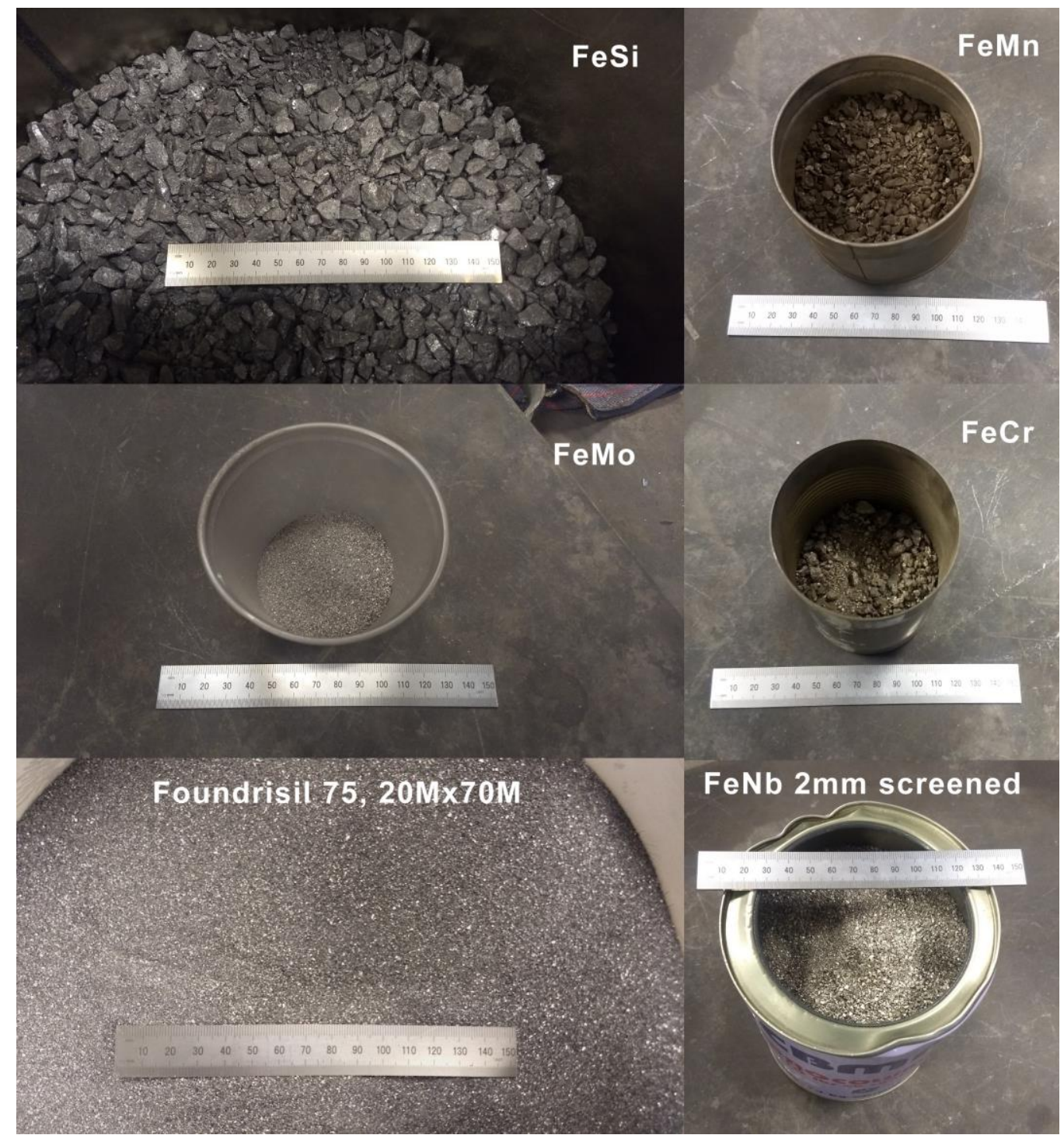

Figure 2.2.1 Alloying additions used to meet individual chemistries specs.

\subsection{Melting Practices}

Melting was conducted in a $23 \mathrm{~kg}(50 \mathrm{lb})$ Dura-Line induction furnace (Inductotherm) outfitted with a new liner to eliminate contamination from previous melts. It was determined early on that FeNb additions did not fully dissolve until the melt was heated to $1500^{\circ} \mathrm{C}$ and held for a short amount of time. As a result, a melting practice was developed where the melt was brought up to $1500^{\circ} \mathrm{C}$ and held for two minutes before dropping the temperature down to $\sim 1420^{\circ} \mathrm{C}$ for holding and chemistry corrections. After chemistry corrections, the furnace was quickly brought up to a target tapping temperature of $1500^{\circ} \mathrm{C}$ 
and then poured into a fiber ladle (Joy-Mark). Foundrisil 75 (Elkem) at $0.35 \mathrm{wt} \%$ was added instream while tapping from the furnace into the ladle. Castings were shaken out once all sections were below $500^{\circ} \mathrm{C}$, which was approximately 45 minutes after pouring.

\subsection{Mold Design}

A total of five castings were produced for each alloy, one bar casting with varying section sizes to evaluate the effects of cooling rate, three $22 \mathrm{~mm}$ bar castings primarily for tensile specimens, and one fluidity casting to measure the relative fluidity between alloys. All patterns utilized a parabolic sprue design following equation 2.4.1 to minimize air aspiration more effectively than a traditional tapered sprue. Equation 2.4.1 was derived using the Bernoulli relationship to calculate the sprue radius, $r$, as a function of height from the base of the sprue, $h$, the desired volumetric flow rate, $\dot{Q}$, and the gravitational constant, $g$, of $9.81 \mathrm{~m} / \mathrm{s}^{2}$. The volumetric flow rate was calculated based on a desired mold fill time of 4 - 5 seconds.

$$
r=\sqrt{\frac{\dot{Q}}{\pi \sqrt{2 g h}}}
$$

The mold with varying section sizes was instrumented with type-K thermocouples near the bottom of each bar $(8,14,22$, and $30 \mathrm{~mm}$ ) to collect cooling data (Figure 2.4.1). A thermocouple was also fit in the sprue well to record the initial pouring temperature. Ceramic filters (HIPERCAST by Hofmann Ceramic) were used on both sides of the runner to improve metal flow and cleanliness. Gating geometries were optimized based on results from filling simulations conducted in Inspire Cast (V2020, Altair). 


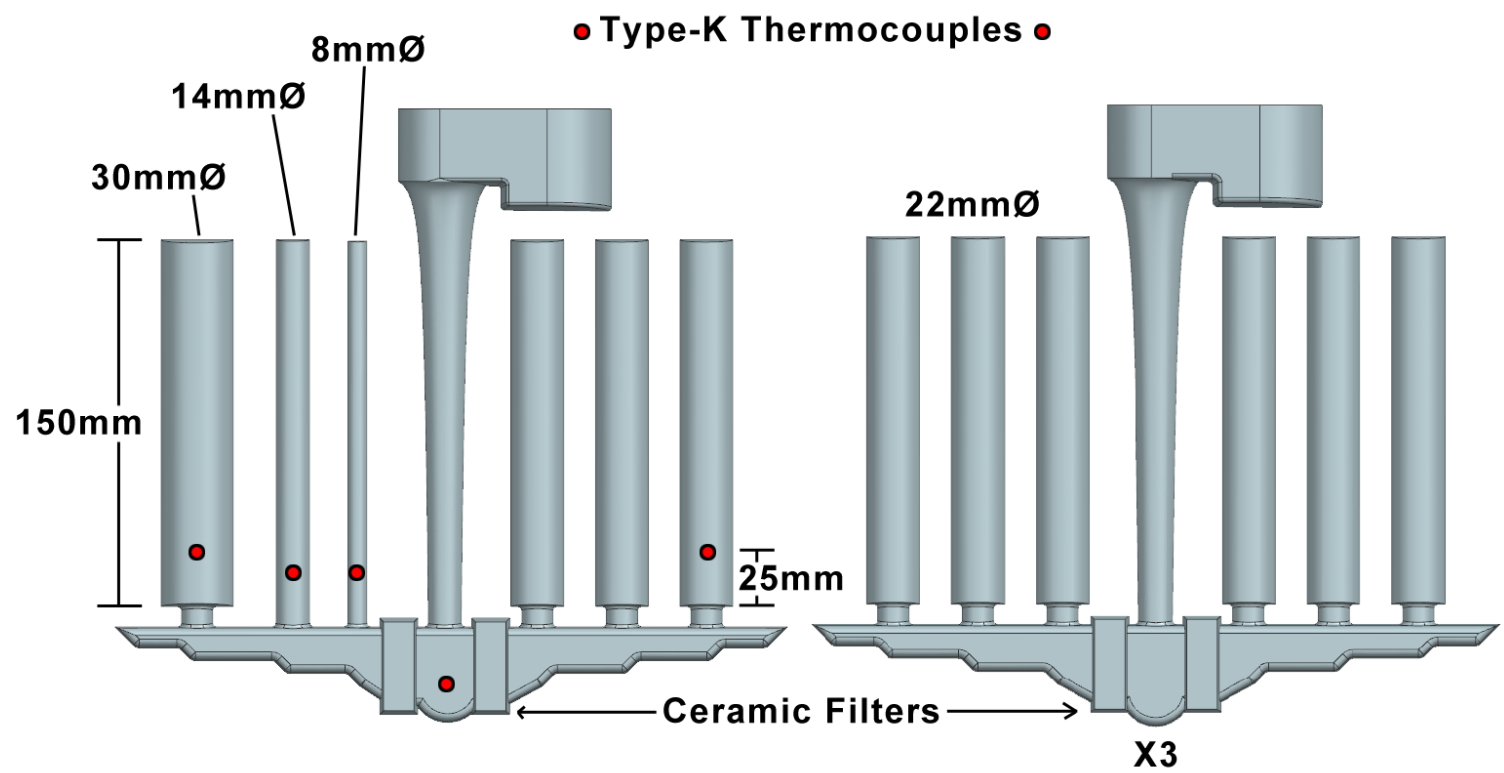

Figure 2.4.1 Illustration of the two different bar castings produced for each alloy and thermocouple placement. Three of the $22 \mathrm{~mm}$ diameter bar castings were produced per heat.

Fluidity was assessed with a fluidity mold with fingers ranging from $1 \mathrm{~mm}$ to $6 \mathrm{~mm}$ in thickness and $250 \mathrm{~mm}$ in length (Figure 2.4.2). The fluidity mold design was inspired by [29]-[31]. The pouring basin was set at a fixed height to maintain a constant head pressure during filling. The finger and runner ends were tapered to a point to minimized hydraulic shock when liquid metal would fill a leg. The fluidity mold was poured last and was outfitted with a thermocouple in the sprue well to record the final pouring temperature. The distance from the runner to the freezing front was measured on each finger to quantify the relative fluidity between alloys. 


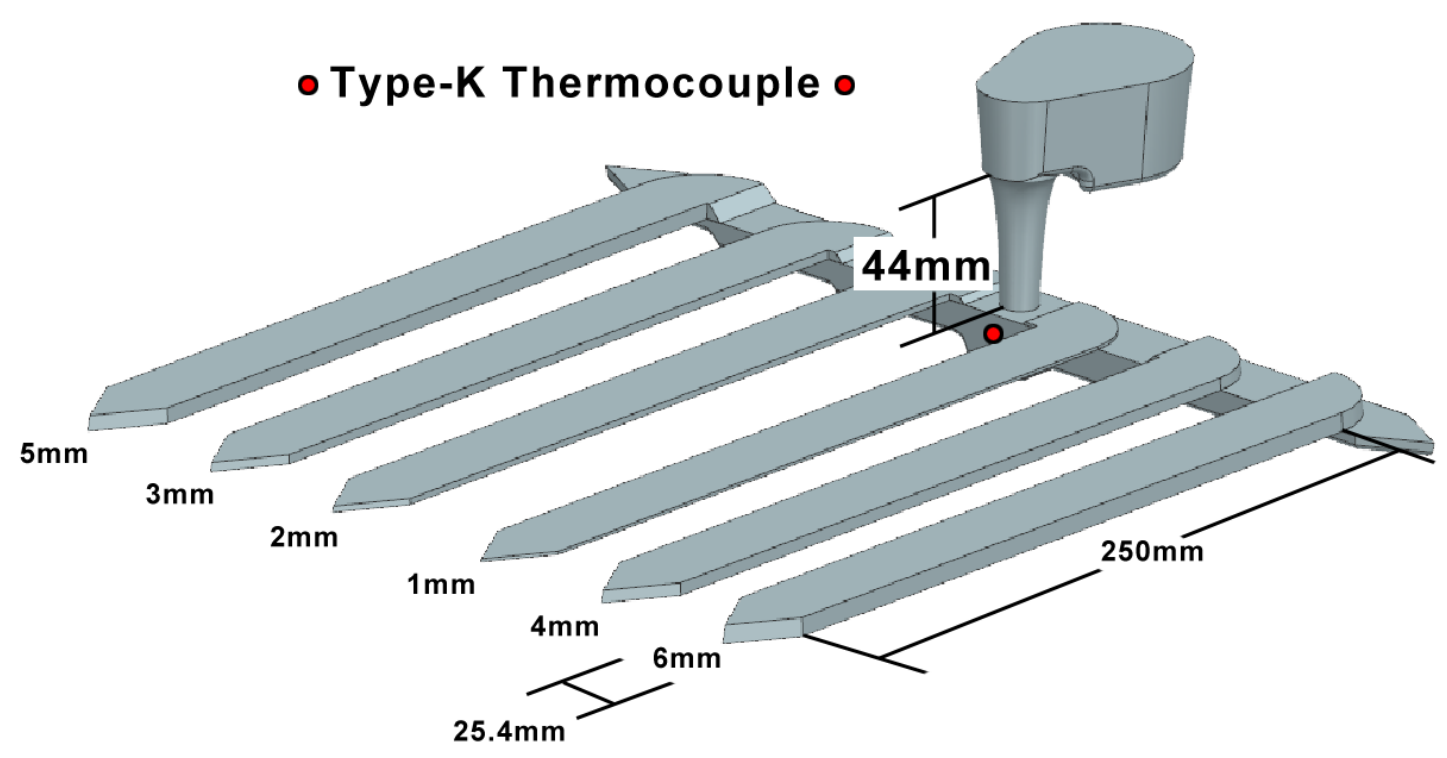

Figure 2.4.2 Fluidity casting geometry poured at the end of each casting run. A type-K thermocouple was placed in the sprue well to record a final pouring temperature.

\subsection{Thermocouples}

An in-house method was developed to create highly responsive single use quartz encapsulated type-K thermocouples to collect cooling data (Figure 2.5.1). The thermocouples were produced by drawing bare thermocouple wire (OMEGA Engineering) down to $0.635 \mathrm{~mm}(0.025 \mathrm{in})$, cutting the wire into $100 \mathrm{~mm}$ sections, straightening it, cleaning the ends with 190 proof ethanol to remove oils, and then joining the dissimilar wires together inside of $2 \mathrm{~mm}$ OD, $1 \mathrm{~mm}$ ID, $75 \mathrm{~mm}$ length quartz tube (Quartz Scientific) using an oxyacetylene torch to melt the junction. Heat was applied until the junction was molten and then was quickly removed. A similar technique was used by NASA to create thermocouples to measure the temperature in jet engines components [32].

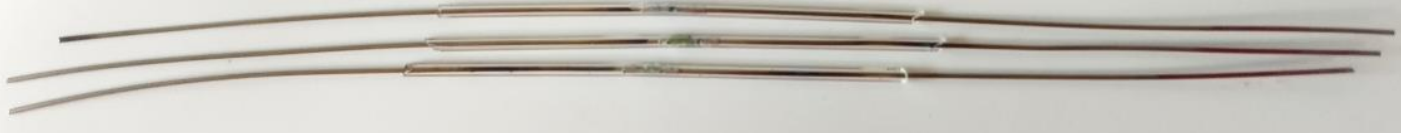

Figure 2.5.1 Quartz encapsulated thermocouples used to measure casting temperature. 
Thermocouples were placed in the mold by drilling a $2 \mathrm{~mm}$ hole through both mold halves, counter-boring the outer faces of the mold, and then carefully feeding the thermocouples through until centered with the mold cavity (Figure 2.5.2). Chemically bonded sand was then packed in the counter-bored hole to seal between the quartz tube and the mold to prevent leaking during filling. The thermocouple wire ends were connected to extension wires by twisting the two tightly to maintain a good connection without introducing a dissimilar metal. A Data Translation DT9828 thermocouple module was used to record temperature at a rate of $5 \mathrm{~Hz}$.

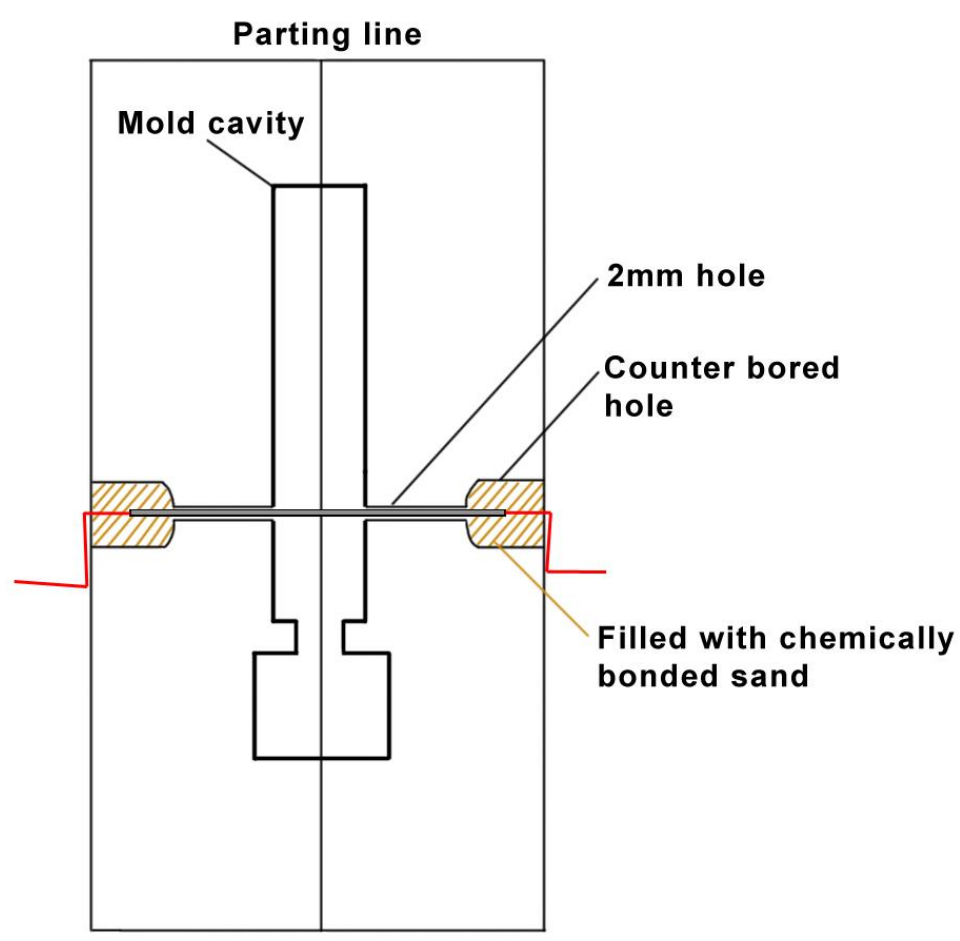

Figure 2.5.2 Illustration of how thermocouples were placed in the mold.

The maximum temperatures experienced by the thermocouples placed in the bar sections was within the nominal type-K thermocouple range; however, the thermocouples in the sprue wells that were measuring pour temperatures briefly experienced maximums above the values tabulated by the National Institute of Standards and Technology (NIST) [33]. 
To account for this and still get temperature data from outside the normal rage, the upper portion of the NIST table for type- $\mathrm{K}$ thermocouples, relating $\mathrm{mV}$ readings to temperature with cold junction compensation, was extrapolated using a second order equation to slightly extend the curve (Figure 2.5.3). The extrapolated portion of this curve, along with cold junction compensation, was used to estimate temperatures exceeding $1370^{\circ} \mathrm{C}$.

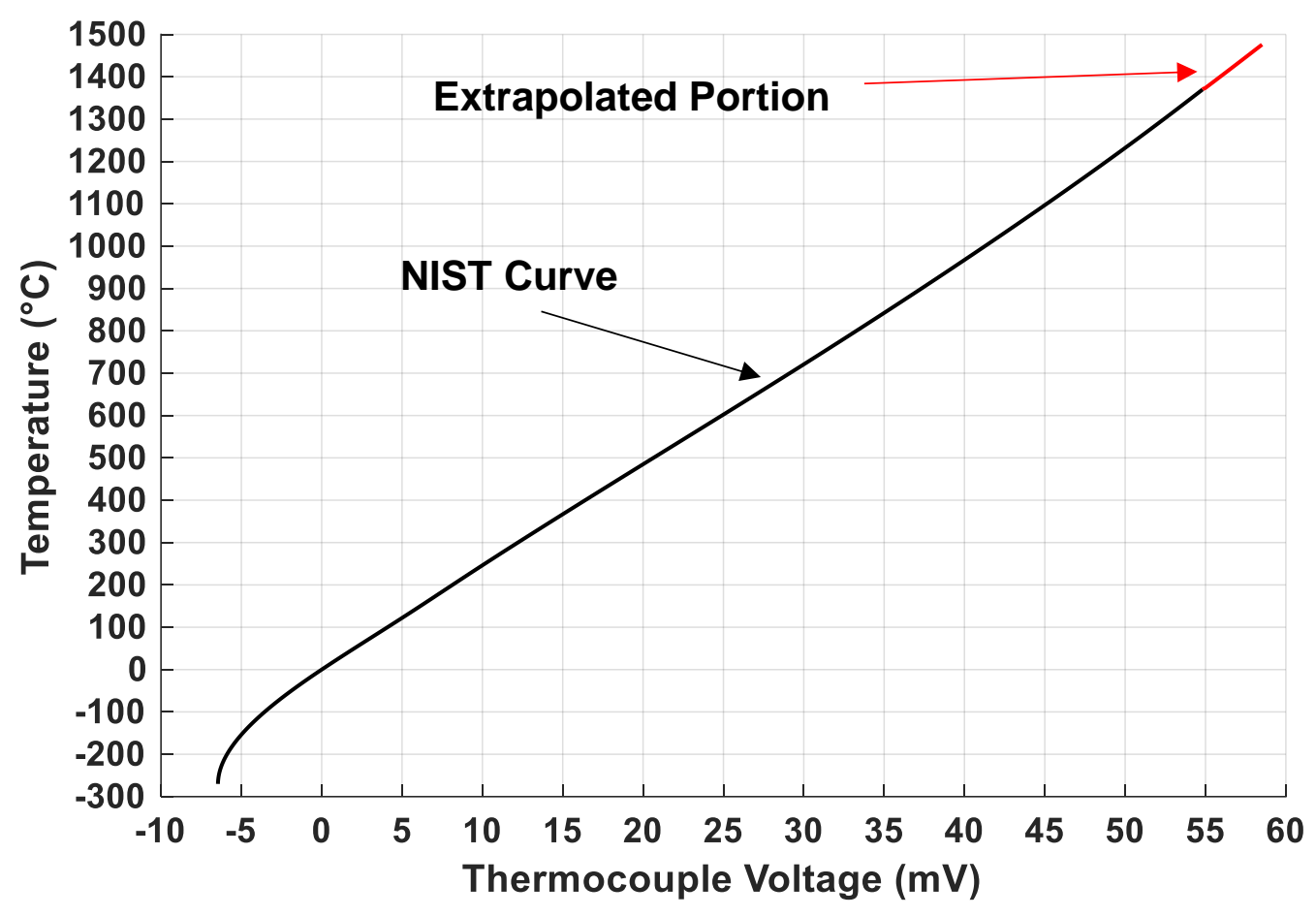

Figure 2.5.3 The extrapolated portion of the NIST type-K thermocouple table used to read temperatures beyond $1370^{\circ} \mathrm{C}$ [33].

\subsection{Mold Making}

Molds were produced using no-bake chemically bonded sand mixed in a Tinker Omega TOM-125. The sand mixture consisted of $1.25 \%$ ALPHASET 9010 resin and 30\% ALPHACURE 110 catalyst. Each bar mold half weighed approximately $10 \mathrm{~kg}$ (22 lbs) while each fluidity mold half weighed approximately $20.4 \mathrm{~kg}(45 \mathrm{lbs})$. The top of each bar was vented by scoring a mold half to create a path for air to escape when filling (Figure 2.6.1). A bead of CoreWeld NB FastDry Stnd (HA International) was used when 
assembling the bar molds to hold the halves together before clamping. Small beads of CoreWeld were also used to fill in any voids created during placement of the thermocouple in the fluidity mold (Figure 2.6.2). Mold permeability was measured on the fluidity mold halves using a Dietert Electronic Permmeter (George Fischer Systems) to gauge potential influences of permeability on fluidity measurements. No such influences were found.

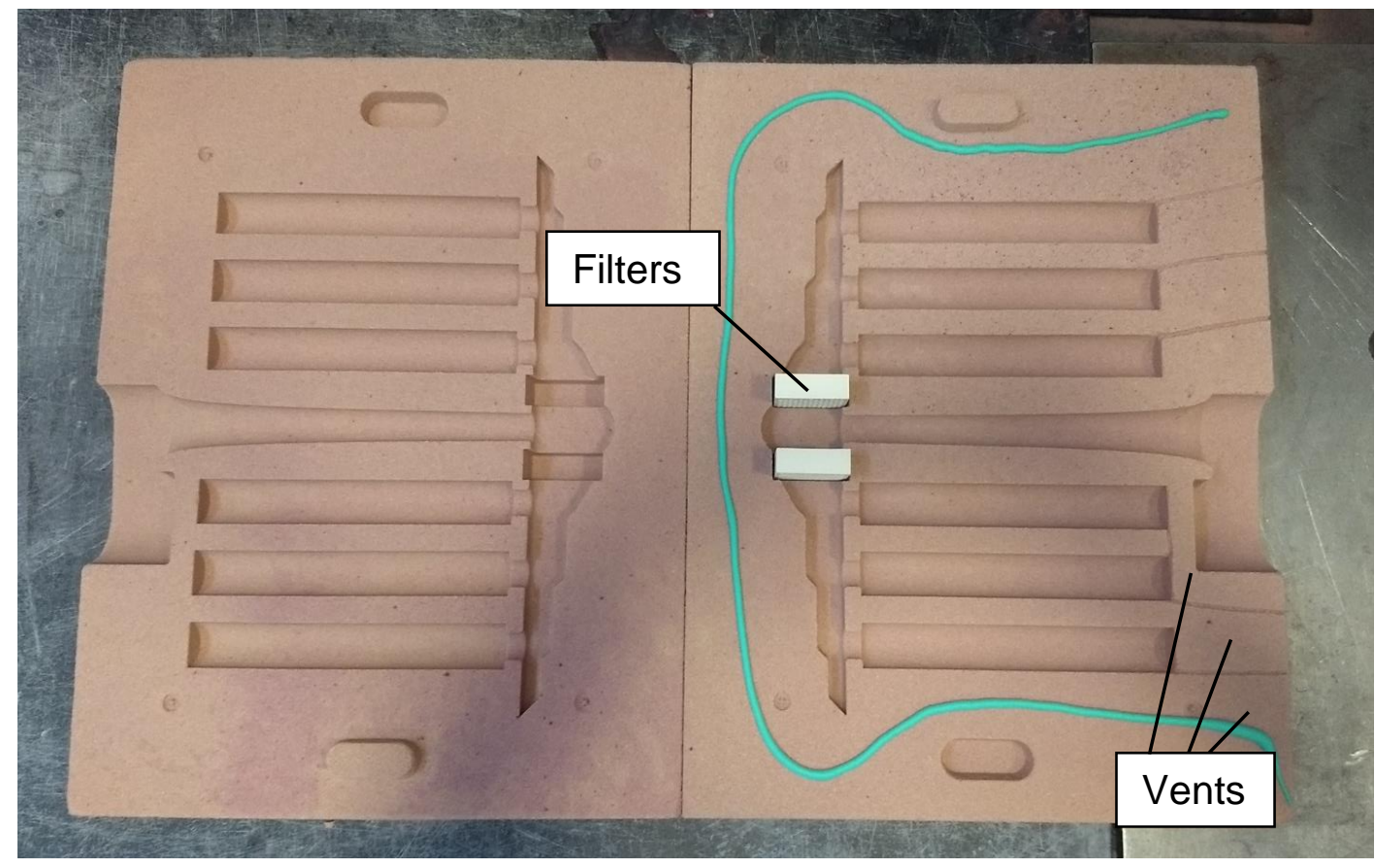

Figure 2.6.1 Bar mold prep with ceramic filters, venting, and a bead of CoreWeld.

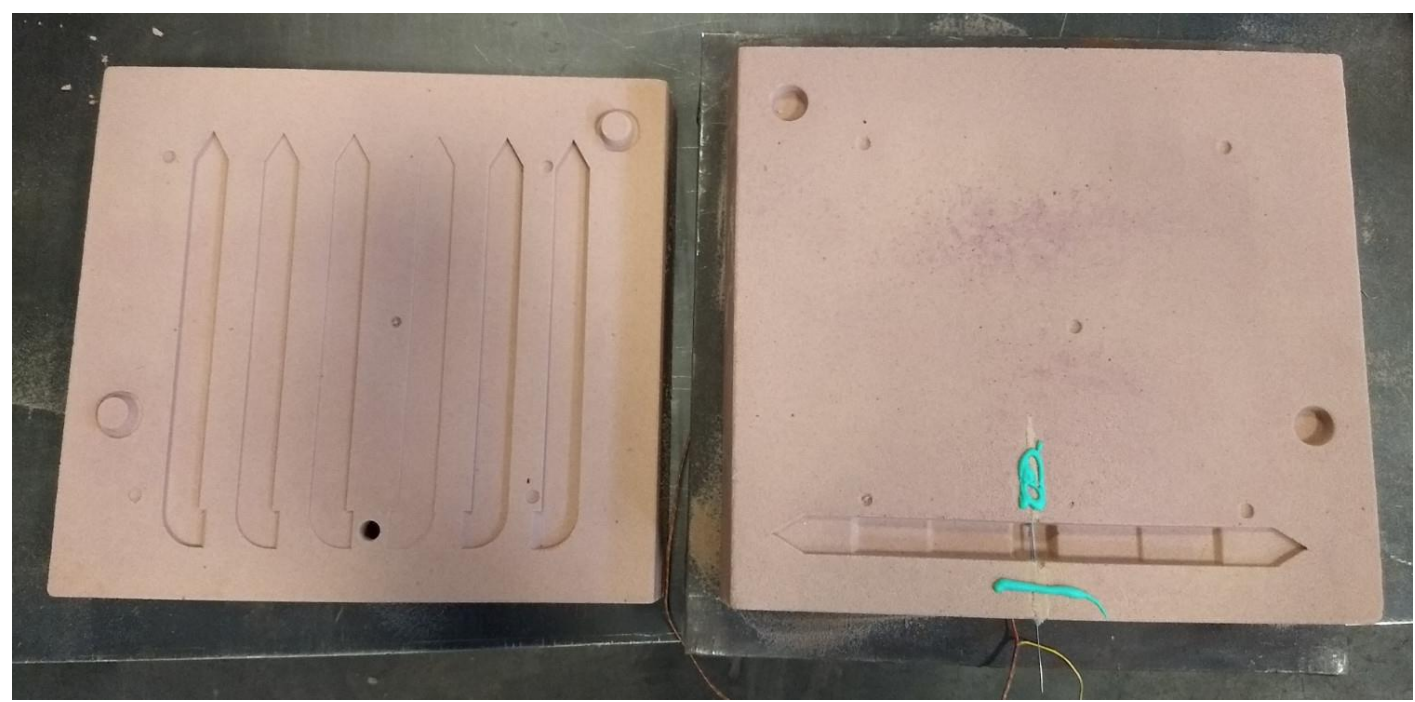

Figure 2.6.2 Mold prep for fluidity mold with CoreWeld used to seal around thermocouple placement. 


\subsection{Sample Sectioning}

Samples for various tests were sectioned from the castings as illustrated in Figure 2.7.1. A total of 20 tensile bars were machined from each alloy allowing four tests per temperature level. These four bars were carefully selected from the different $22 \mathrm{~mm}$ bar castings and bar positions to negate the effect of sample location on tensile strength, should such a trend exist.

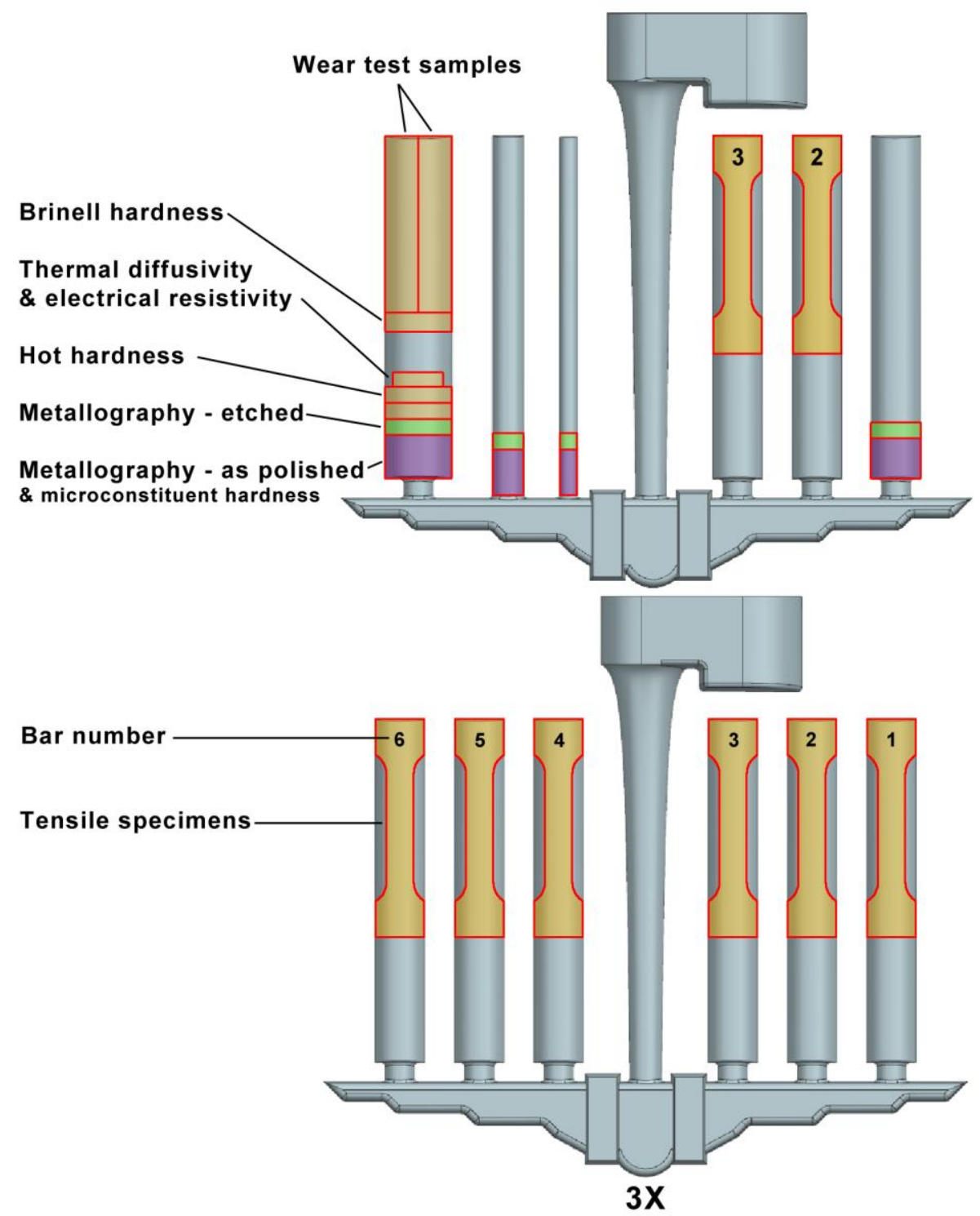

Figure 2.7.1 Illustration of how castings were sectioned to create various test specimens. 


\subsection{Metallography}

Metallography was performed on samples shown in Figure 2.7.1. The samples were mounted in epoxy and polished with a LECO AP-300 auto polisher using the steps listed in Table 2.8.1. Etched samples were prepared with $2 \%$ Nital to reveal pearlite and $2 \%$ Picral to highlight cementite and carbide precipitates.

Table 2.8.1 Polishing and etching steps for metallography.

\begin{tabular}{cccccc}
\hline Step & Media & Time (min) & $\begin{array}{c}\text { Pressure } \\
(\mathbf{l b s} / \mathbf{m o u n t})\end{array}$ & RPM & Head Rotation \\
\hline 1 & 80 grit & Until planer & 5 & 300 & With \\
2 & 320 grit & 2 & 5 & 300 & With \\
3 & $9 \mu$ m diamond & 5 & 5 & 150 & Against \\
4 & $3 \mu$ m diamond & 4 & 5 & 150 & Against \\
5 & $0.04 \mu$ m alumina & 2 & 5 & 150 & Against \\
\hline 6 & $2 \%$ Nital & $10-15$ seconds & \multicolumn{3}{|l}{ For etched samples } \\
7 & $2 \%$ Picral & $15-20$ seconds & \multicolumn{3}{l}{} \\
\hline
\end{tabular}

\subsection{Graphite Analysis}

Six micrographs were taken per section size for each alloy for the purpose of analyzing flake properties. These micrographs were taken at 100X magnification for the $30 \mathrm{~mm}$ and $22 \mathrm{~mm}$ bar sections, $200 \mathrm{X}$ for the $14 \mathrm{~mm}$ bar, and 500X for the $8 \mathrm{~mm}$ bar to resolve the much finer graphite features.

A custom MATLAB program was created to quickly and consistently quantify graphite flake morphologies. The program functioned by loading micrographs, binarizing the images using an adaptive technique, known as Bradley's method [34], that is insensitive to light gradients, removing regions smaller than 25 pixels in diameter, and then eroding the images until the optical fringe around flakes was removed. The remaining regions in the binary images were then measured for the following properties: graphite fraction, mean flake length, maximum flake length (at the 95 percentile), mean flake area, flake aspect ratio, and mean flake spacing. The flakes touching the edges of the micrographs were 
removed from all the above measurements except for graphite fraction. This insured that only flakes captured in their entirety were included in the analysis.

Mean flake spacing was measured by overlaying a 142-710 $\mu \mathrm{m}$ diameter circle onto the processed binary image from each micrograph and recording the number of intersections the circle made with the graphite flakes. The mean flake spacing was calculated using equation 2.9.1. This was repeated five times per micrograph with circles placed at random.

$$
\text { Flake Mean Spacing }=\frac{\# \text { Flake Intercepts }}{\text { Circle Perimeter }}
$$

\subsection{Hardness Testing}

Brinell hardness testing was conducted on samples machined from the $30 \mathrm{~mm}$ bar (Figure 2.7.1) with the test surface ground to 180 grit. A Dyna Brinell Hardness Tester (DynaTech) equipped with a $5 \mathrm{~mm}$ ball was used with $750 \mathrm{kgf}$ and 15 second dwell to produce seven indentations per alloy. The indentations were measured using a NewAge Brinell Optical Scanning System paired with C.A.M.S. Testing System software (NewAge Industries).

Microconstituent microhardness was measured using a LECO M-400-G1 hardness machine with a Vickers indenter, $0.2 \mathrm{kgf}$, and 15 second dwell time. Ten indentions were made per alloy on samples machined from the $30 \mathrm{~mm}$ bar (Figure 2.7.1).

\subsection{Tensile Testing}

Twenty $12.7 \mathrm{~mm}$ (0.5 in) gauge round tensile specimens were machined for each alloy from the $22 \mathrm{~mm}$ bars per ASTM E8 [35]. Four tests per temperature were conducted at room temperature, $380^{\circ} \mathrm{C}, 480^{\circ} \mathrm{C}, 580^{\circ} \mathrm{C}$, and $680^{\circ} \mathrm{C}$ for each alloy to establish high temperature strength behavior. An Instron 4206 equipped with custom grips (Figure 2.11.1) was used for tensile testing at a crosshead speed of $5.1 \mathrm{~mm} /$ minute $(0.2 \mathrm{in} /$ minute $)$ which corresponds to a strain rate of $1.7 \times 10^{-3} \mathrm{~s}^{-1}$. This slightly fast strain rate was selected so that samples broke in 10-20 seconds to limit temperature variations during testing. There was no concern of the strain rate effecting results since gray iron is nearly strain rate insensitive [36]. 


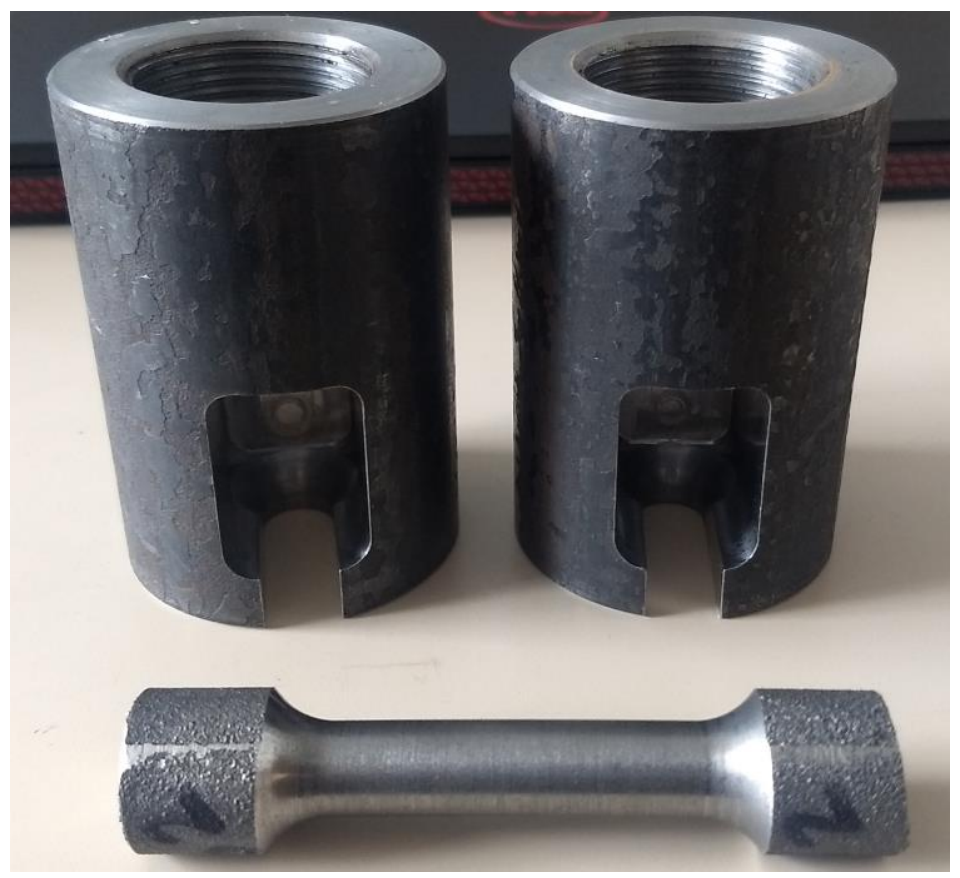

Figure 2.11.1 Grips made to speed up the tensile testing process.

Due to material property limitations, it was not safe to heat the tensile testing fixturing beyond $400^{\circ} \mathrm{C}$ using a Thermolyne high temperature tube furnace (type 54500). Specimens tested above room temperature were coated with two layers of low thermal conductivity zirconia (Pyro-Paint, Aremco Products) at the grip contact to minimize heat transfer during testing. Two hours after applying each coat of zirconia, the bars were placed in a convection oven at $93^{\circ} \mathrm{C}$ for two hours to fully cure the coating. The same procedure was used to coat the contact points on the grips. Each tensile bar was instrumented with a special limit accuracy type-K thermocouple inserted $\sim 10 \mathrm{~mm}$ into the end of the bar to track temperature during heating and testing (Figure 2.11.2). Tensile bars were placed in an electric muffle furnace (SNOL 8.2/1100, Umega Group) and superheated by $20-50^{\circ} \mathrm{C}$ above the target testing temperature. Once the bar of interest reached the desired superheat and the grip temperature reached $380-400^{\circ} \mathrm{C}$ (as measured with a thermocouple placed on the surface), the bar was quickly removed from the furnace using a pair of insulated tongs, placed in the fixturing, and pulled. The time taken to test bars once placed in the grips was 10-20 seconds, during which the bars would cool by $20-50^{\circ} \mathrm{C}$. The temperature at break was 
recorded as the temperature of the test. Thirteen bars were heated at once and tested over the course of approximately one hour.
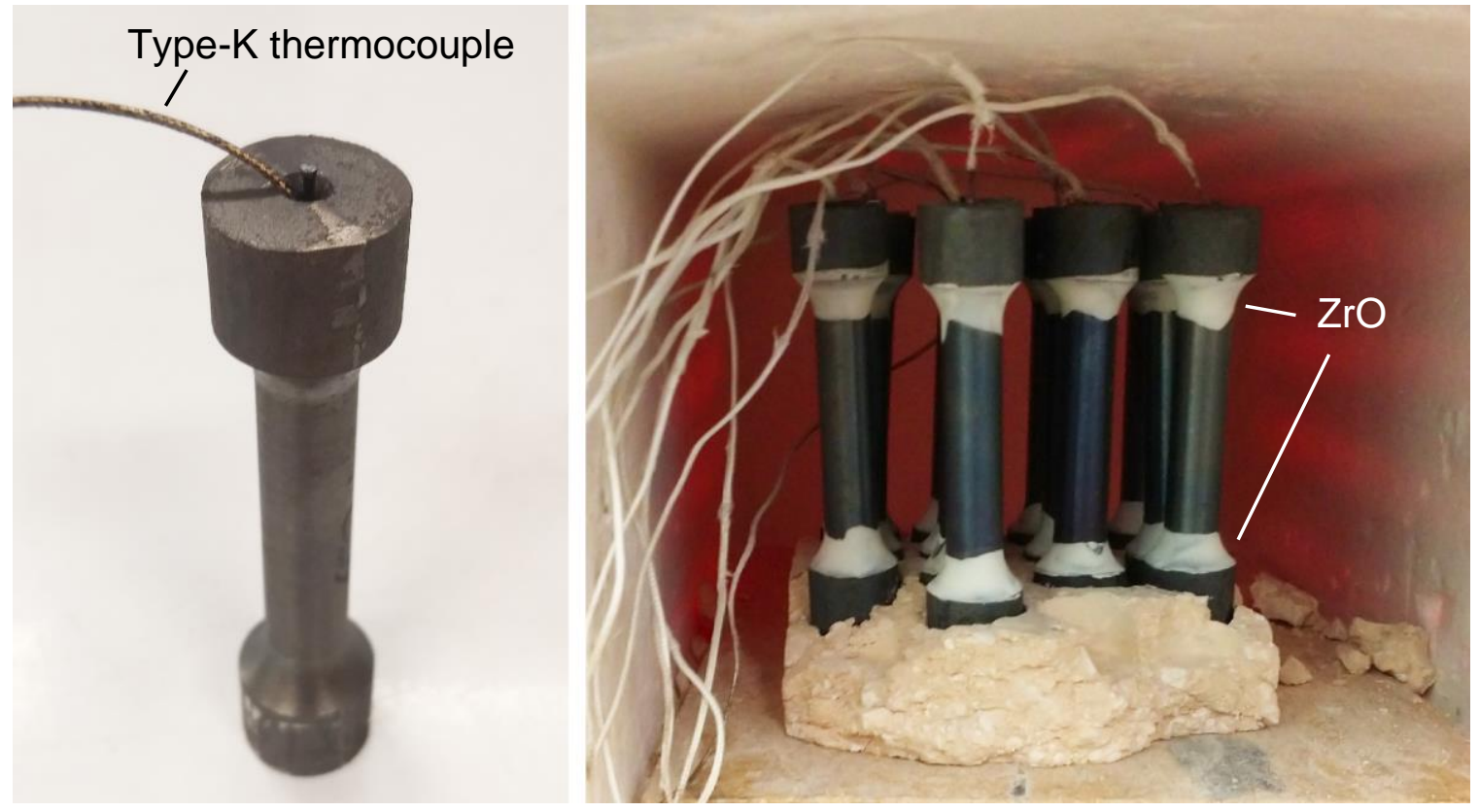

Figure 2.11.2 Left: thermocouple placement in tensile bar. Right: 13 bars with zirconia coating placed in furnace for heating.

\subsection{Wear Testing}

Four cycles of ASTM G65 sand abrasion wear testing were conducted on samples machined from the $30 \mathrm{~mm}$ bar for each alloy (Figure 2.7.1). The test surface of the samples was ground to 180 grit, ultrasonically cleaned in 200 proof ethanol, force-air dried, and weighed using a balance with $0.001 \mathrm{~g}$ precision. A Falex Friction and Wear Test Machine was used to perform ASTM G65 procedure E with a wheel speed of 200 \pm 1 RPM, load of $30 \mathrm{lbs}$, and test time of five minutes [37]. After testing, samples were cleaned using compressed air and reweighed. The volume loss was calculated using equation 2.12.1. The density of each alloy was measured using a QCD-1 Specific Gravity and Porosity Measurement System (Q. C. Designs) which utilizes the Archimedes principle for measuring density. 


$$
\text { Volume loss }\left(\mathrm{mm}^{3}\right)=\frac{\text { mass loss }(\mathrm{g})}{\text { density }\left(\frac{\mathrm{g}}{\mathrm{cm}^{3}}\right)} * 1000
$$

The wheel diameter was measured after each test to correct for wear using equation 2.12.2.

$$
\text { Actual volume loss, } A V L=\text { volume loss } * \frac{9 \text { in }}{\text { wheel diameter after use }}
$$

Friction force, $F$, was measured at the two, three, and four minute mark during the test to get an average value to calculate the friction coefficient, $\mu$, using equation 2.12 .3 where $N$ is the normal load of $30 \mathrm{lbs}$.

$$
F=\mu N
$$

\subsection{Thermal Diffusivity}

Thermal diffusivity was measured using the flash method on $25.4 \mathrm{~mm}$ diameter by $4 \mathrm{~mm}$ thick disks machined from the $30 \mathrm{~mm}$ bar (Figure 2.7.1). The samples were ground to 600 grit, coated in colloidal graphite, and tested at $100,200,300,400$, and $500^{\circ} \mathrm{C}$ using a Flashline System X-Platform instrument (Anter Corp.) according to ASTM E1461 [38]. Six measurements were taken per datapoint for a total of 390 measurements.

\subsection{SEM Analysis}

An FEI Philips XL 40 Environmental Scanning Microscope was used to acquire backscatter (BSE) and secondary electron images (SE) for analysis of the microstructure and carbides in each alloy. Energy dispersive spectroscopy (EDS) was used to acquire spectra to qualitatively classify secondary phases.

An Hitachi S-4700 field emission SEM was used to collect SE images of etched samples for pearlite spacing measurements using the circular grid method [39]. To accomplish this, eight high resolution SE images were taken per alloy at 3000X magnification at roughly one quarter of the diameter inward on the $30 \mathrm{~mm}$ bar. These images were processed in a custom MATLAB program that binarized them, inscribed a circle 7.5-15 $\mu \mathrm{m}$ in diameter 
at a random location, and then counted the cementite plate intercepts with the circle. This was repeated ten times per image for a total of 80 measurements per alloy (Figure 2.14.1)

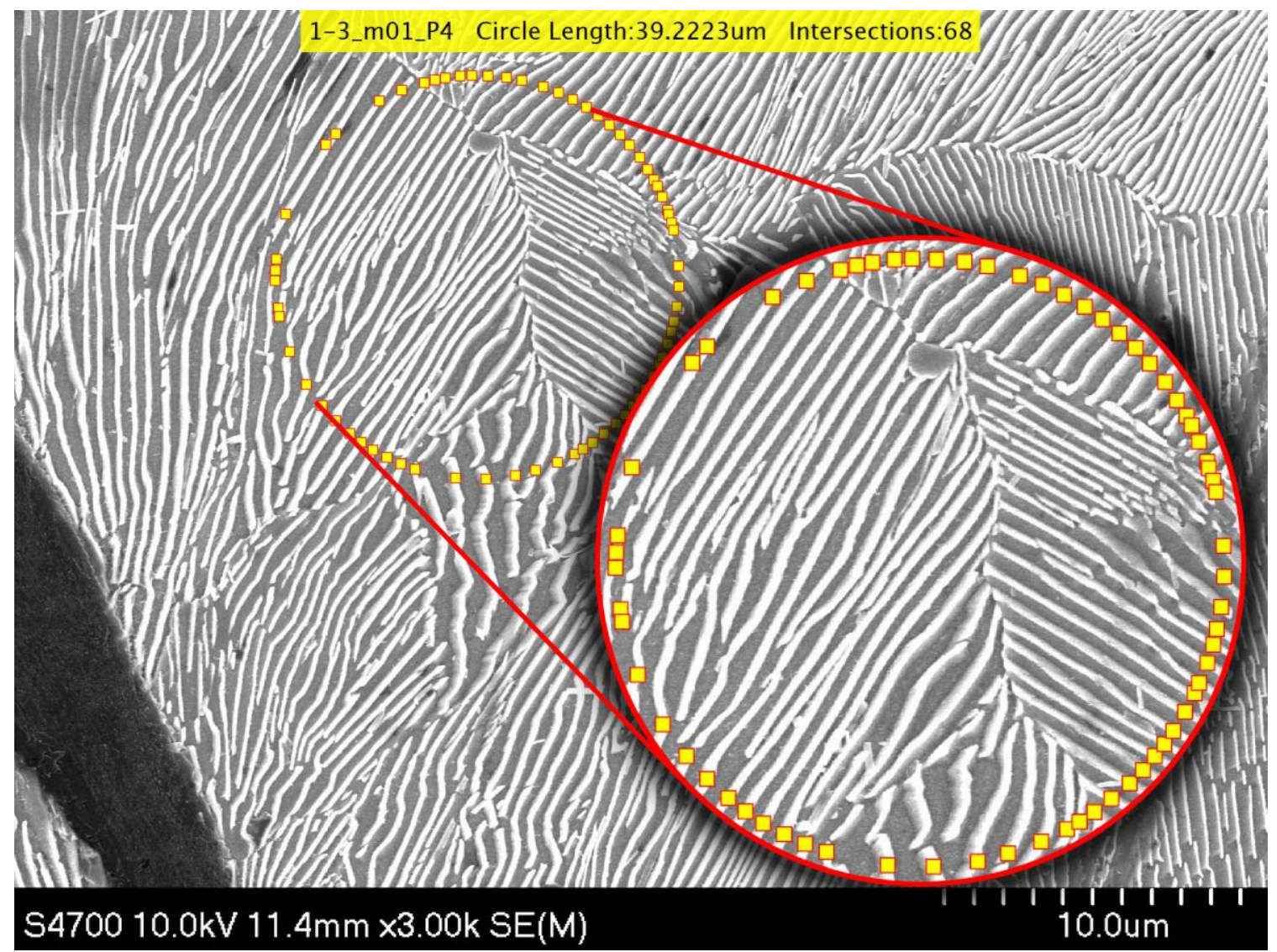

Figure 2.14.1 Example process image from a custom MATLAB program used to measure pearlite spacing. The yellow squares mark the cementite intersections detected. The red highlighted circle is a magnified view of the area of interest.

The program results were checked manually and measurements with gross intersection discrepancies were removed from further analysis. The mean random spacing, $\overline{\sigma_{r}}$, was calculated using equation 2.14.1. Equation 2.14.2 was used to estimate the mean true spacing [39].

$$
\begin{gathered}
\overline{\sigma_{r}}=\frac{\# \text { Intersections }}{\text { Circle Perimeter }} \\
\bar{\sigma}_{t} \approx 0.5 \cdot \overline{\sigma_{r}}
\end{gathered}
$$




\subsection{Electrical Resistivity}

Electrical resistivity was measured on the same samples used to measure thermal diffusivity (Figure 2.7.1). Samples were ground to 600 grit and cleaned using ethanol. A Keithley 2182A Nanovoltmeter and 6221 Current Source were used in conjunction with a Lucus Labs 302 Base and an in-line Jandel Four Point Prob to measure resistivity using the four-point probe method. The current source and voltmeter were turned on six hours in advance to reach an equilibrium temperature. The reverse current method was employed to minimize any interference effects from thermal gradients in the instrument wiring and sample-to-probe contact. This was accomplished by generating a $\pm 10 \mathrm{~mA}, 60 \mathrm{~Hz}$, square wave, measuring the potential in the middle of the square wave, taking the difference of two subsequent potential measurements, and dividing by the current to get resistance. Each test cycle consisted of taking 500 resistance values and then averaging them. Ten of these tests were conducted per alloy while repositioning and rotating the sample between tests. Resistivity, $\rho$, was then calculated using equation 2.15.1 where $t$ is sample thickness, $R$ is the measured resistance, and $f_{1}$ and $f_{2}$ are geometric correction factors [40]. The first correction factor, $f_{1}$, can be calculated using equation 2.15.2 where $s$ is the probe spacing $(1 \mathrm{~mm})[40]$.

$$
\begin{array}{r}
\rho=\frac{\pi}{\ln (2)} t * R * f_{1} * f_{2} \\
f_{1}=\frac{\ln (2)}{\ln \left[\frac{\sinh \left(\frac{t}{s}\right)}{\sinh \left(\frac{t}{2 s}\right)}\right]}
\end{array}
$$

The second correction factor, $f_{2}$, was determined to be 0.9875 from a published chart pertaining to circular and rectangular specimens [40]. 


\section{Results}

\subsection{Alloy Chemistries}

Due to carbon's tendency to burn off at high melt temperatures, the final carbon level was lower than the proposed target of $3.72 \mathrm{wt} \%$ for most of the high CE alloys (Table 3.1.1). Three versions of alloy 12 were produced but only two, labeled 12 and 13, were characterized. Alloy 13 was the second attempt at producing alloy 12, but CE was lower and niobium was higher than the target.

Table 3.1.1 Final chemistries (wt $\%$ ) measured using type-standardized OES.

\begin{tabular}{ccccccccccccc}
\hline Alloy & Classification & $\mathbf{C}$ & $\mathbf{S i}$ & $\mathbf{P}$ & $\mathbf{C u}$ & $\mathbf{M n}$ & $\mathbf{C r}$ & $\mathbf{S n}$ & $\mathbf{S}$ & $\mathbf{M o}$ & $\mathbf{N b}$ & $\mathbf{C E}$ \\
\hline 1 & Low CE & 3.365 & 1.778 & 0.042 & 0.258 & 0.718 & 0.245 & 0.006 & 0.076 & 0.014 & 0.002 & 3.972 \\
2 & Low CE & 3.322 & 1.798 & 0.043 & 0.258 & 0.721 & 0.251 & 0.006 & 0.081 & 0.014 & 0.124 & 3.936 \\
3 & Low CE & 3.371 & 1.805 & 0.043 & 0.261 & 0.712 & 0.445 & 0.006 & 0.083 & 0.016 & 0.123 & 3.987 \\
4 & Low CE & 3.344 & 1.777 & 0.043 & 0.260 & 0.716 & 0.253 & 0.006 & 0.082 & 0.373 & 0.003 & 3.951 \\
5 & Low CE & 3.394 & 1.783 & 0.045 & 0.259 & 0.723 & 0.254 & 0.006 & 0.077 & 0.372 & 0.124 & 4.003 \\
6 & Low CE & 3.341 & 1.777 & 0.044 & 0.260 & 0.711 & 0.436 & 0.006 & 0.081 & 0.373 & 0.124 & 3.948 \\
\hline 7 & High CE & 3.667 & 1.958 & 0.044 & 0.254 & 0.738 & 0.258 & 0.007 & 0.091 & $<0.010$ & 0.003 & 4.334 \\
8 & High CE & 3.600 & 1.938 & 0.043 & 0.250 & 0.733 & 0.251 & 0.006 & 0.075 & $<0.010$ & 0.222 & 4.260 \\
9 & High CE & 3.727 & 1.899 & 0.048 & 0.258 & 0.716 & 0.545 & 0.008 & 0.091 & $<0.010$ & 0.225 & 4.376 \\
10 & High CE & 3.657 & 1.980 & 0.042 & 0.251 & 0.692 & 0.252 & 0.007 & 0.079 & 0.456 & 0.004 & 4.331 \\
11 & High CE & 3.655 & 1.993 & 0.045 & 0.258 & 0.733 & 0.253 & 0.007 & 0.086 & 0.462 & 0.226 & 4.334 \\
12 & High CE & 3.649 & 1.917 & 0.047 & 0.254 & 0.718 & 0.541 & 0.008 & 0.078 & 0.441 & 0.222 & 4.304 \\
13 & High CE & 3.553 & 1.945 & 0.043 & 0.258 & 0.701 & 0.551 & 0.007 & 0.075 & 0.439 & 0.254 & 4.216 \\
\hline
\end{tabular}

\subsection{Castings and Fluidity}

The castings produced during each heat were high quality and had good surface finish and minimal flashing (Figure 3.2.1). All sections of interest were free of porosity and shrinkage. Porosity was only noted in the sprue and runner of some castings. 


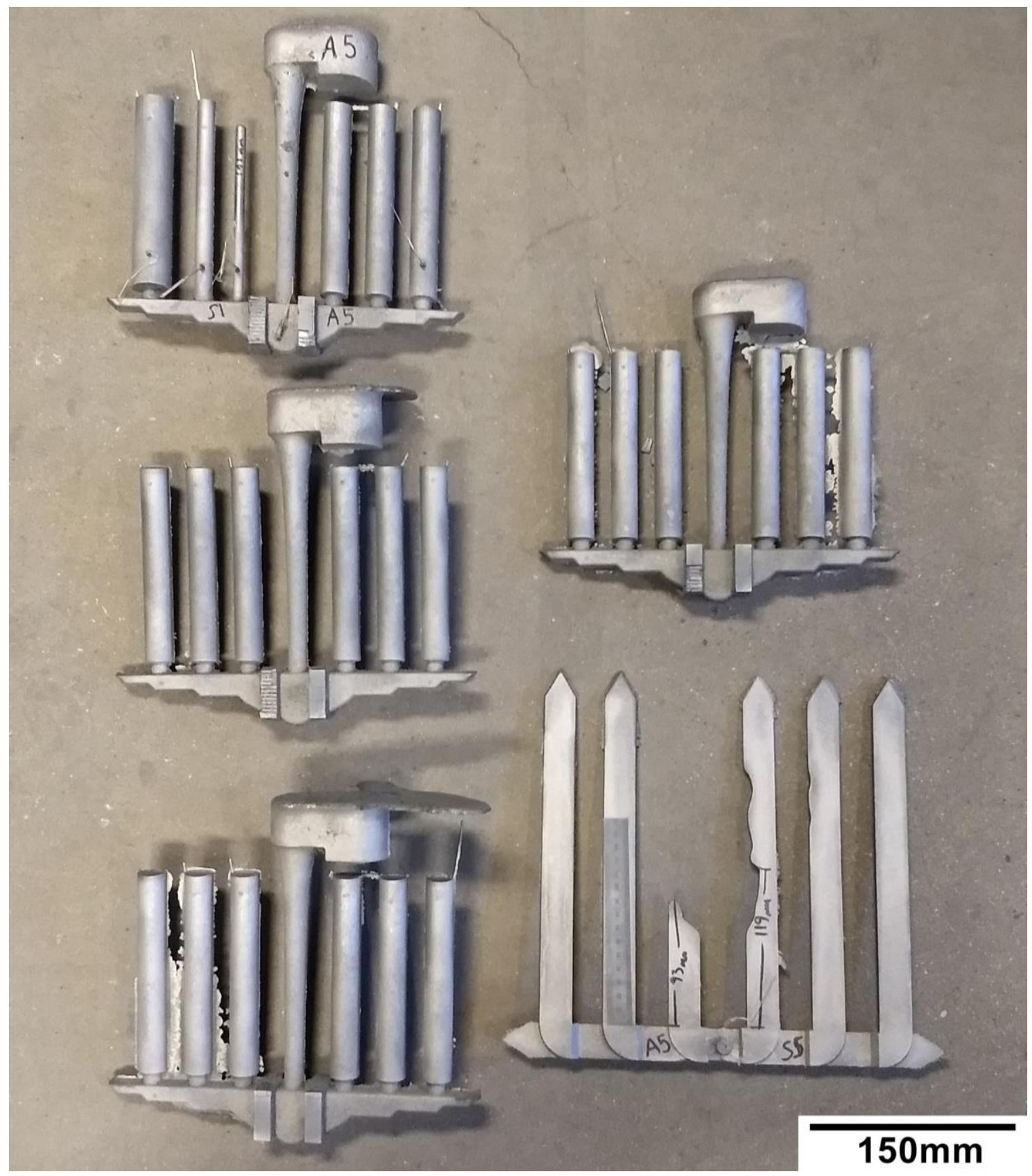

Figure 3.2.1 Example of castings produced from each heat after sandblasting.

Only the 1 and $2 \mathrm{~mm}$ fingers of the fluidity castings exhibited incomplete filling (Figure 3.2.2), so a metric was developed to quantify the relative fluidity of each melt by totaling up the distance the metal had traveled in the 1 and $2 \mathrm{~mm}$ fingers (Table 3.2.1). No obvious trend in finger length was apparent among alloys; however, there was a notable difference 
between the high and low CE alloys when grouped. The high CE alloys tended to be more fluid with the $2 \mathrm{~mm}$ finger filling in nearly all cases.

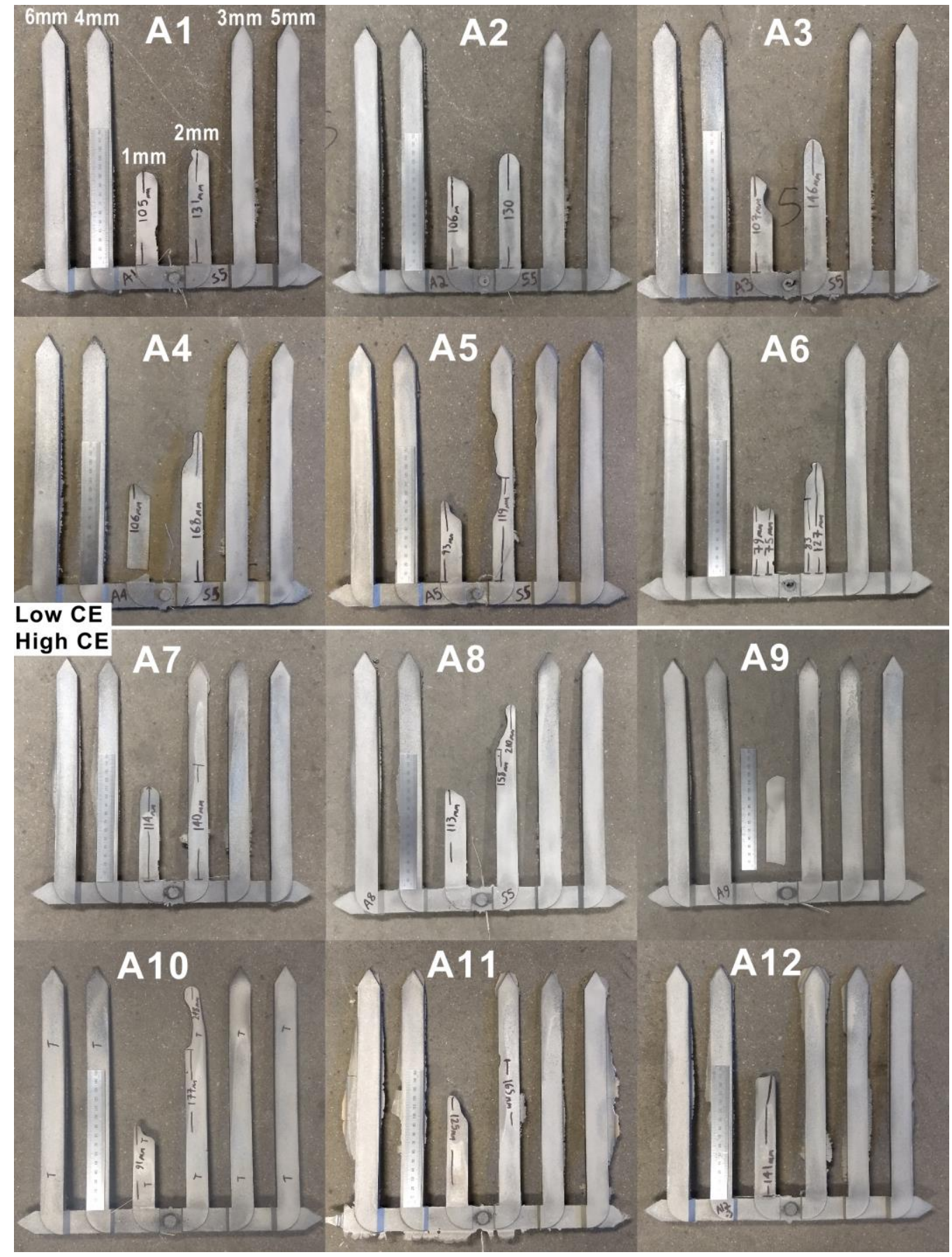

Figure 3.2.2 Fluidity castings produced for each alloy. 
The initial and final pouring temperature for each alloy was measured with type-K thermocouples embedded in the sprue of the first and last mold poured. Tapping temperature was either estimated or measured seconds before tapping (Table 3.2.1). Cooling curve plots for the 8, 14, 22, and $30 \mathrm{~mm}$ bars are shown in Appendix B (Figure 7.2.1 and Figure 7.2.2).

Table 3.2.1 Tapping temperatures, pouring temperatures, and finger fluidity measurements for each alloy. Tapping temperatures designated as $(\sim)$ are estimated.

\begin{tabular}{ccccccc}
\hline Alloy & $\begin{array}{c}\text { Tapping } \\
\text { Temp }\left({ }^{\circ} \mathbf{C}\right)\end{array}$ & $\begin{array}{c}\text { Initial Pour } \\
\text { Temp }\left({ }^{\circ} \mathbf{C}\right)\end{array}$ & $\begin{array}{c}\text { Final Pour } \\
\text { Temp }\left({ }^{\circ} \mathbf{C}\right)\end{array}$ & $\begin{array}{c}\mathbf{1 ~ m m} \\
\text { Finger Fill } \\
(\mathbf{m m})\end{array}$ & $\begin{array}{c}\mathbf{2 ~ m m} \\
\text { Finger Fill } \\
(\mathbf{m m})\end{array}$ & $\begin{array}{c}\text { Total } \\
\text { Fill } \\
(\mathbf{m m})\end{array}$ \\
\hline 1 & $\sim 1500$ & 1395 & 1387 & 105 & 131 & 236 \\
2 & $\sim 1500$ & 1393 & 1384 & 106 & 130 & 236 \\
3 & 1508 & 1403 & 1390 & 107 & 146 & 253 \\
4 & $\sim 1500$ & 1410 & 1377 & 106 & 168 & 274 \\
5 & $\sim 1500$ & 1396 & 1382 & 93 & 119 & 212 \\
6 & $\sim 1500$ & 1395 & 1387 & 79 & 127 & 206 \\
\hline 7 & 1503 & 1398 & 1373 & 114 & 272 & 386 \\
8 & $\sim 1500$ & 1395 & 1376 & 113 & 210 & 323 \\
9 & $\sim 1500$ & 1391 & 1383 & 119 & 272 & 391 \\
10 & 1503 & 1396 & 1383 & 91 & 248 & 339 \\
11 & 1500 & 1400 & 1384 & 125 & 272 & 397 \\
12 & 1500 & 1396 & 1392 & 141 & 272 & 413 \\
13 & 1511 & - & - & 127 & 272 & 399 \\
\hline
\end{tabular}

\subsection{Graphite Properties}

Optical microscopy of etched and un-etched samples was used to evaluate the microstructure of each alloy and quantify graphite flake properties with a purpose-built MATLAB program (see Appendix $\mathrm{C}$ for micrographs). At least six fields of view per sample were used to quantify graphite properties. The $30 \mathrm{~mm}$ bar was evaluated in detail since most of the test specimens were sectioned from it (Table 3.3.1). 
Table 3.3.1 Graphite properties measured for the $30 \mathrm{~mm}$ bar. Percent pearlite and ASTM A247 graphite distribution was determined by visual inspection. All other properties were measured using a custom MATLAB program on six to eight $100 \mathrm{X}$ micrographs per alloy. Uncertainty in values corresponds to 95\% standard error.

\begin{tabular}{cccccccc}
\hline Alloy & $\begin{array}{c}\text { Pearlite } \\
(\boldsymbol{\%})\end{array}$ & $\begin{array}{c}\text { Graphite } \\
(\boldsymbol{\%})\end{array}$ & $\begin{array}{c}\text { Graphite } \\
\text { Distribution }\end{array}$ & $\begin{array}{c}\text { Mean Flake } \\
\text { Length }(\boldsymbol{\mu m})\end{array}$ & $\begin{array}{c}\text { Max Flake } \\
\text { Length } \\
(\boldsymbol{\mu m})\end{array}$ & $\begin{array}{c}\text { Flake Mean } \\
\text { Aspect } \\
\text { Ratio }\end{array}$ & $\begin{array}{c}\text { Mean Flake } \\
\text { Spacing } \\
(\boldsymbol{\mu m})\end{array}$ \\
\hline 1 & $>95$ & $12.8 \pm 0.5$ & A, E & $44 \pm 2$ & $115 \pm 10$ & $3.8 \pm 0.2$ & $39 \pm 1$ \\
2 & $>95$ & $11.7 \pm 0.4$ & A, E & $41 \pm 2$ & $109 \pm 10$ & $3.8 \pm 0.2$ & $41 \pm 1$ \\
3 & $>95$ & $12.3 \pm 0.4$ & A, E & $41 \pm 2$ & $105 \pm 10$ & $3.8 \pm 0.2$ & $43 \pm 2$ \\
4 & $>95$ & $11.1 \pm 0.5$ & A, E & $43 \pm 3$ & $114 \pm 10$ & $4.1 \pm 0.3$ & $42 \pm 2$ \\
5 & $>95$ & $9.4 \pm 0.5$ & A, E & $43 \pm 2$ & $107 \pm 10$ & $4.6 \pm 0.2$ & $46 \pm 2$ \\
6 & $>95$ & $10.6 \pm 0.4$ & A, E & $39 \pm 4$ & $108 \pm 20$ & $3.8 \pm 0.3$ & $43 \pm 2$ \\
\hline 7 & $>95$ & $15.3 \pm 0.4$ & A, B & $53 \pm 4$ & $149 \pm 20$ & $4.0 \pm 0.4$ & $30 \pm 1$ \\
8 & $>95$ & $13.0 \pm 0.6$ & A & $49 \pm 3$ & $132 \pm 10$ & $4.5 \pm 0.3$ & $35 \pm 1$ \\
9 & $>95$ & $10.8 \pm 0.7$ & A, B & $51 \pm 3$ & $140 \pm 10$ & $4.9 \pm 0.2$ & $38 \pm 1$ \\
10 & $>95$ & $14.6 \pm 0.3$ & A & $54 \pm 5$ & $165 \pm 20$ & $4.1 \pm 0.2$ & $35 \pm 1$ \\
11 & $>95$ & $14.5 \pm 0.4$ & A, E & $44 \pm 4$ & $136 \pm 20$ & $3.5 \pm 0.4$ & $30 \pm 1$ \\
12 & $>95$ & $14 \pm 1$ & A & $49 \pm 3$ & $142 \pm 10$ & $4.3 \pm 0.3$ & $35 \pm 1$ \\
13 & $>95$ & $11.1 \pm 0.6$ & A, E & $43 \pm 3$ & $116 \pm 10$ & $4.0 \pm 0.3$ & $38 \pm 1$ \\
\hline
\end{tabular}

The matrix of all alloys consisted primarily of pearlite with no ferrite observed. The percent graphite measured in the high CE alloys was on average $2 \%$ higher than the low CE alloys. The graphite morphology was primarily type A with small amounts of interdendritic type E flakes and rosette-like type B flakes. Graphite flakes were on average $7 \mu \mathrm{m}$ longer for the high CE alloys with the longest flakes being $30 \mu \mathrm{m}$ longer. The flake aspect ratio remained essentially the same with only a $5 \%$ increase noted for the high CE alloys. The mean flake spacing was on average $8 \mu \mathrm{m}$ greater for the low CE alloys, likely due to the decreased density of flakes overall. A more detailed graph of flake spacing as related to chemistry for the $30 \mathrm{~mm}$ bar is presented in Figure 3.3.1.

Similar measurements were conducted on the 8, 14, and $22 \mathrm{~mm}$ bars using micrographs taken at 500X, 200X and 100X, respectively. The percent graphite remained constant among the different section sizes (Figure 3.3.2). 


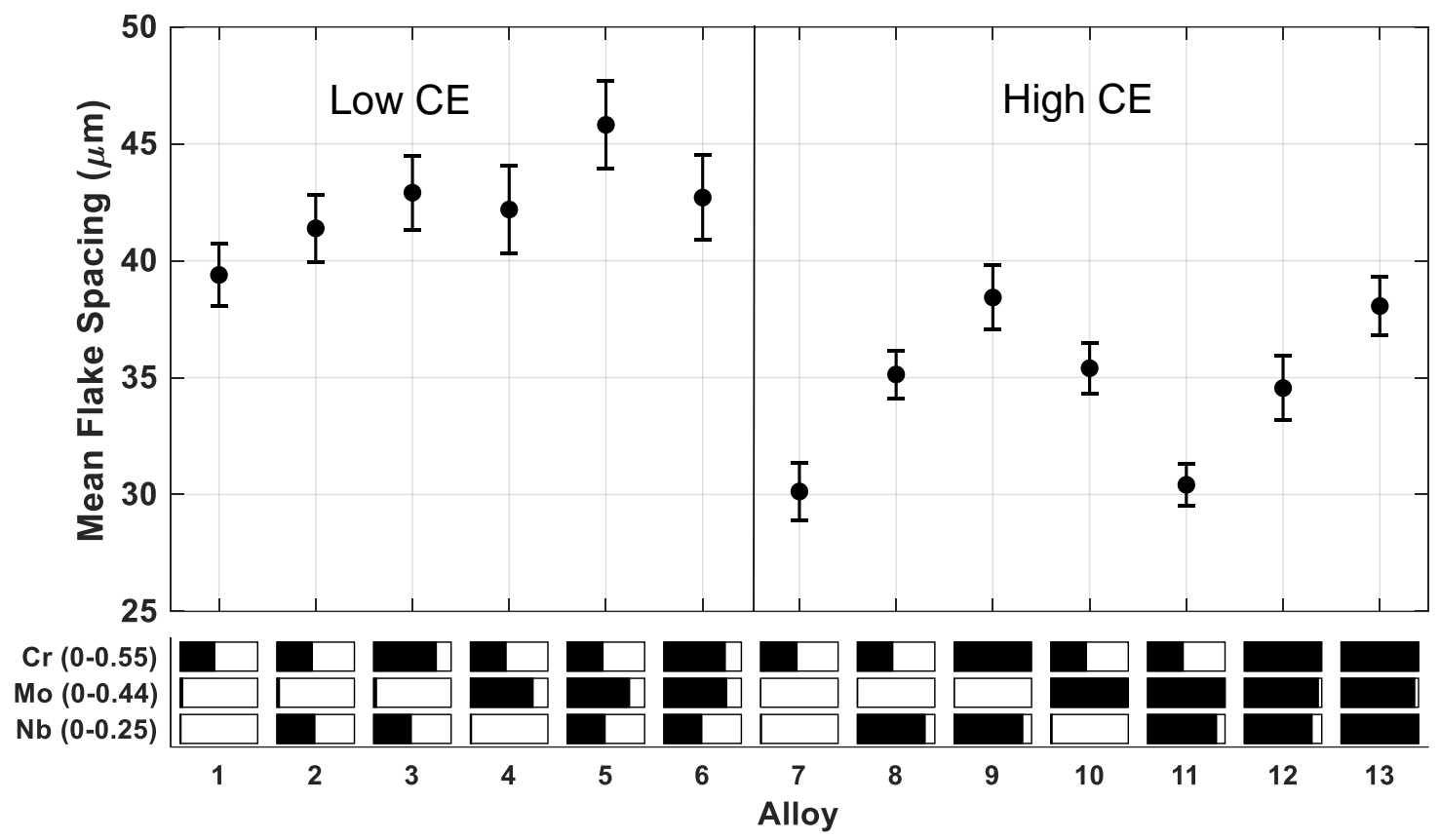

Figure 3.3.1 Mean flake spacing measured from the $30 \mathrm{~mm}$ bar using the circular grid intercept method. Error bars represent $95 \%$ standard error. Bars on bottom of graphs visually show $\mathrm{Cr}, \mathrm{Mo}$, and $\mathrm{Nb}$ additions with respect to the highest concentration measured.

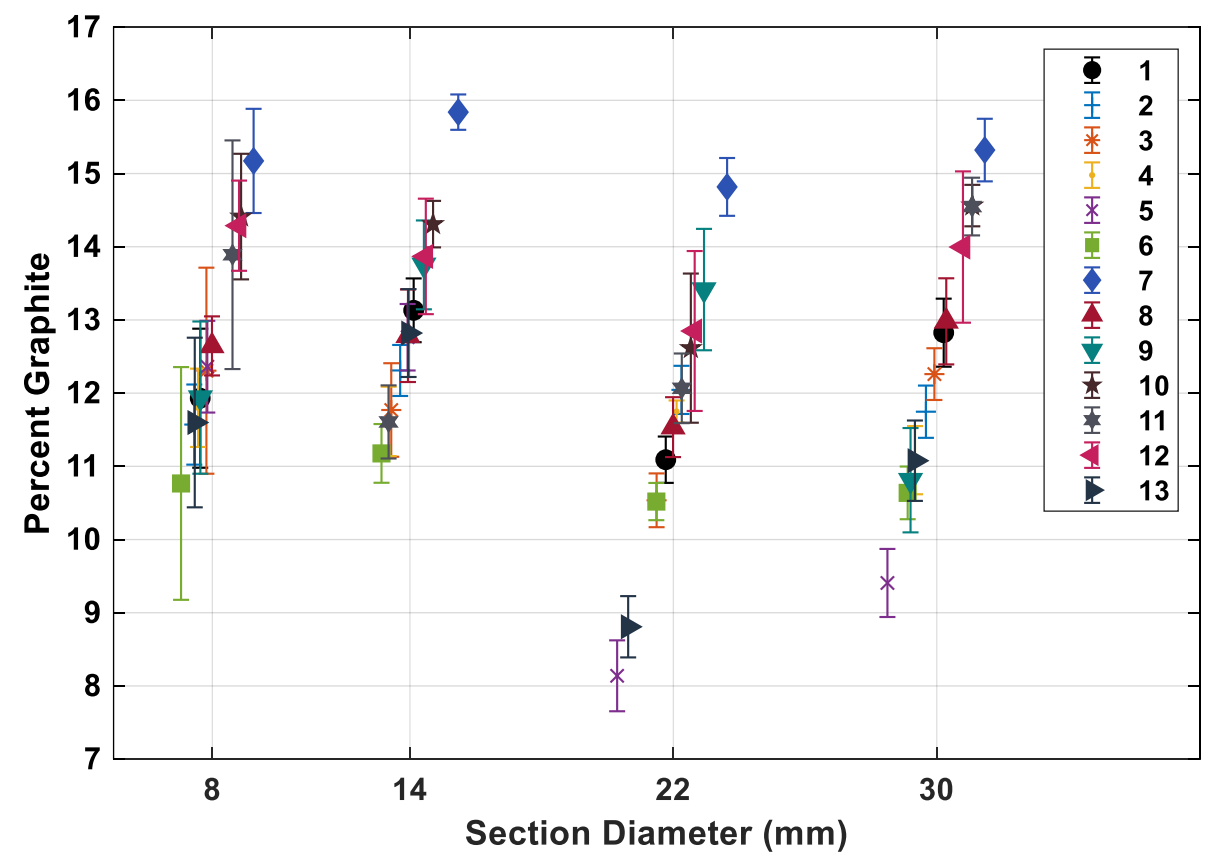

Figure 3.3.2 Percent graphite measured as a function of section size. Error bars represent 95\% standard error. 
The mean flake length was similar in the 22 and $30 \mathrm{~mm}$ sections but decreased in the 8 and $14 \mathrm{~mm}$ sections due to the higher cooling rate (Figure 3.3.3). A similar but more gradual trend was observed for the maximum flake length (Figure 3.3.4).

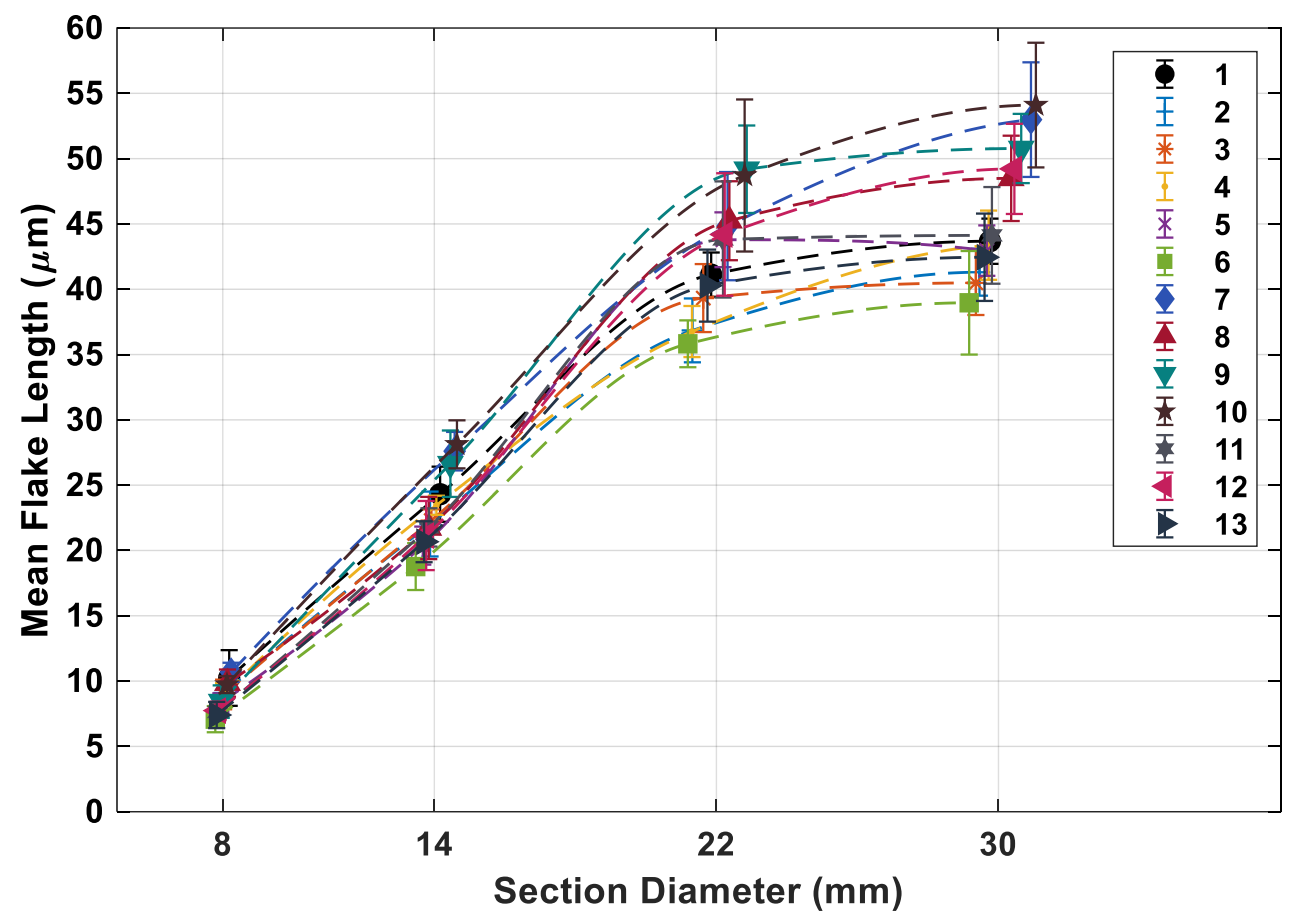

Figure 3.3.3 Mean flake length measured for each section size. Error bars represent 95\% standard error.

No obvious change was apparent for the flake aspect ratio (length/width) in the 22 and 30 $\mathrm{mm}$ sections; however, the ratio did decrease in the 8 and $14 \mathrm{~mm}$ bar sections (Figure 3.3.5). 


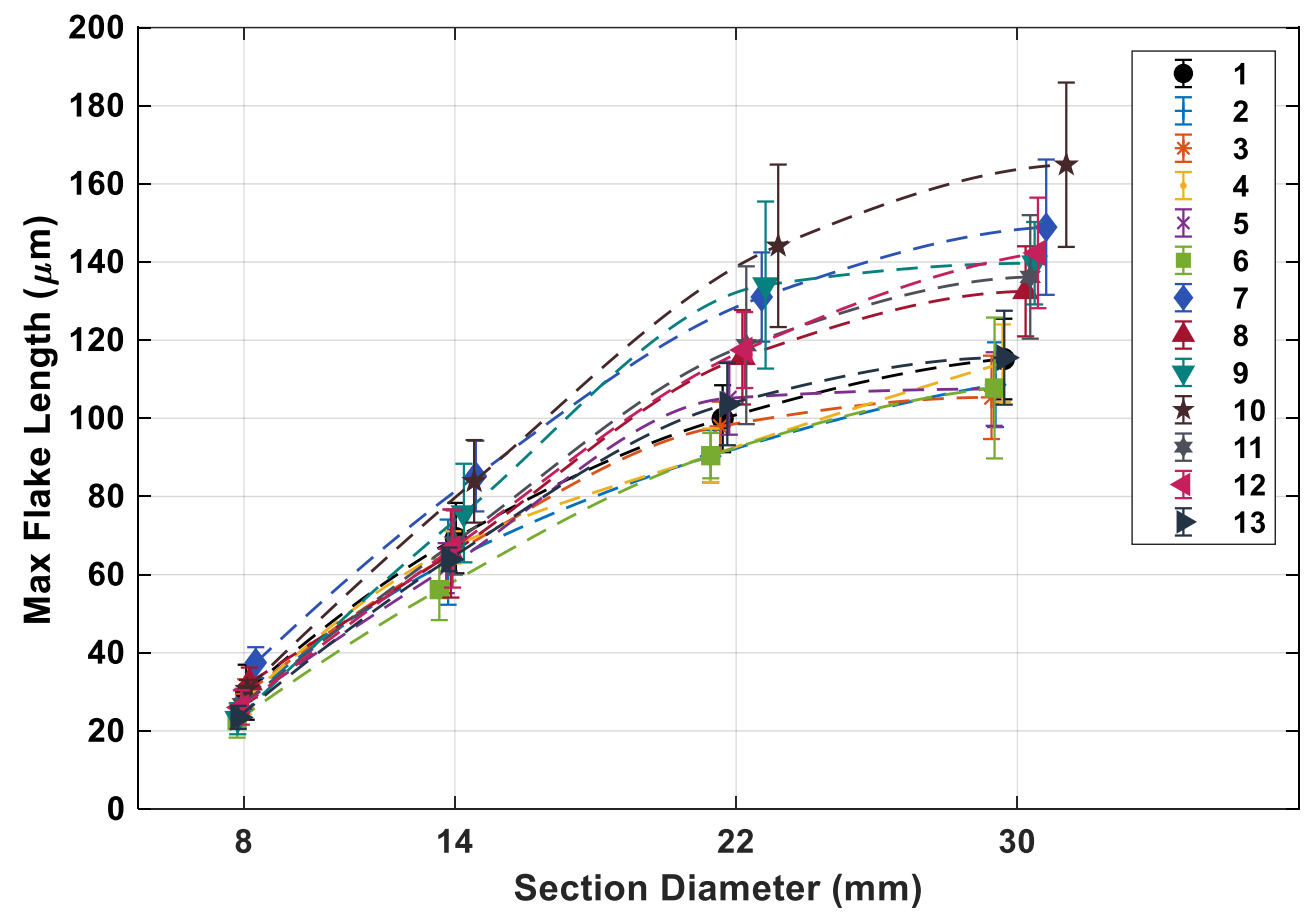

Figure 3.3.4 Max flake length for each section. Error bars represent 95\% standard error.

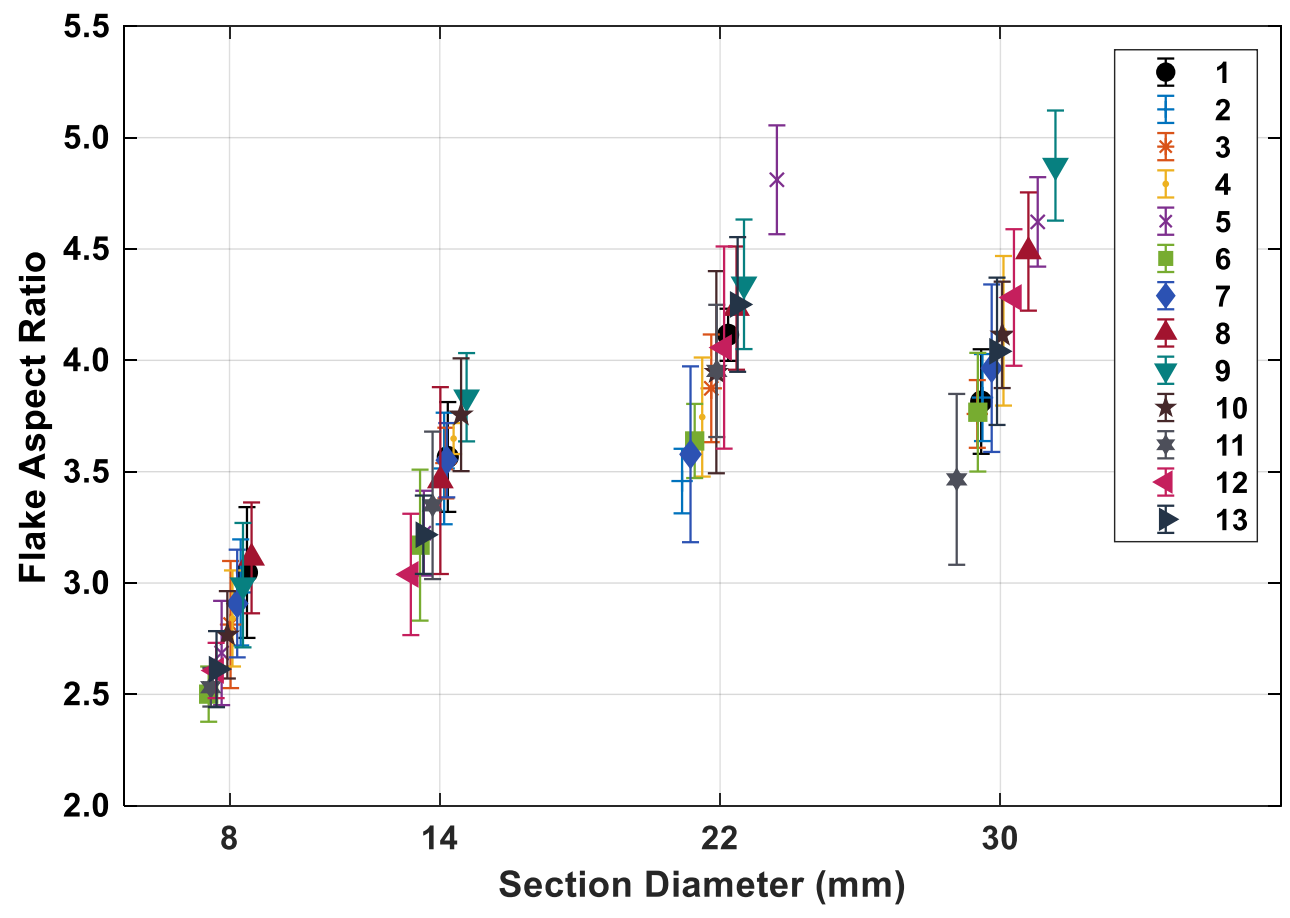

Figure 3.3.5 Graphite flake aspect ratio (length/width) for each section size. Error bars represent $95 \%$ standard error. 


\subsection{Secondary phases}

The secondary phases detected in the $30 \mathrm{~mm}$ bar were qualitatively evaluated using SEMEDS. They included $\mathrm{MnS}$ (typical for cast iron), $\mathrm{Mo}_{2} \mathrm{C}, \mathrm{NbC}$, mixed (Mo, $\mathrm{Nb}$ )C, and Morich cementite $\left(\mathrm{Fe}_{3} \mathrm{C}\right)$ regions (Table 3.4.1).

Table 3.4.1 Precipitated phases found in the $30 \mathrm{~mm}$ bar of each alloy qualitatively evaluated using SEM-EDS.

\begin{tabular}{cl|cccc}
\hline Alloy & Additions & \multicolumn{4}{|c}{ Precipitated Phases } \\
\hline 1 & $\mathrm{Cr}$ & $\mathrm{MnS}$ & & & \\
2 & $\mathrm{Cr}, \mathrm{Nb}$ & $\mathrm{MnS}$ & $\mathrm{NbC}$ & & \\
3 & $\mathrm{Cr}, \mathrm{Nb}$ & $\mathrm{MnS}$ & $\mathrm{NbC}$ & $\mathrm{Mo}_{2} \mathrm{C}$ & \\
4 & $\mathrm{Cr}, \mathrm{Mo}$ & $\mathrm{MnS}$ & & $\mathrm{Mo}_{2} \mathrm{C}$ & $(\mathrm{Mo}, \mathrm{Nb}) \mathrm{C}$ \\
5 & $\mathrm{Cr}, \mathrm{Mo}, \mathrm{Nb}$ & $\mathrm{MnS}$ & $\mathrm{NbC}$ & $\mathrm{Mo}_{2} \mathrm{C}$ & $(\mathrm{Mo}, \mathrm{Nb}) \mathrm{C}$ \\
6 & $\mathrm{Cr}, \mathrm{Mo}, \mathrm{Nb}$ & $\mathrm{MnS}$ & $\mathrm{NbC}$ & & \\
7 & $\mathrm{Cr}$ & $\mathrm{MnS}$ & & & \\
8 & $\mathrm{Cr}, \mathrm{Nb}$ & $\mathrm{MnS}$ & $\mathrm{NbC}$ & & \\
9 & $\mathrm{Cr}, \mathrm{Nb}$ & $\mathrm{MnS}$ & $\mathrm{NbC}$ & & \\
10 & $\mathrm{Cr}, \mathrm{Mo}$ & $\mathrm{MnS}$ & & $\mathrm{Mo}_{2} \mathrm{C}$ & \\
11 & $\mathrm{Cr}, \mathrm{Mo}, \mathrm{Nb}$ & $\mathrm{MnS}$ & $\mathrm{NbC}$ & $\mathrm{Mo}_{2} \mathrm{C}$ & $(\mathrm{Mo}, \mathrm{Nb}) \mathrm{C}$ \\
12 & $\mathrm{Cr}, \mathrm{Mo}, \mathrm{Nb}$ & $\mathrm{MnS}$ & $\mathrm{NbC}$ & $\mathrm{Mo}_{2} \mathrm{C}$ & $(\mathrm{Mo}, \mathrm{Nb}) \mathrm{C}$ \\
13 & $\mathrm{Cr}, \mathrm{Mo}, \mathrm{Nb}$ & $\mathrm{MnS}$ & $\mathrm{NbC}$ & $\mathrm{Mo}_{2} \mathrm{C}$ & $(\mathrm{Mo}, \mathrm{Nb}) \mathrm{C}$ \\
\hline
\end{tabular}

Most of the niobium carbides $(\mathrm{NbC})$ were $\mathrm{X}-\mathrm{Y}$ shaped, suggesting they were eutectic carbides that formed at the boundary of eutectic cells during the later stages of solidification [6] (Figure 3.4.1 and Figure 3.4.2). Few primary, blocky, $\mathrm{NbC}$ and (Mo, $\mathrm{Nb}$ )C carbides were observed. The Mo-rich carbide phases (right in Figure 3.4.1) appeared similar to the $\mathrm{Mo}_{2} \mathrm{C}$ carbides observed in gray iron produced by Mohmand and Fredriksson [41]. 

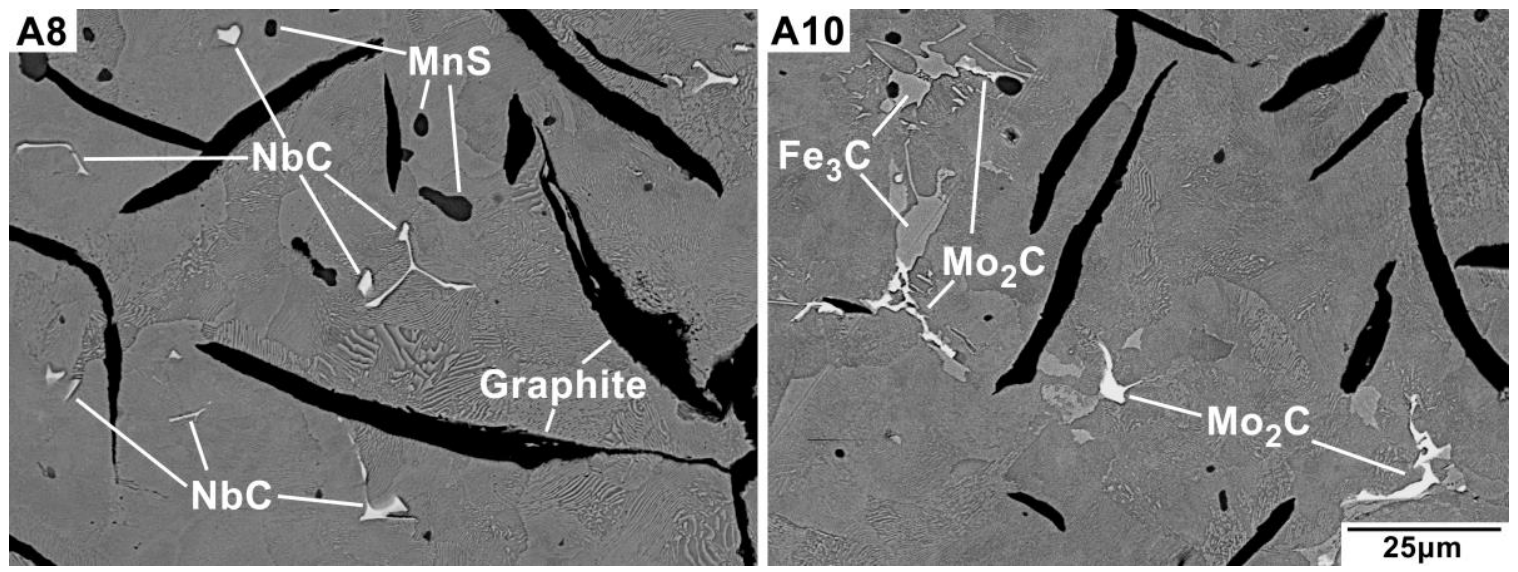

Figure 3.4.1 Backscatter electron images of the $30 \mathrm{~mm}$ bar for alloy 8 (left) and alloy 10 (right).

The alloys containing $\mathrm{Mo}$ and $\mathrm{Nb}$ tended to form mixed $(\mathrm{Mo}, \mathrm{Nb}) \mathrm{C}$ that was more rounded in shaped than the $\mathrm{NbC}$ and was often found near patches of cementite (Figure 3.4.2). These alloys also had Mo-rich areas in many of the cementite regions (right in Figure 3.4.2).
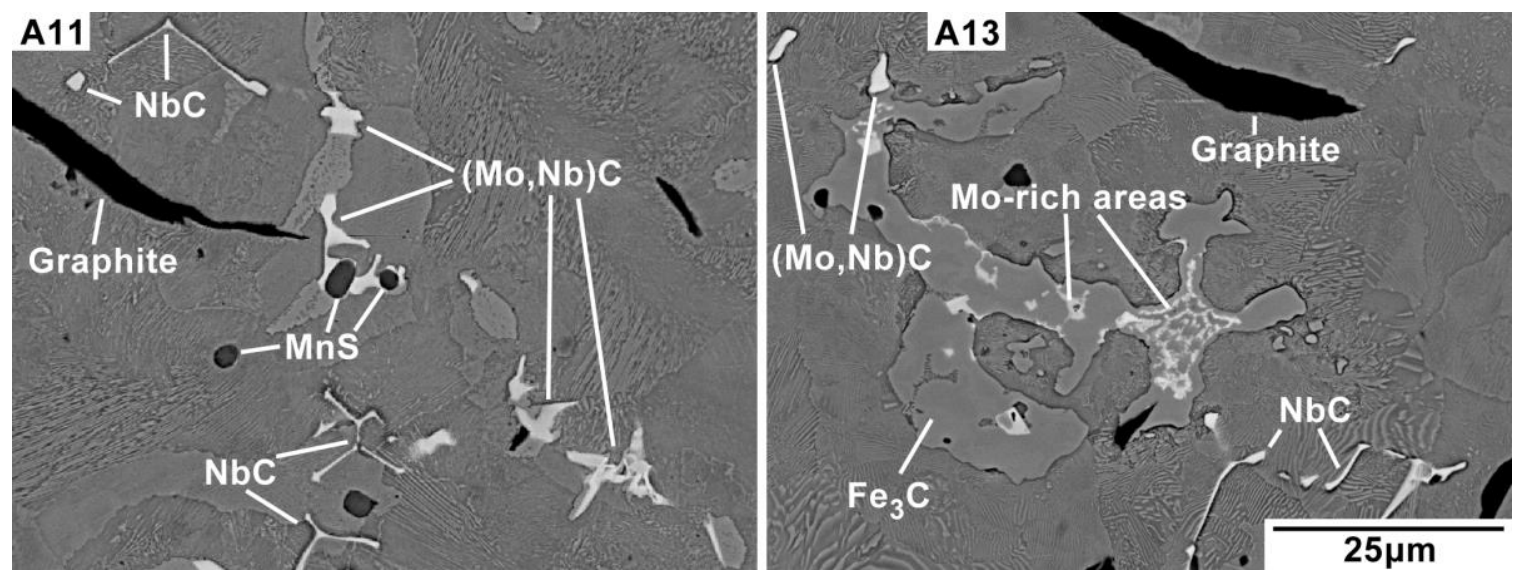

Figure 3.4.2 Backscatter electron images of the $30 \mathrm{~mm}$ bar for alloy 11 (left) and alloy 13 (right).

An example of how some of these phases appeared under optical microscopy is presented in Figure 3.4.3. A more magnified view of eutectic $\mathrm{NbC}$ is shown in Figure 3.4.4. 


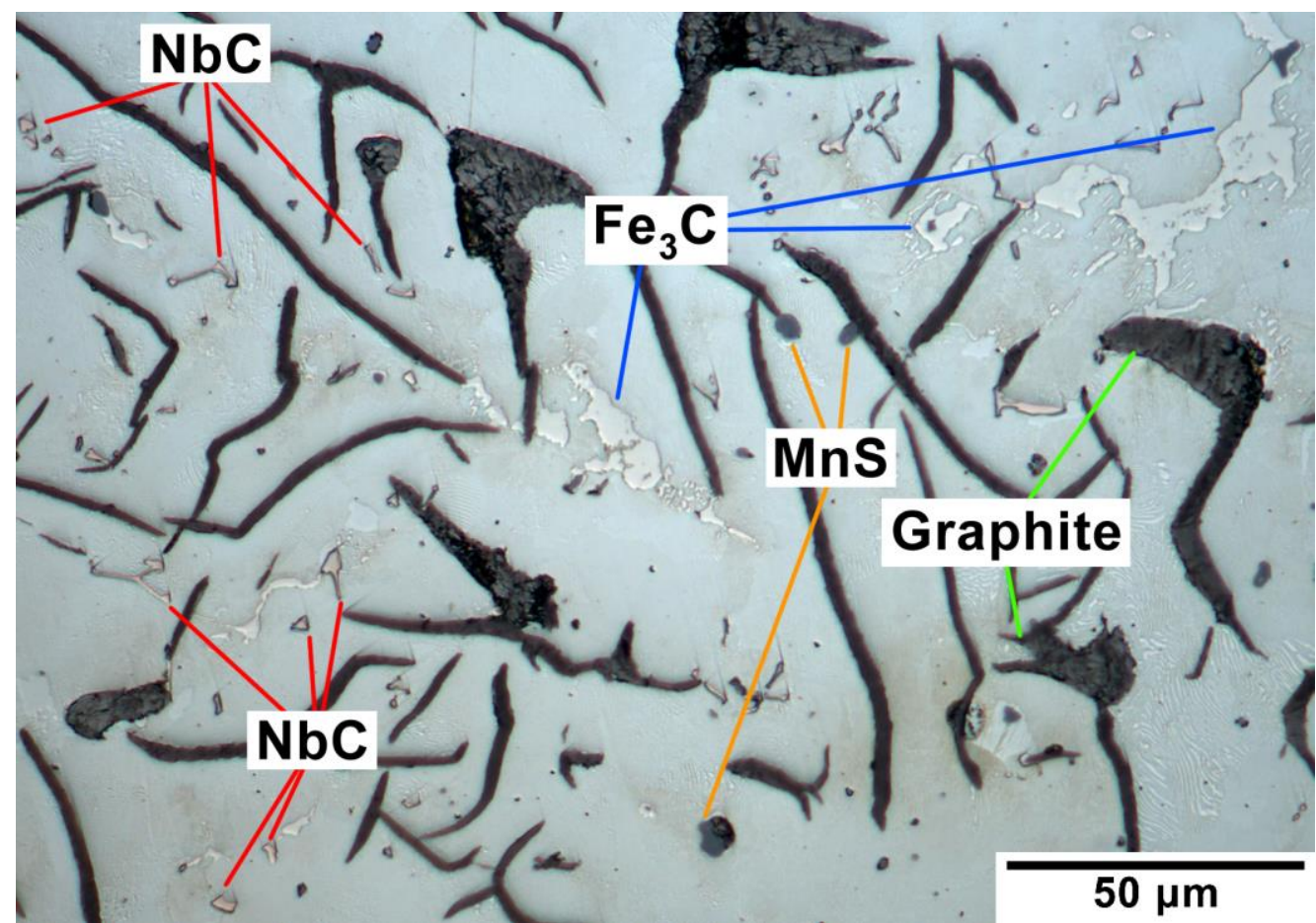

Figure 3.4.3 Example of phase appearance under optical microscopy at 500X. This micrograph was taken from the $30 \mathrm{~mm}$ bar of alloy 12 .

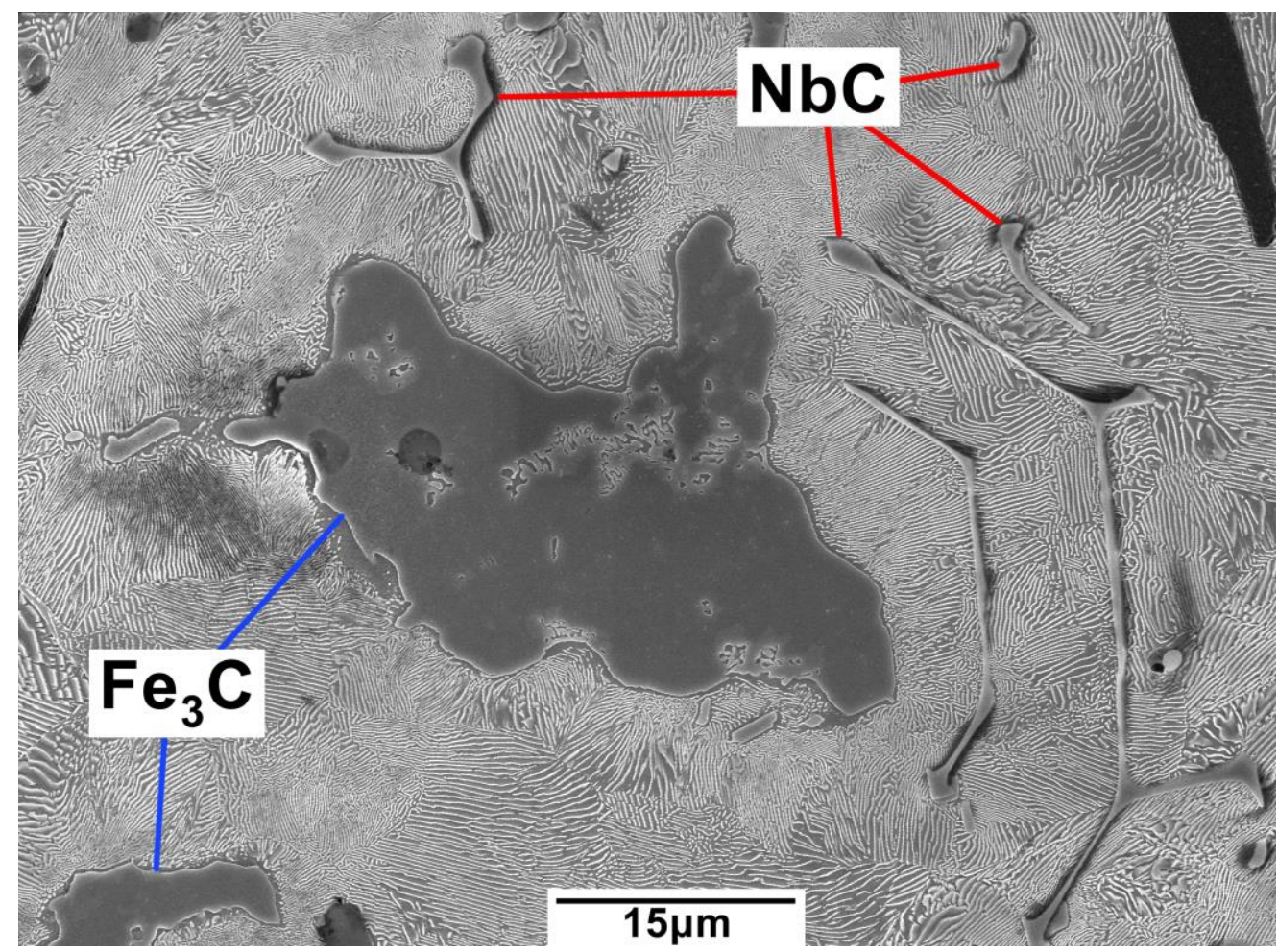

Figure 3.4.4 FE-SEM secondary electron image of cementite and eutectic niobium carbides (NbC). Image was taken from the $30 \mathrm{~mm}$ bar of alloy 12 at $1500 \mathrm{X}$. 


\subsection{Wear Testing}

Two sets of data were collected for ASTM G65 sand abrasion wear testing: the material volume loss during the test and the coefficient of friction between the sand-coated rubber wheel rubbing and the metal surface. The high CE alloys had higher wear with a $\sim 10 \mathrm{~mm}^{3}$ increase in volume loss (Figure 3.5.1). As more alloying addition were made, the volume loss tended to decrease for both alloy groups, with the lowest being the most alloyed variants, alloy 6 and 13. A $~ 16 \%$ improvement was observed from alloy 1 to alloy 6 , a $\sim 25 \%$ improvement was observed from alloy 7 to 12 , and $\sim 39 \%$ for alloy 7 to 13 . The coefficient of friction appears to remain constant $(\sim 0.41)$ with no obvious correlation to alloying (Figure 3.5.2).

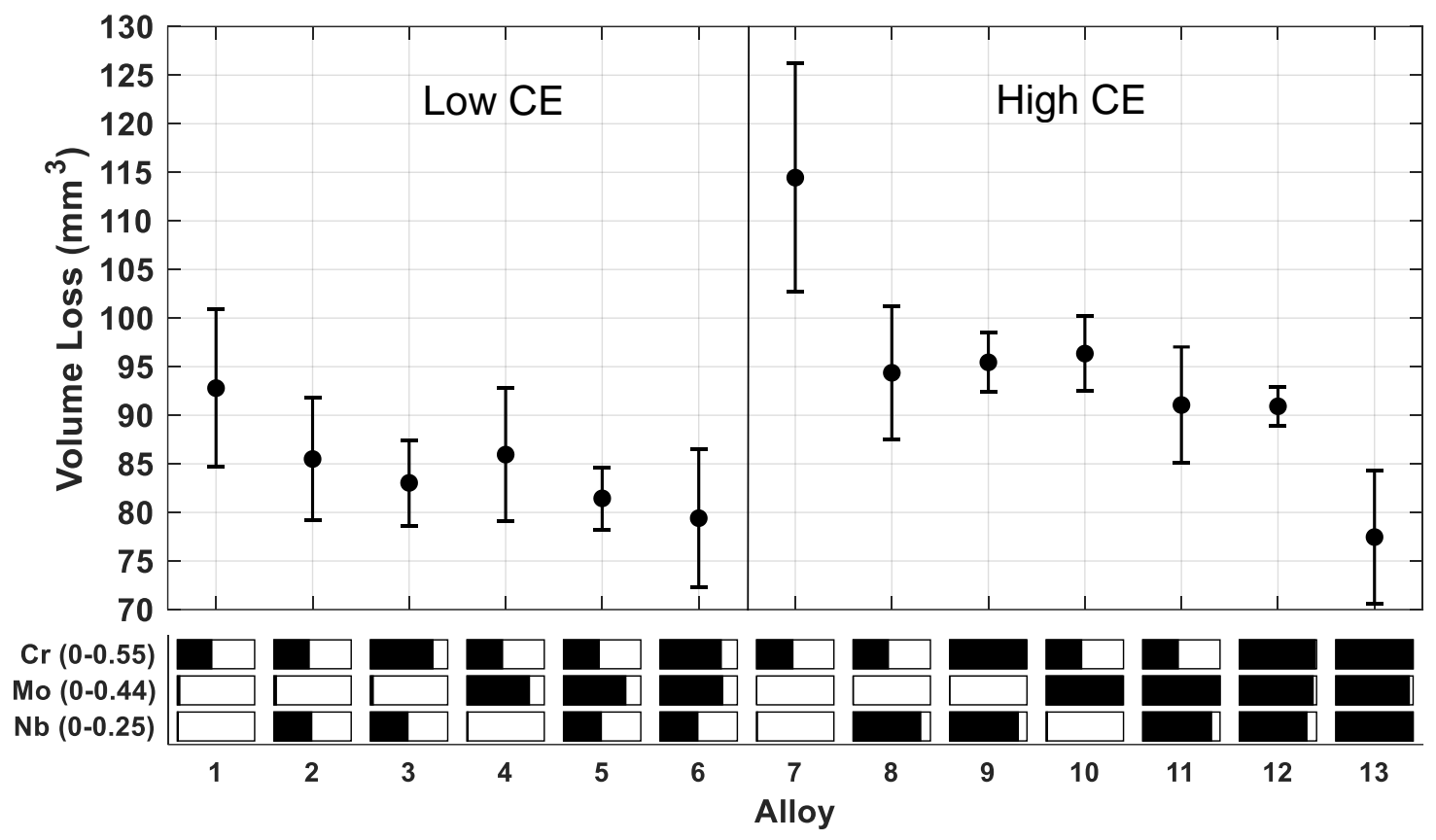

Figure 3.5.1 ASTM G65 sand abrasion wear testing on the $30 \mathrm{~mm}$ bar for each alloy. Error bars represent $95 \%$ standard error from four measurements per alloy. 


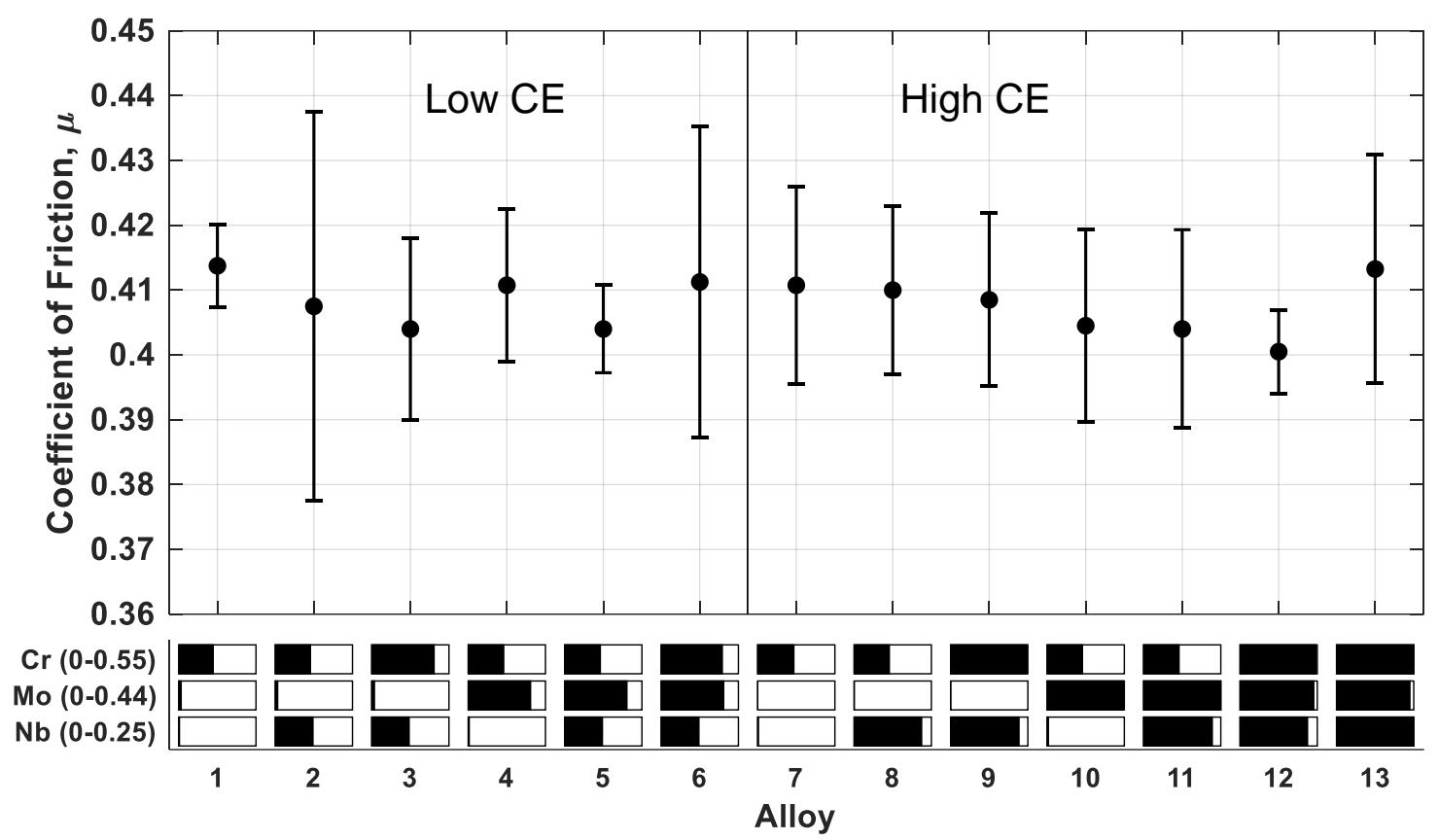

Figure 3.5.2 Coefficient of friction measured during sand abrasion wear testing on the $30 \mathrm{~mm}$ bar from each alloy. Error bars represent $95 \%$ standard error from four measurements per alloy.

\subsection{Electrical Resistivity}

The electrical resistivity for the high CE alloys was higher and had more variation than the low CE alloys (Figure 3.6.1). Alloying tended to decrease resistivity, with niobium appearing to have the greatest effect. 


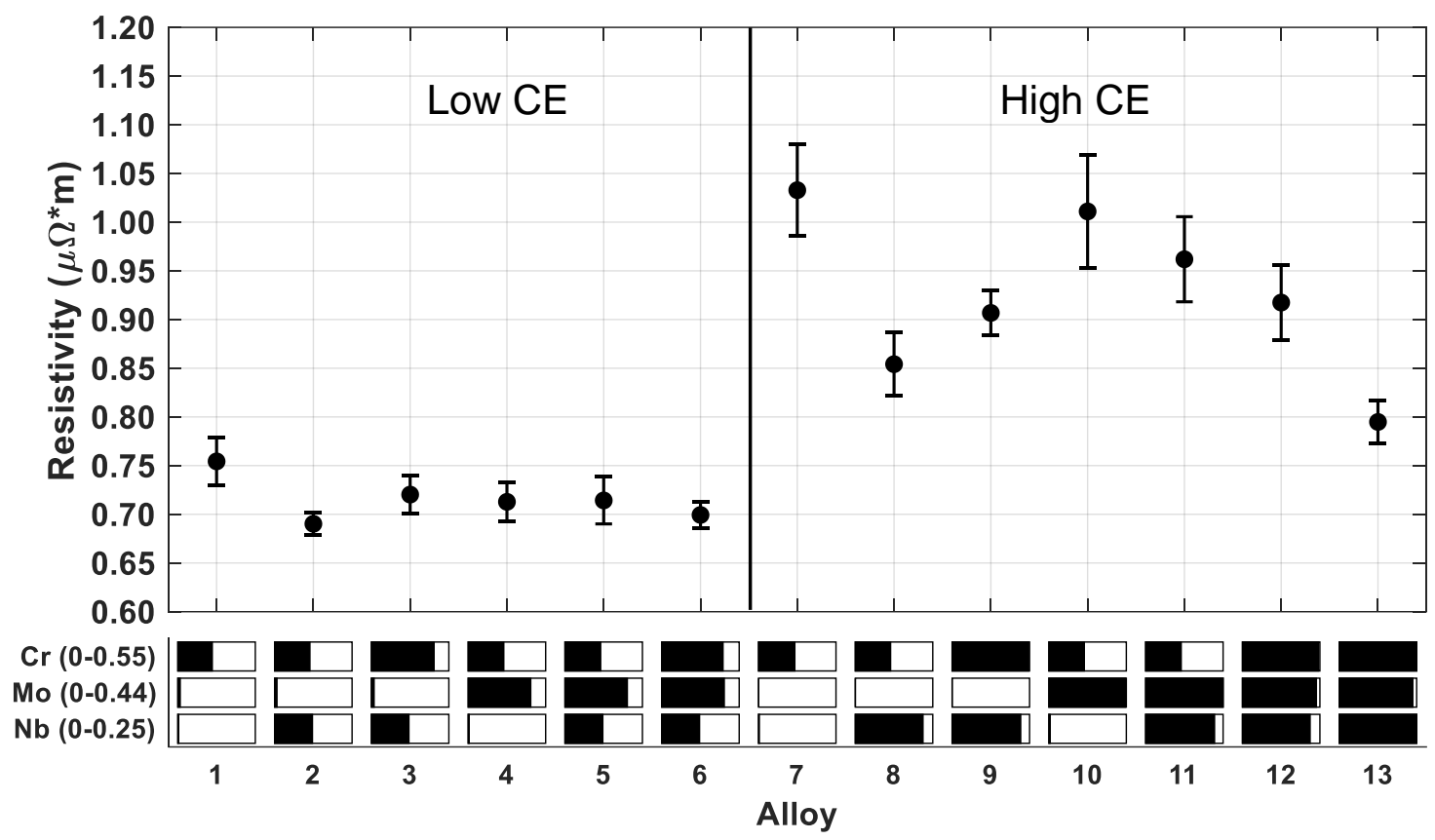

Figure 3.6.1 Electrical resistivity of the $30 \mathrm{~mm}$ bar sections measured using the 4-point probe technique. Error bars represent $95 \%$ standard error from ten measurements per alloy.

\subsection{Strength}

Brinell hardness of the $30 \mathrm{~mm}$ bars had a wide distribution of values, with the low $\mathrm{CE}$ alloys being $\sim 28 \mathrm{HB}$ harder than the high CE alloys (Figure 3.7.1). Alloying additions within each group increased hardness as expected. 


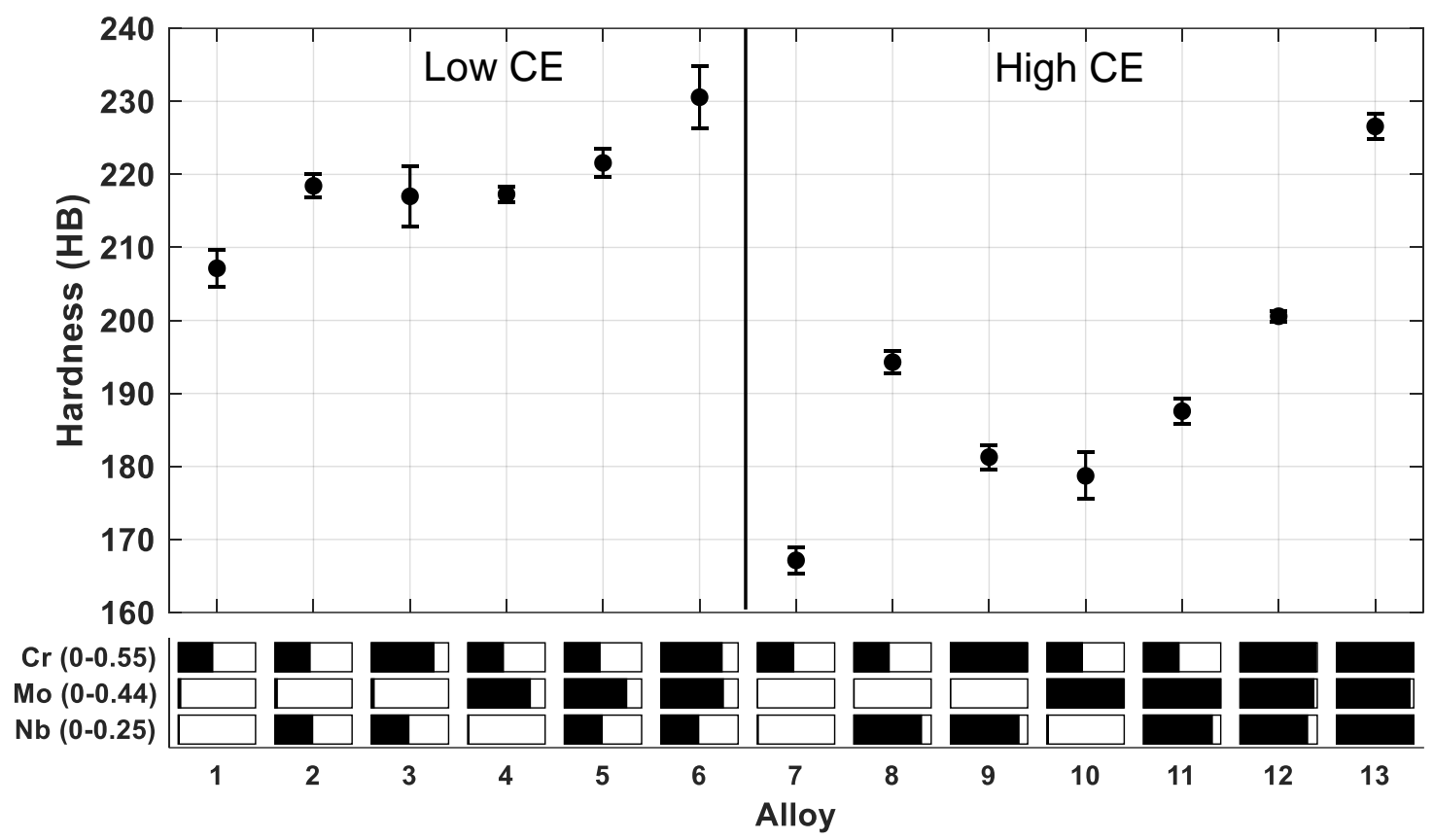

Figure 3.7.1 Brinell hardness of the $30 \mathrm{~mm}$ bar. A $5 \mathrm{~mm}$ ball was used with $750 \mathrm{kgf}$ load and 15 second dwell time. Error bars represent 95\% standard error from seven measurements per alloy.

Pearlite microconstituent hardness was slightly higher $(\sim 23 \mathrm{HV})$ for the high CE alloys (Figure 3.7.2), but there was more measurement variation. Similar to the Brinell results, alloying additions tended to increase hardness. 


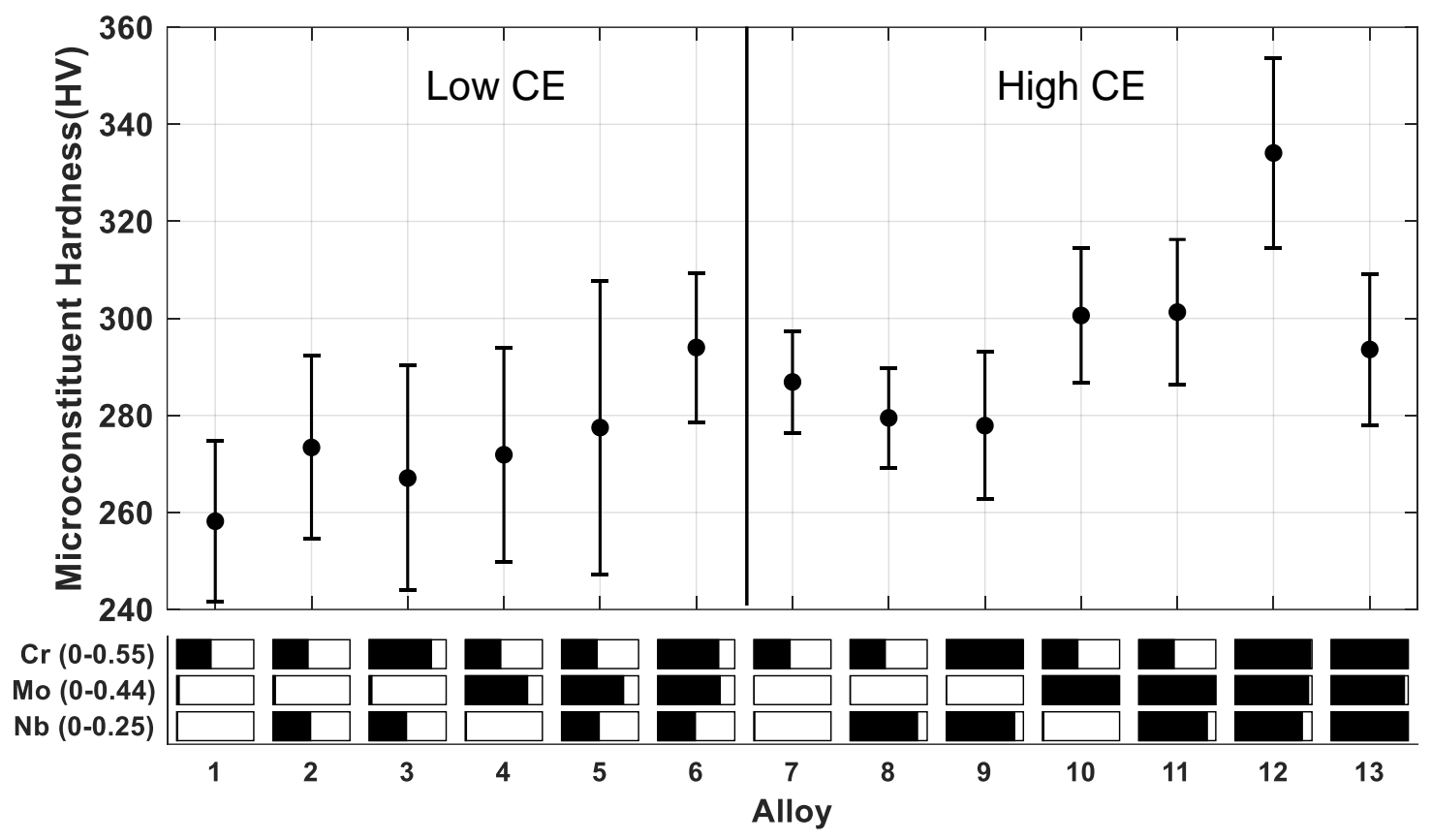

Figure 3.7.2 Vickers hardness of the matrix microconstituent for the $30 \mathrm{~mm}$ section of each alloy. A $0.2 \mathrm{kgf}$ load and 15 second dwell time was used. Error bars represent $95 \%$ standard error from ten measurements per alloy

Ultimate tensile strength (UTS) it typically used to quantify strength in gray iron because of its brittle nature and non-linear elastic behavior. Ultimate tensile strength was measured at room temperature, $380,480,580$ and $680^{\circ} \mathrm{C}$. The difference among the high and low CE groups was significant, with the high CE alloys having a $115 \mathrm{MPa}$ lower strength on average at room temperature; this general trend continued at higher temperatures (Figure 3.7.3). For all alloys, tensile strength was maintained until $\sim 380^{\circ} \mathrm{C}$. After $380^{\circ} \mathrm{C}$, a drop of approximately $0.4 \mathrm{MPa} /{ }^{\circ} \mathrm{C}$ was observed for the high $\mathrm{CE}$ alloys and $0.7 \mathrm{MPa} /{ }^{\circ} \mathrm{C}$ for low CE alloys. Out of the 260 tensile bars tested, none failed prematurely, suggesting good casting quality; however, nine high temperature datapoints were removed from analysis due to excessive cooling and subsequent strength gain during testing. A graph focused on the high temperature datapoints can be found in Appendix D (Figure 7.4.1). 


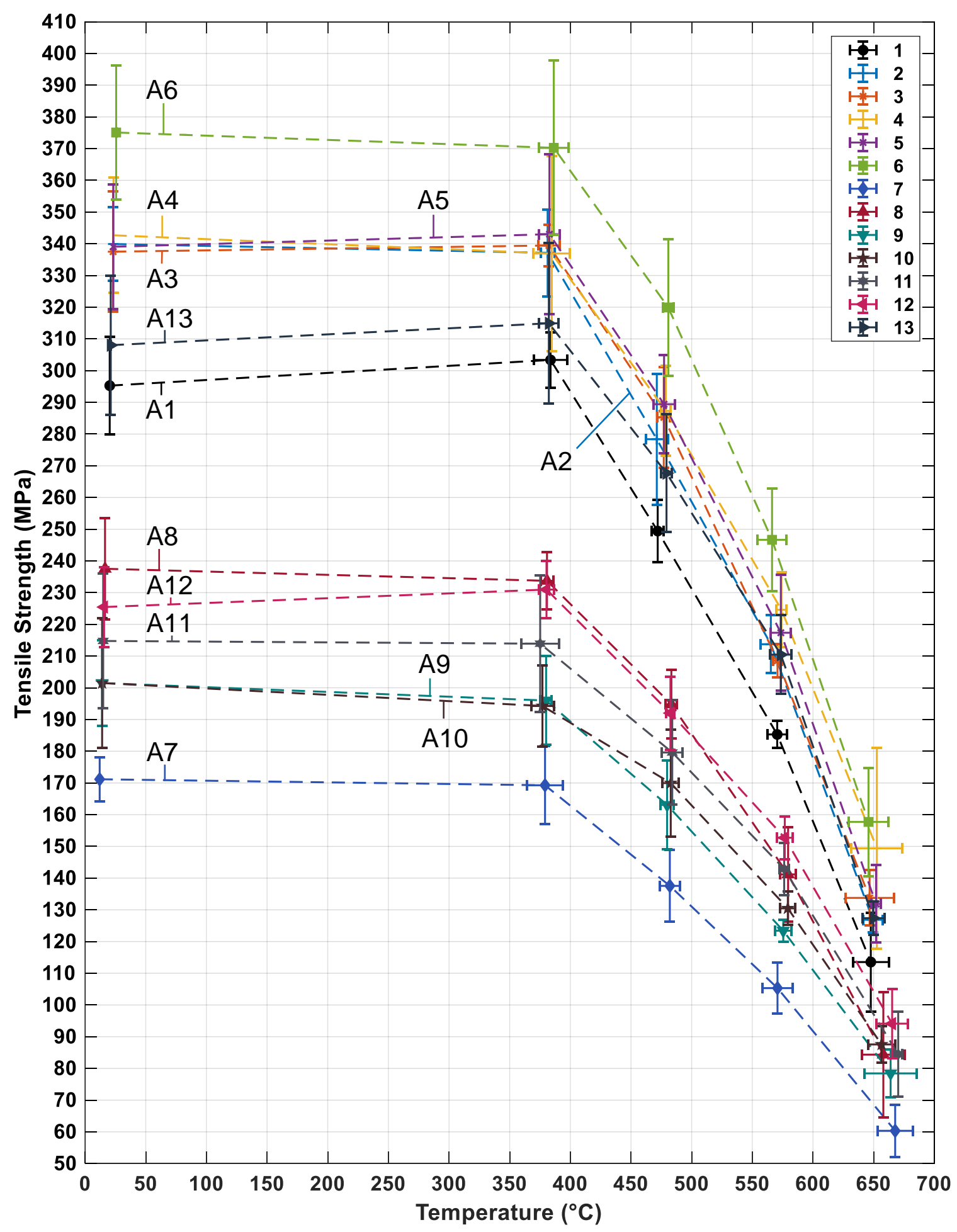

Figure 3.7.3 Ultimate tensile strength vs temperature for ASTM E8 standard 0.5 in tensile rounds machined from the $22 \mathrm{~mm}$ bar sections of each alloy. The temperature recorded was the temperature at fracture. Error bars represent 95\% standard error from four measurements per alloy. 
Tensile strength at room temperature is shown in Figure 3.7.4 for easy comparison with alloy chemistry. Alloys 2-5 had little difference, with variations in $\mathrm{Cr}$, Mo, and $\mathrm{Nb}$ producing the same results. There was a similar trend for alloys $8-12$; however, $\mathrm{Nb}$ appeared to be more potent than $\mathrm{Cr}$ and Mo at increasing strength in the high $\mathrm{CE}$ alloys.

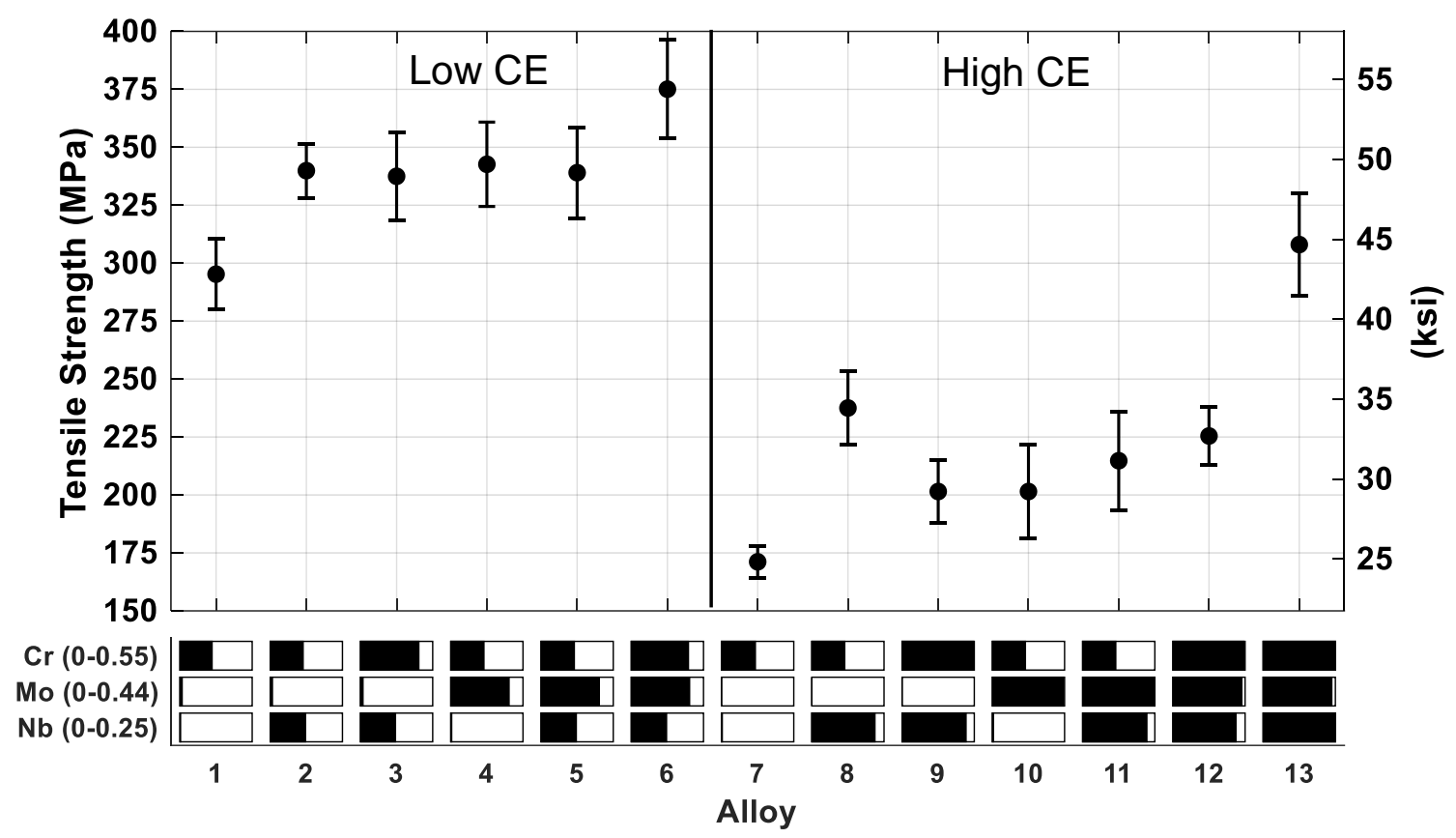

Figure 3.7.4 Room temperature ultimate tensile strength measured from ASTM E8 standard 0.5 in tensile rounds machined from the $22 \mathrm{~mm}$ bar sections of each alloy. Error bars represent 95\% standard error from four measurements per alloy.

Room temperature modulus was recorded using the secant method. Unfortunately, due to extensometer slippage, the low CE modulus data was not analyzed. The extensometer grips were tightened before testing the high CE alloys and a good dataset was produced (Figure 3.7.5). Modulus data mirrored the tensile strength data well with alloys 8 and 13 having the highest modulus out of the alloys analyzed. 


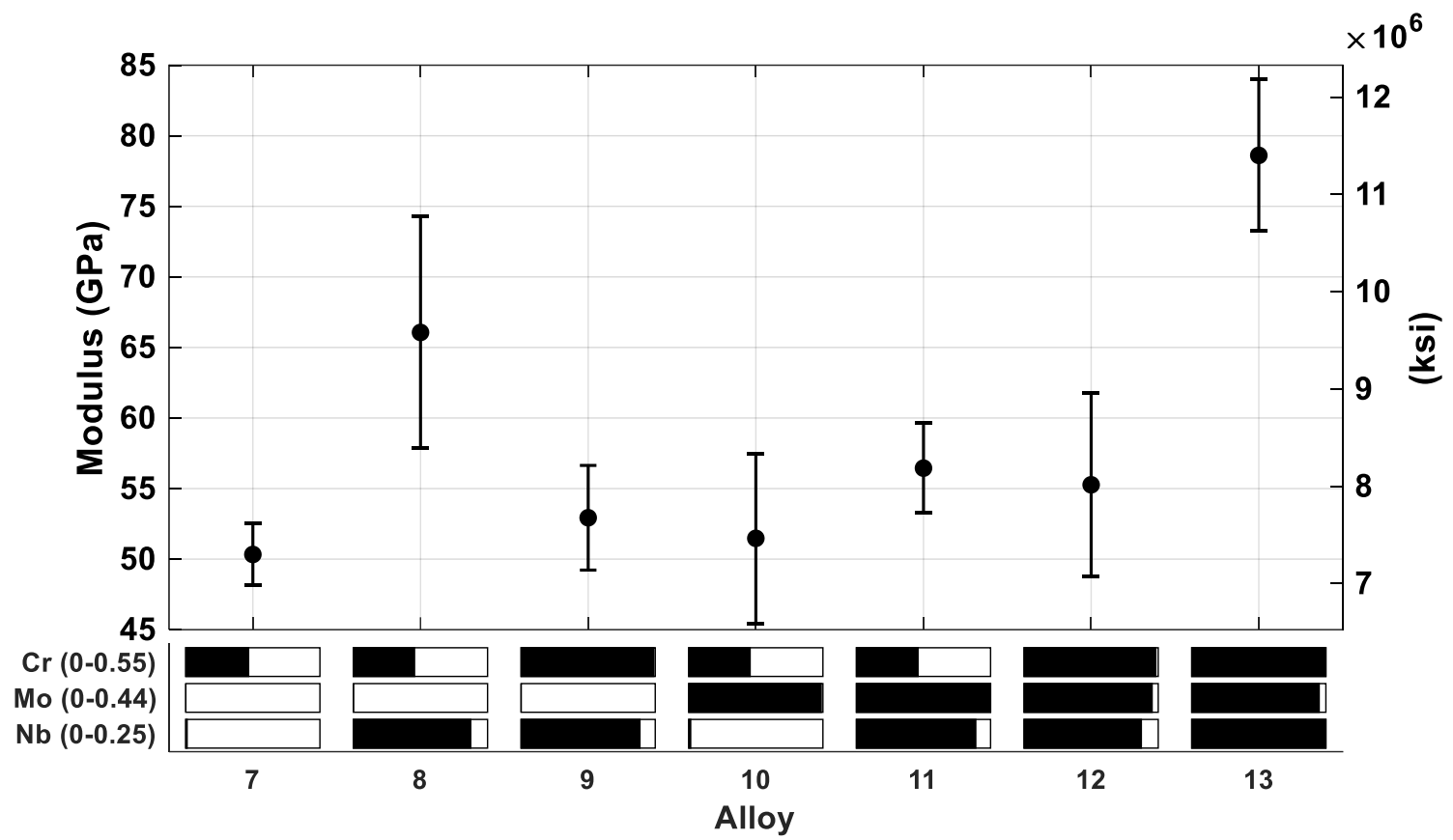

Figure 3.7.5 Modulus data for the high CE alloys calculated using the secant method. Error bars represent $95 \%$ standard error from four measurements per alloy.

\subsection{Pearlite Spacing}

The mean true pearlite spacing noticeably varied among alloys but there was no clear trend other than high $\mathrm{CE}$ alloys having a slightly smaller average pearlite spacing than the low CE alloys (Figure 3.8.1). 


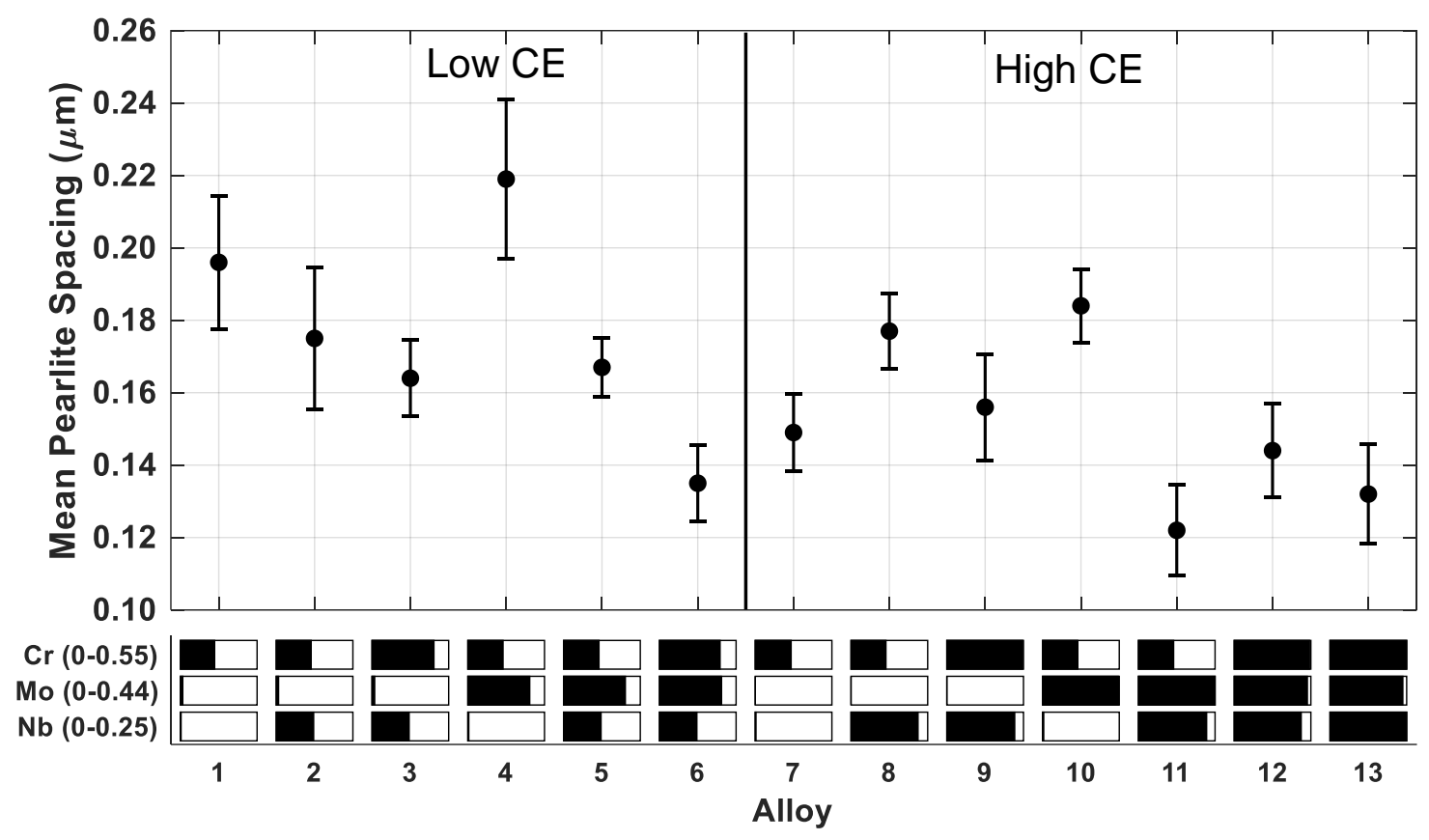

Figure 3.8.1 True mean pearlite spacing estimated from mean random spacing measurements of cementite using the circular grid intersection technique on FE-SEM images. Eight 3500X images were taken per alloy and ten circles were inscribed per image. Error bars represent 95\% standard error from 80 measurements per alloy.

\subsection{Thermal Diffusivity}

Thermal diffusivity was measured at $100,200,300,400$, and $500^{\circ} \mathrm{C}$ from samples taken from the $30 \mathrm{~mm}$ bars (Figure 3.9.1). The maximum difference in values was $17 \%$ between alloy 7 and alloy 6 at $100^{\circ} \mathrm{C}$. The high CE alloys tended to have higher thermal diffusivity than the low CE alloys. All thermal diffusivity values followed a near-linear trend inversely related to temperature. The range of values decreased with increasing temperature. This is similar to data collected by Hecht et al. [22]. 


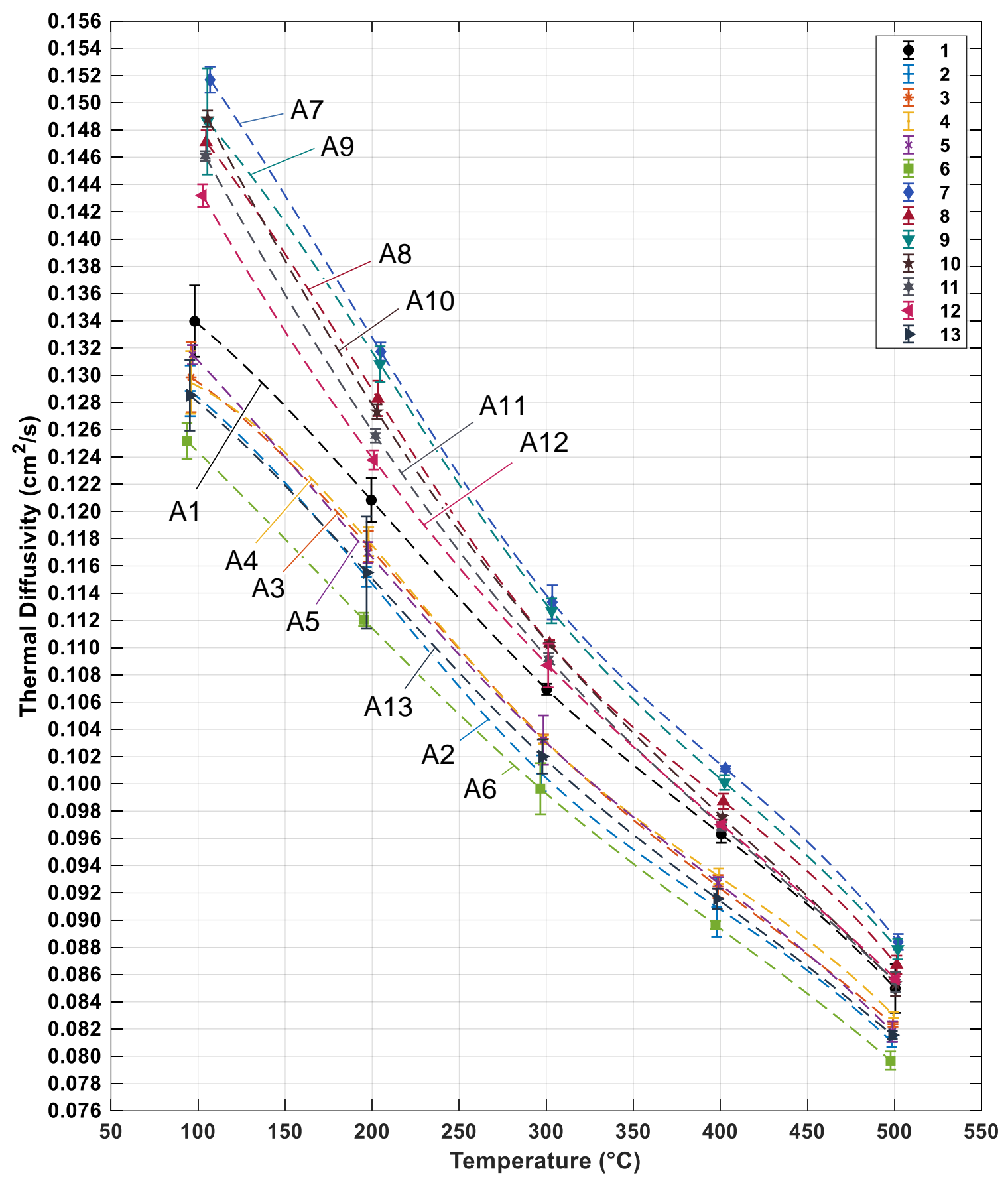

Figure 3.9.1 Thermal diffusivity measured from the $30 \mathrm{~mm}$ bars at temperatures from $100-500^{\circ} \mathrm{C}$. Error bars represent $95 \%$ standard error from six measurements per alloy. Datapoints have been offset slightly from their temperature mark to make error bars easier to observe. 
Thermal diffusivity data measured at $100^{\circ} \mathrm{C}$ are presented in Figure 3.9.2 for comparison by alloying additions. As more alloying additions were made to base alloys 1 and 7 , thermal diffusivity tended to decrease, with alloy 6 having the lowest value.

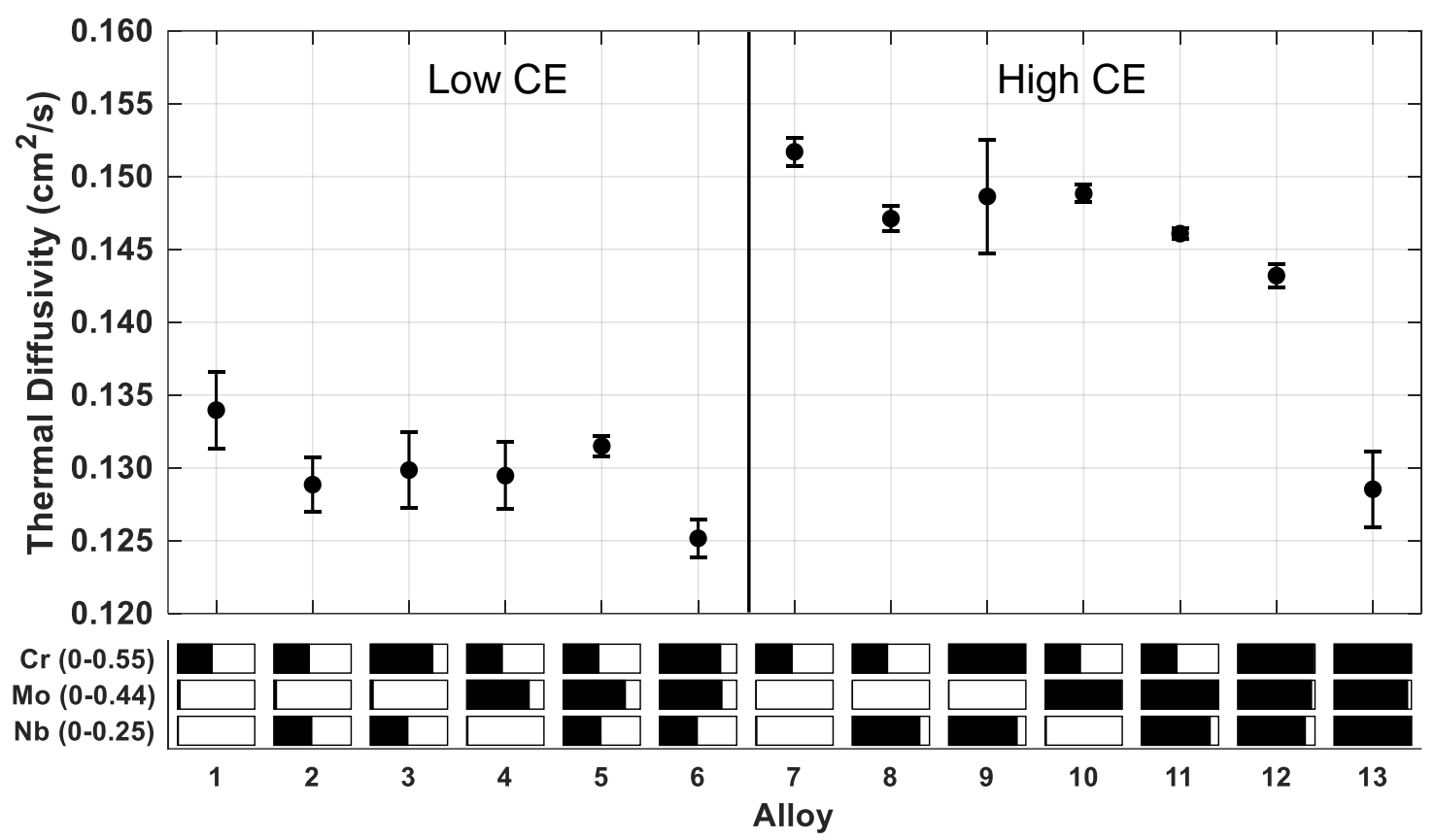

Figure 3.9.2 Thermal diffusivity at $100^{\circ} \mathrm{C}$ for all alloys measured from the $30 \mathrm{~mm}$ bars. Error bars represent $95 \%$ standard error from six measurements per alloy. 


\section{Discussion}

\subsection{Design of Experiment}

The statistical software program Minitab (V19) was used to establish a $2^{4}$ factorial design of experiments (DOE) to analyze the factors responsible for many of the properties measured (Table 4.1.1). Alloy 13 was not incorporated into the DOE because it had 13\% higher niobium than the target and a $0.1 \mathrm{wt} \%$ lower CE than the target. These two factors are likely responsible for the increase in mechanical properties. To simplify the DOE and eliminate a third level for $\mathrm{Cr}, \mathrm{Mo}$, and $\mathrm{Nb}$, a high/low approach was taken for coding the levels by averaging the high chemistry values shown in Table 3.1.1.

Table 4.1.1 Design of experiment analyzed in Minitab. Specific values for the high levels were taken as averages from the actual chemistries in alloys 1 through 12.

\begin{tabular}{ccccc}
\hline & \multicolumn{4}{c}{ Factors and Levels } \\
\cline { 2 - 5 } Alloy & $\mathbf{C E}$ & $\mathbf{C r}$ & $\mathbf{M o}$ & $\mathbf{N b}$ \\
\hline 1 & 3.97 & 0.25 & 0.00 & 0.00 \\
2 & 3.97 & 0.25 & 0.00 & 0.17 \\
3 & 3.97 & 0.50 & 0.00 & 0.17 \\
4 & 3.97 & 0.25 & 0.41 & 0.00 \\
5 & 3.97 & 0.25 & 0.41 & 0.17 \\
6 & 3.97 & 0.50 & 0.41 & 0.17 \\
7 & 4.32 & 0.25 & 0.00 & 0.00 \\
8 & 4.32 & 0.25 & 0.00 & 0.17 \\
9 & 4.32 & 0.50 & 0.00 & 0.17 \\
10 & 4.32 & 0.25 & 0.41 & 0.00 \\
11 & 4.32 & 0.25 & 0.41 & 0.17 \\
12 & 4.32 & 0.50 & 0.41 & 0.17 \\
\hline
\end{tabular}

The forward selection and backward elimination methods were employed separately to create models for each property analyzed, typically resulting in similar models. Only factors with a $p$-value less than 0.05 were kept in the models. Two-way interaction terms between $\mathrm{Cr}$, Mo, and $\mathrm{Nb}$ were allowed as well as the 3-way interaction term, $\mathrm{Cr} * \mathrm{Mo} * \mathrm{Nb}$; however, these terms were found to be statistically insignificant in most cases. The main effects plots were derived from models calculated using the forward selection method since 
it tends to be more conservative and focused on including only the most influential terms and interactions. For the sake of presentation, all 4 factors are included in all main effects plots, but the gray shaded factors are statistically insignificant and not included in the subsequent models.

\subsection{Graphite Flake Properties}

As expected, the amount of graphite present is linked to $\mathrm{CE}$ with a higher $\mathrm{CE}$ resulting in more graphite. Although cooling rates vary significantly from the $8 \mathrm{~mm}$ section size up to the $30 \mathrm{~mm}$ (see cooling curves in Appendix B), the percent graphite remained relatively constant among each alloy (Figure 3.3.2).

Aside from CE, niobium was found to be statistically significant in refining the mean and maximum graphite flake length (Figure 4.2.1). This reinforces what has been observed by previous research [6]. Chromium and molybdenum do not appear to interact with or change the flake refining effect of $\mathrm{Nb}$ when alloyed together.

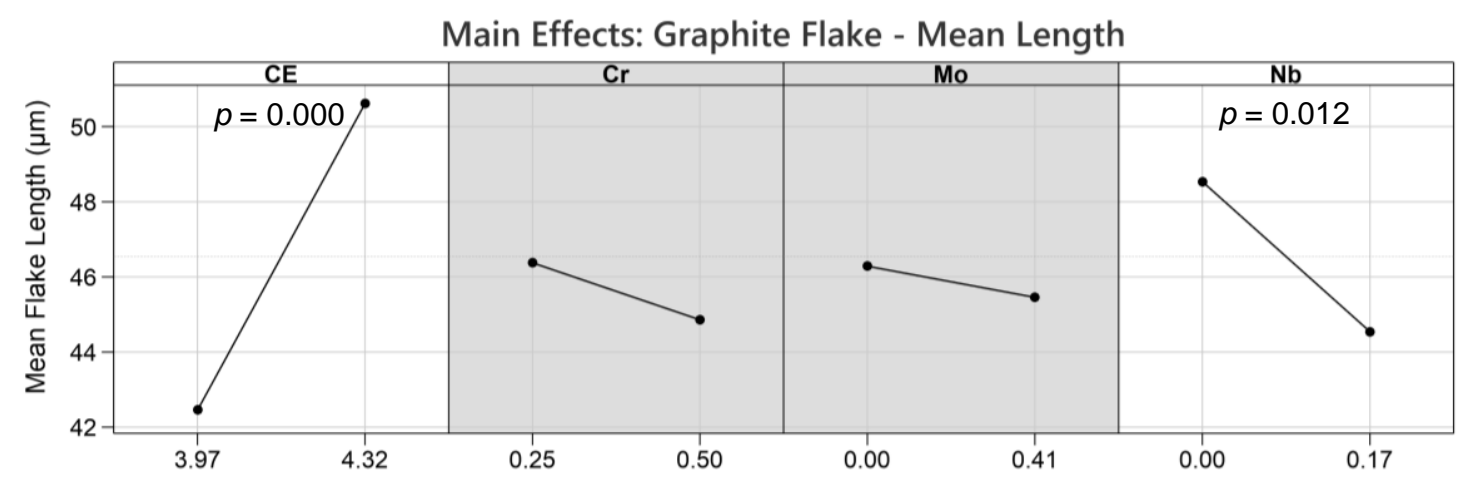

Figure 4.2.1 Main effects plots for mean graphite flake length. Model $R^{2}=0.86$.

Alloying additions did not affect the graphite flake aspect ratio per the DOE, although a decrease with smaller section size can be seen in Figure 3.3.5. This is logical because the larger cooling rate in smaller section sizes does not allow graphite flakes to grow significantly after nucleating. The 8 and $14 \mathrm{~mm}$ section sizes were primarily type $\mathrm{D}$ and $\mathrm{E}$ interdendritic graphite whose length is limited by dendrite arm spacing. 
Carbon equivalent was the only significant factor $\left(p=0.000, R^{2}=0.74\right)$ on mean graphite flake spacing with an increase in CE resulting in a decrease in spacing. This appears reasonable when reviewing the results of mean flake length in Figure 4.2.1. Flakes in higher CE alloys grow to be longer, requiring more interweaving for the same flake density, leading to a smaller edge-to-edge flake spacing.

\subsection{Pearlite Spacing}

Niobium was the only statistically significant factor affecting pearlite spacing with an increase in $\mathrm{Nb}$ leading to refinement (Figure 4.3.1). Although the model fit is poor $\left(R^{2}=\right.$ 0.34), this finding does show that $\mathrm{Nb}$ is more potent at refining pearlite than $\mathrm{Cr}$ and Mo.

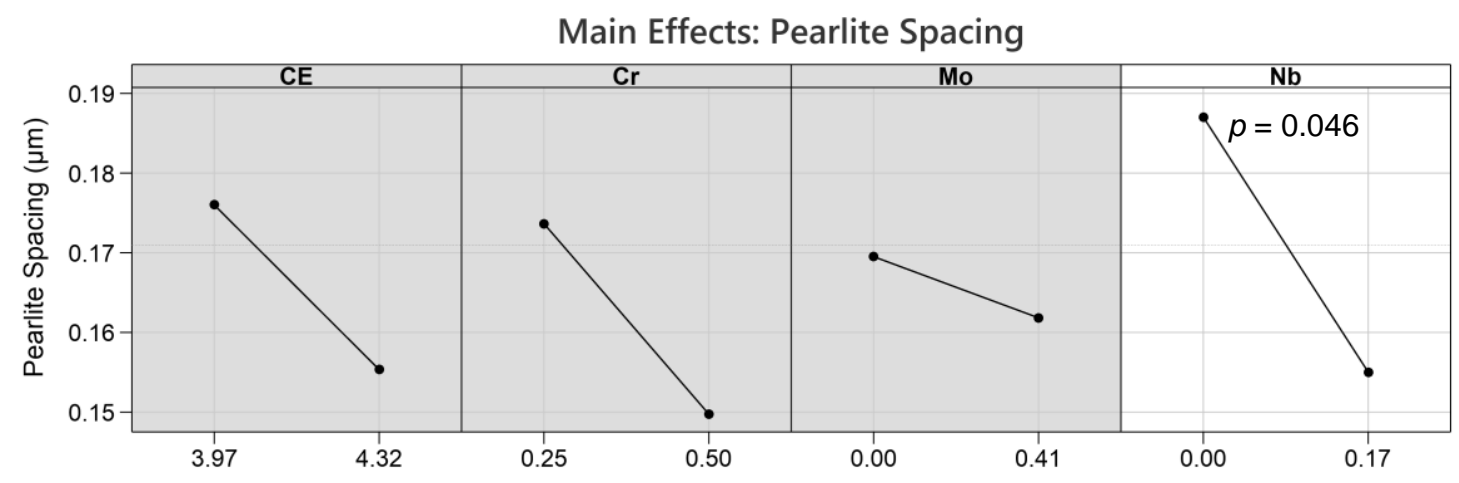

Figure 4.3.1 Main effects plot for the true mean pearlite spacing measured from the 30 mm bars. Model $R^{2}=0.34$.

\subsection{Strength}

Three factors were found to be statistically significant for Brinell macro hardness (Figure 4.4.1). An increase in CE causes a decrease in hardness, as expected, due to the presents of more graphite which is unable to support as much of a compressive load as the pearlite matrix. Both $\mathrm{Mo}$ and $\mathrm{Nb}$ tend to increase hardness, with $\mathrm{Nb}$ being more potent and more statistically significant. 


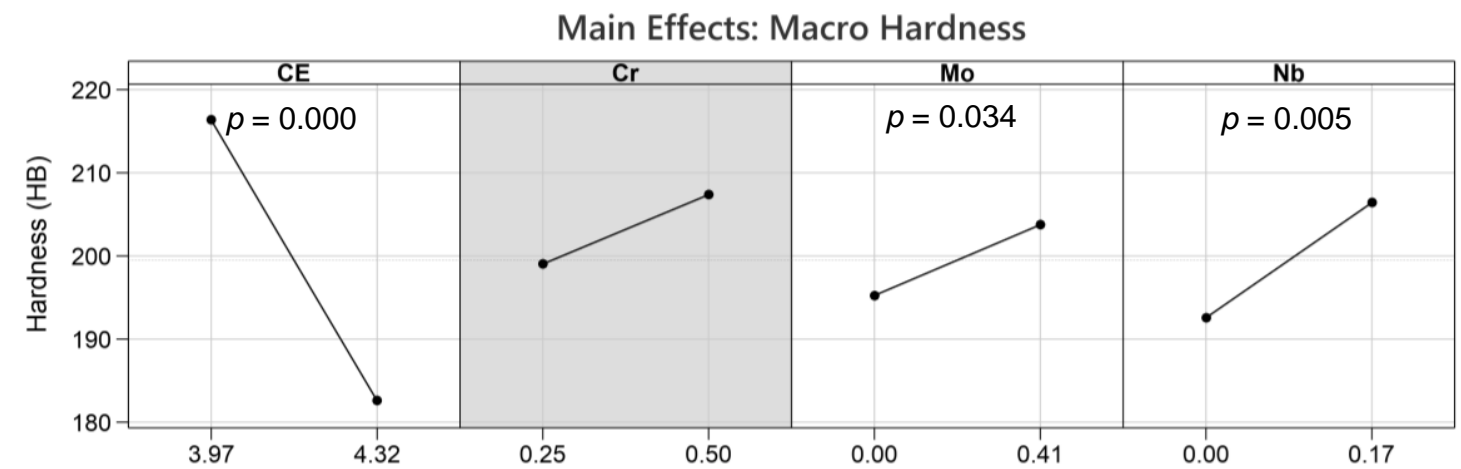

Figure 4.4.1 Main effects plots for Brinell hardness measured from the $30 \mathrm{~mm}$ bars. Model $R^{2}=0.94$.

Vickers hardness of the pearlite matrix was found to be influenced most by $\mathrm{CE}$ and Mo (Figure 4.4.2). Based on the SEM-EDS results, many of the cementite patches analyzed were rich in Mo (right in Figure 3.4.2). This likely explains the increase in pearlite hardness with Mo additions.

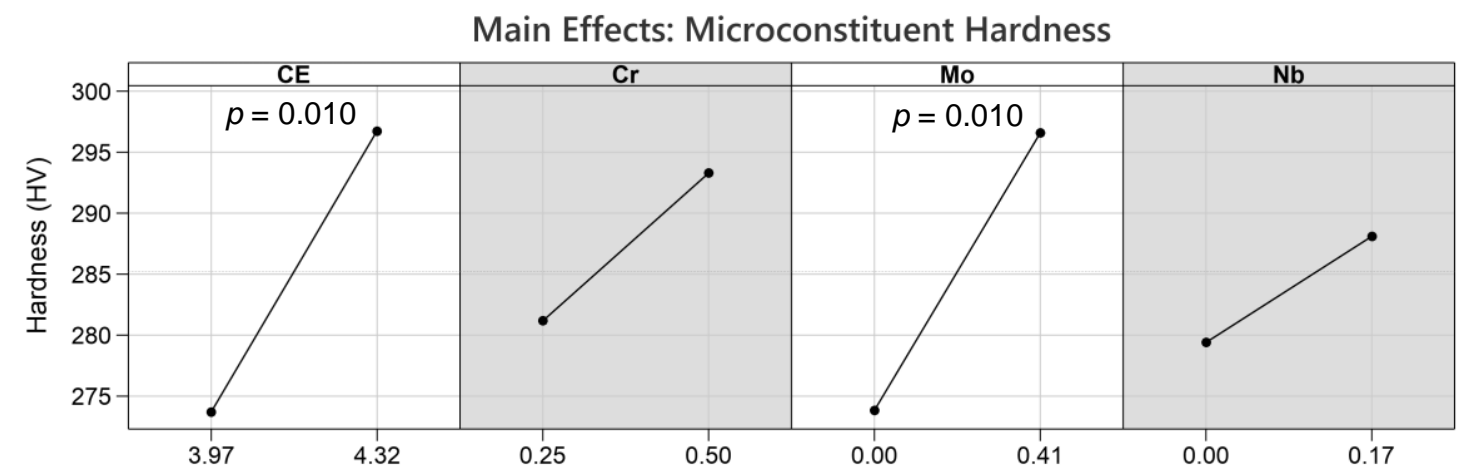

Figure 4.4.2 Main effects plots for Vickers microhardness conducted on the matrix microconstituent, pearlite, in the $30 \mathrm{~mm}$ bars. Model $R^{2}=0.70$.

Two factors, $\mathrm{CE}$ and $\mathrm{Nb}$, were found to be statistically significant for tensile strength (Figure 4.4.3). The effect of CE on tensile strength is obvious and can be seen in Figure 3.7.4. The finding that $\mathrm{Nb}$ is statistically significant in increasing strength is no surprise and is likely due to the refinement effects of $\mathrm{Nb}$, such as reducing pearlite spacing and mean flake length, as discussed earlier. 


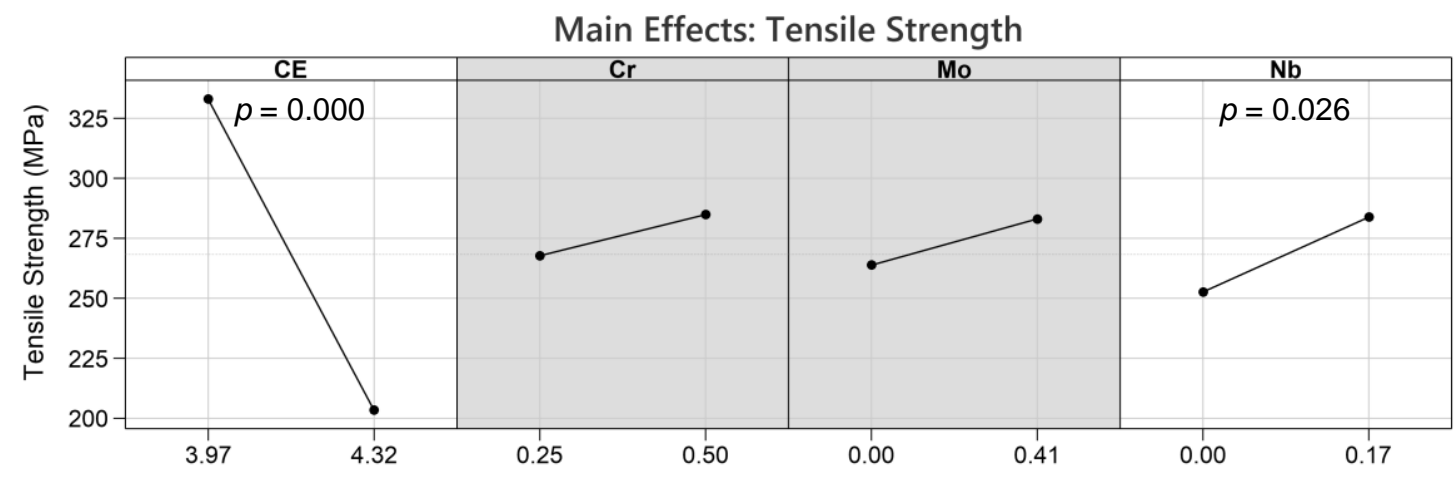

Figure 4.4.3 Main effects plots for tensile strength of the $22 \mathrm{~mm}$ bars at room temperature. Model $R^{2}=0.94$.

Unfortunately the modulus data for the low CE alloys was compromised due to extensometer slippage. The high CE data set was analyzed with a 3-factor DOE that did not include CE; however, no statistically significant factors were found. When compared with the ultimate tensile strength for the high CE alloys (Figure 3.7.4), it appears that modulus very closely follows the same trend, with alloy 13 being the highest at $79 \mathrm{GPa}$ and alloy 8 being the second highest at $66 \mathrm{GPa}$ (Figure 3.7.5). Alloy 13 was $0.1 \mathrm{wt} \%$ lower in $\mathrm{CE}$ and $0.03 \mathrm{wt} \%$ higher in $\mathrm{Nb}$ than the rest of the high $\mathrm{CE}$ alloys (Table 3.1.1). This, combined with the formation of more carbides, is likely what caused an increase in tensile strength, Brinell hardness, modulus, and wear resistance.

\subsection{Resistivity and Strength}

Similar to tensile strength, $\mathrm{CE}$ and $\mathrm{Nb}$ were the only statistically significant factors influencing electrical resistivity, with an increase in $\mathrm{CE}$ raising resistivity and $\mathrm{Nb}$ lowering it (Figure 4.5.1). The refining effects of $\mathrm{Nb}$ introduce more interfaces and scattering events for electrons and phonons and these are likely the cause for an increase in electrical resistance with $\mathrm{Nb}$ additions [24]. 
Main Effects: Electrical Resistivity

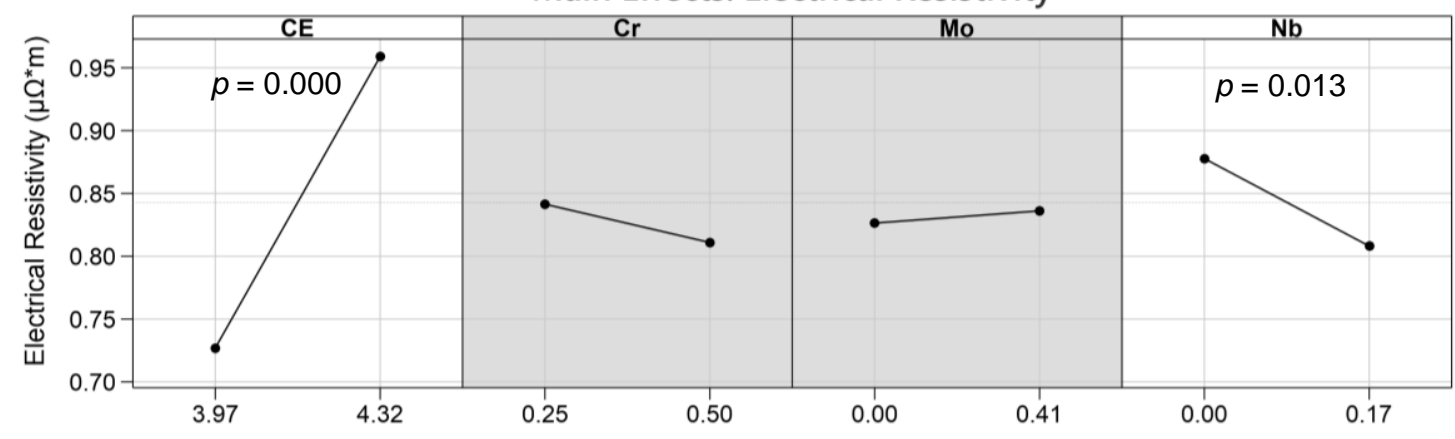

Figure 4.5.1 Main effects plots for electrical resistivity measured from the $30 \mathrm{~mm}$ bars. Model $R^{2}=0.93$.

When constructing a Pearson correlation matrix from all the response variables, a striking correlation was found between tensile strength and resistivity. Upon further research, such a trend has been observed by Bieroński et al. and is compared in Figure 4.5.2 [42]. An additional dataset recorded using the same methods proposed here, except on OEM rotor samples, is also included in the graph (red datapoints).

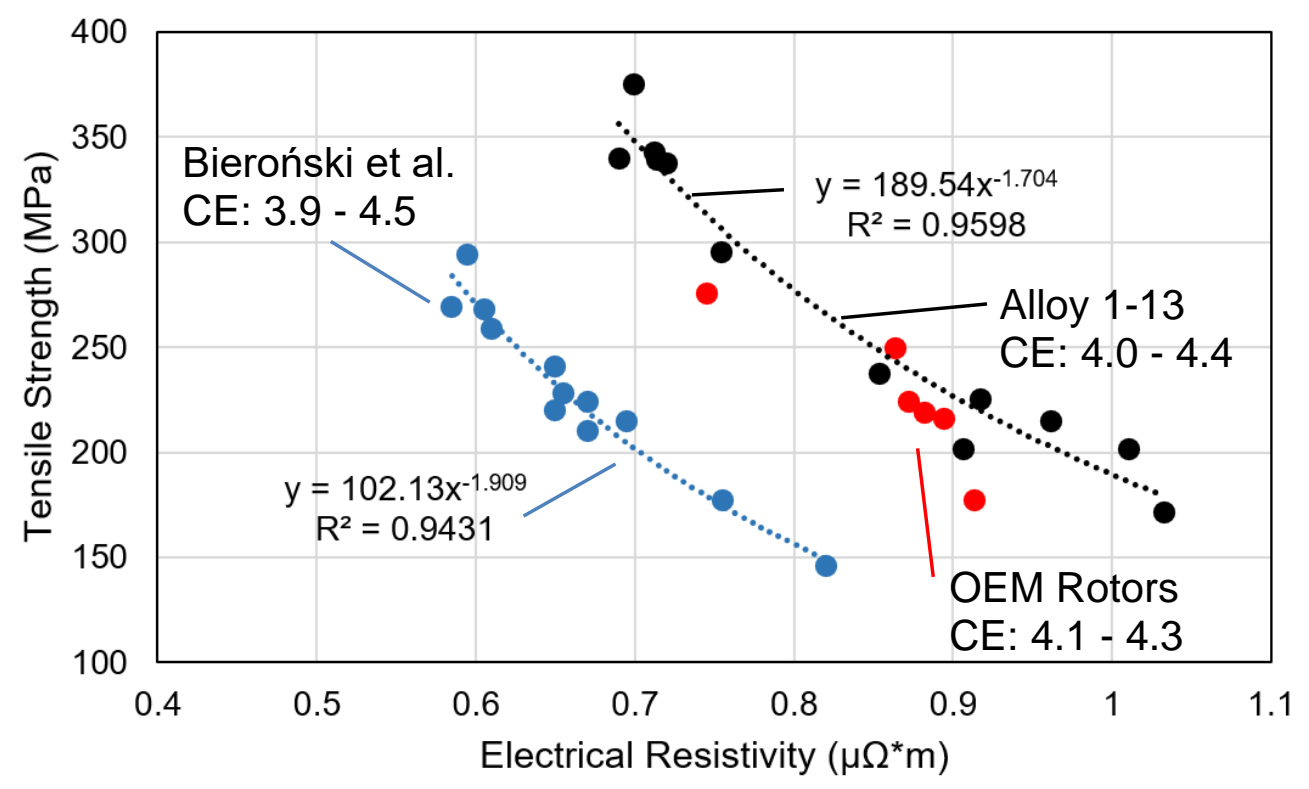

Figure 4.5.2 The power law correlation observed between tensile strength and electrical resistivity. Black data is from in the current study, red are measurements taken using the same methodology and sample prep except samples were machined from rotors from six different OEMs, and blue is data from literature [42]. 
The measurements of electrical resistivity taken on OEM rotor samples aligned with the trend derived using alloy 1-13 data; however, the literature reported dataset is offset by $\sim 0.22 \mu \Omega * \mathrm{~m}$ even though the range of CE for all datasets overlap. The cause of the discrepancy may be due to the geometry of the samples tested and the testing method used. Bieroński et al. utilized the four-point probe technique on $120 \times 40 \times 15 \mathrm{~mm}$ samples with the probe placed on the lateral ends of the longest side, essentially treating it as a wire and calculating resistivity using the measured resistance, cross-sectional area, and length of the sample. The method employed in this study utilized disk-shaped samples nominally $25 \mathrm{~mm}$ in diameter and $4 \mathrm{~mm}$ thick. The probes were placed in a line, $1 \mathrm{~mm}$ apart, on the center of the sample. This configuration requires a much more involved calculation to determine the correction factor for the geometry (see section 2.15). Since sample geometry has a large influence when relating measured resistance to true resistivity, the difference in methods used here and in Bieroński's work may be the cause of the discrepancy. Another possibility could be the cooling rate of Bieronski's samples being greater, resulting in finer flake morphologies than what was present in the $30 \mathrm{~mm}$ bar and brake rotor samples. A refinement in flake morphology could lead to a decrease in resistivity due to having fewer electron and phonon scattering sources [24]. This can be linked back to $\mathrm{Nb}$ being statistically significant in refining graphite flake length (Figure 4.2.1), tensile strength (Figure 4.4.3), and electrical resistivity (Figure 4.5.1).

\subsection{Effects on Fluidity}

A brief look at the fluidity for all alloys reveals no trend other than the high $\mathrm{CE}$ alloys filling more than the low CE alloys (Figure 3.2.2). These results were quantified (Table 3.3.1) and analyzed in the DOE. It was confirmed that CE was the only statistically significant factor contributing to fluidity, with a high value increasing fluidity (Figure 4.6.1). This result demonstrates that the alloying additions $\mathrm{Cr}, \mathrm{Mo}$, and $\mathrm{Nb}$ do not have a noticeable effect on fluidity. The effect of CE, or carbon more specifically, on fluidity was also mentioned in the ASM handbook on cast irons [19]. 


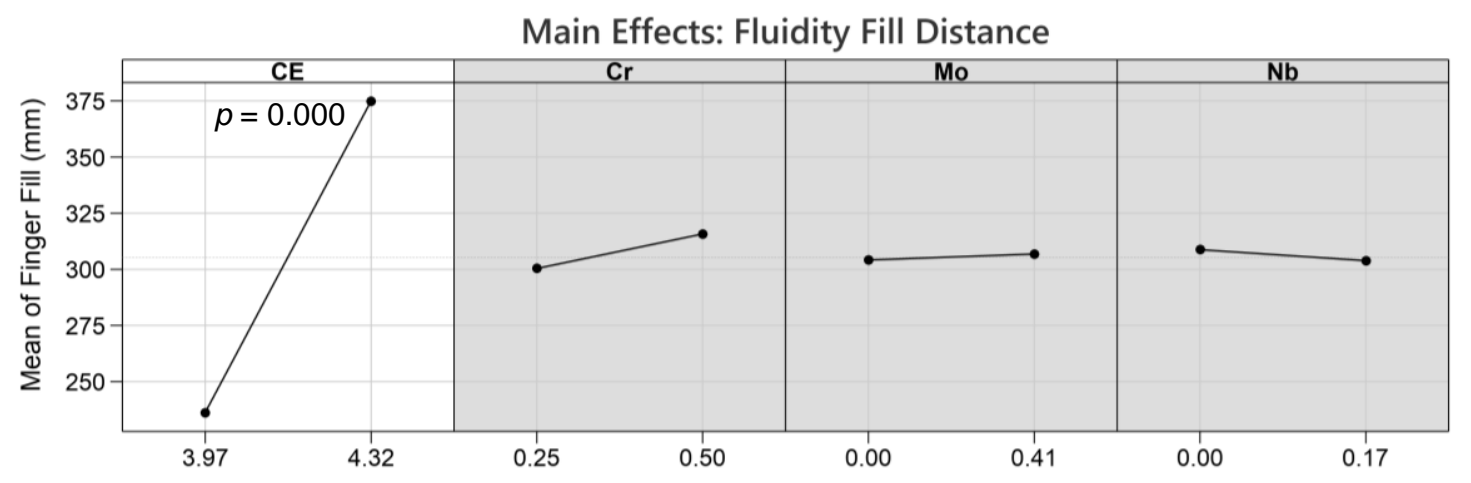

Figure 4.6.1 Main effects for the fluidity as measured using a custom 6-finger fluidity mold. Model $R^{2}=0.86$.

\subsection{Wear Resistance}

Three factors were significant in affecting wear resistance: $\mathrm{Mo}, \mathrm{CE}$, and $\mathrm{Nb}$, with the latter two being most significant (Figure 4.7.1). Increasing CE causes an increase in wear while $\mathrm{Mo}$ and $\mathrm{Nb}$ decrease wear. When considering effects of Mo and $\mathrm{Nb}$ on a weight percent basis, $\mathrm{Nb}$ dominates by being $~ 3.5$ times more potent per wt $\%$ in reducing wear. This is likely due to not only the precipitation of $\mathrm{NbC}$, but also niobium's refining effects on graphite flake morphology and pearlite spacing, as already shown.

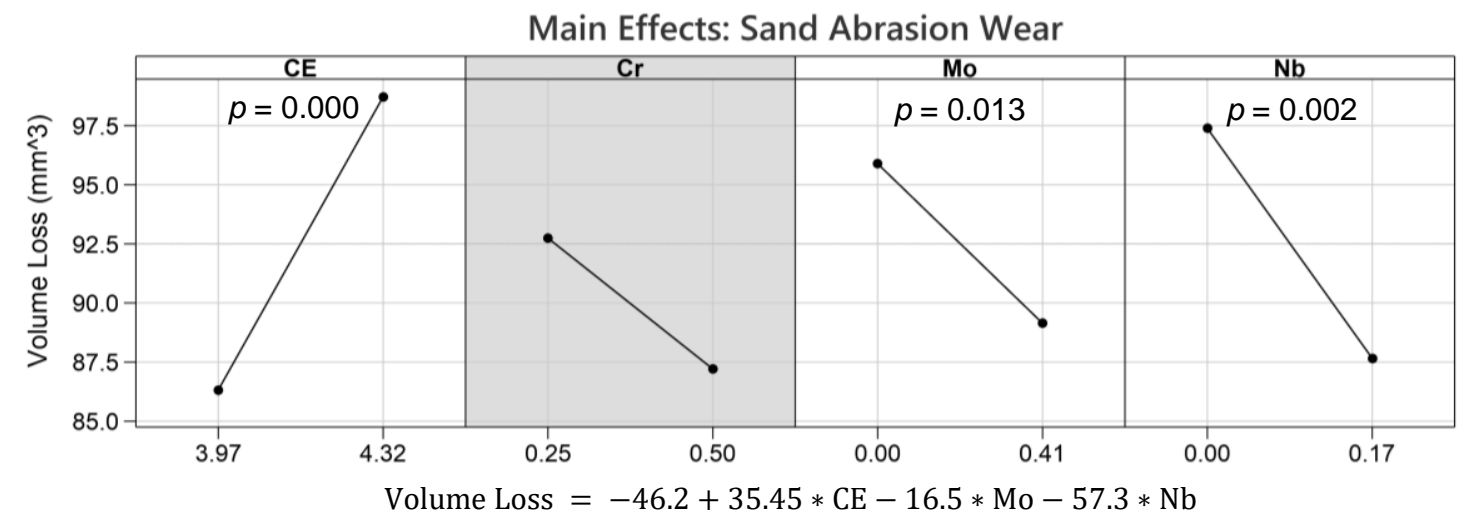

Figure 4.7.1 Main effects plots for amount of wear experienced during sand abrasion wear testing on the $30 \mathrm{~mm}$ bars. Model $R^{2}=0.89$. 


\subsection{Thermal diffusivity}

Increasing alloying additions in the high and low CE alloys tended to decrease thermal diffusivity as more carbides were formed and the graphite flake morphology changed to have more type E graphite (Figure 3.9.2). The main effects plots for thermal diffusivity at $100^{\circ} \mathrm{C}$ show that $\mathrm{CE}$ is statistically significant at increasing thermal diffusivity while $\mathrm{Cr}$, $\mathrm{Mo}$, and $\mathrm{Nb}$ negatively affect it, with $\mathrm{Nb}$ being statistically significant (Figure 3.8.1). Niobium is a significant term likely due to the refining effect is has on flake length (Figure 4.2.1).

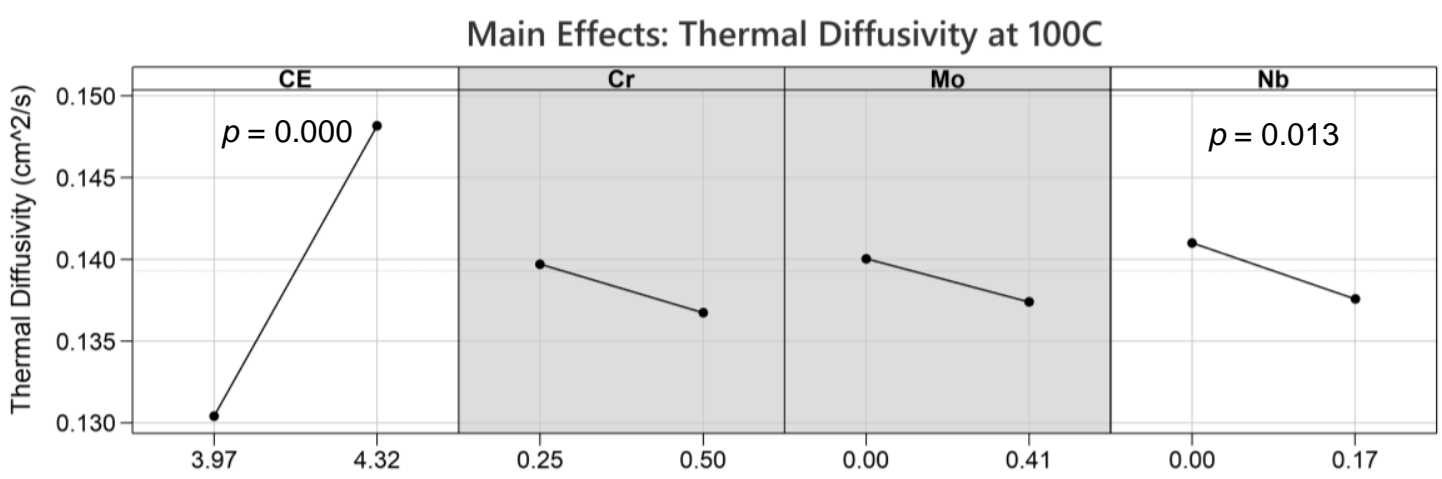

Figure 4.8.1 Main effects plots for thermal diffusivity at $100^{\circ} \mathrm{C}$ for the $30 \mathrm{~mm}$ bar. Model $R^{2}=0.93$. 


\section{Conclusion}

Maintaining good thermal and mechanical properties simultaneously in gray iron is ideal for brake rotor applications but is difficult given the trade-off between these metrics. The data presented here reveal one solution to this problem. By observing the properties between alloy 1 to 2 , and 7 to 8 , simply alloying with a moderate amount of chromium at $0.25 \mathrm{wt} \%$ and moderate amount of niobium, $0.12-0.22 \mathrm{wt} \%$, a large increase can be seen across the board for mechanical properties while only decreasing thermal diffusivity by $\sim 4 \%$. The $0.22 \mathrm{wt} \%$ addition in alloy 8 also resulted in the largest increase in wear resistance by $\sim 17 \%$ over the base alloy 7 . Alloying with additional amounts of $\mathrm{Cr}$ and $\mathrm{Mo}$ do not appear to increase mechanical properties significantly beyond the base-line $\mathrm{Nb}$ additions. Rather, more carbides form, the graphite morphology degrades, and thermal diffusivity decreases further. These findings suggest that $\mathrm{Nb}$, when coupled with a moderate amount of chromium, is effective for high CE gray irons to maintain thermal diffusivity AND mechanical and wear properties.

Chromium, molybdenum, and niobium had no discernable effect on fluidity; rather, CE was the only statistically significant factor. A strong power law correlation was observed between tensile strength and electrical resistivity. Tensile strength for all the gray iron alloys remained constant up to $\sim 380^{\circ} \mathrm{C}$ before dropping at a rate not substantially effected by alloying additions.

The following conclusions highlight specific effects for $\mathrm{Cr}$, $\mathrm{Mo}$, and $\mathrm{Nb}$.

\subsection{Chromium}

Increasing chromium from $0.25-0.55 \mathrm{wt} \%$ was not statistically significant in any of the mechanical or microstructural properties measured. Chromium largely remained in solution and in small concentrations within $\mathrm{NbC}, \mathrm{Mo}_{2} \mathrm{C},(\mathrm{Mo}, \mathrm{Nb}) \mathrm{C}$, and cementite phases.

\subsection{Molybdenum}

Molybdenum tended to form $\mathrm{Mo}_{2} \mathrm{C}$ precipitates when niobium was not present. When alloyed with niobium, $(\mathrm{Mo}, \mathrm{Nb}) \mathrm{C}$ precipitates formed, and molybdenum-rich patches were 
found in cementite regions. Molybdenum was statistically significant in increasing hardness and wear resistance.

\subsection{Niobium}

Niobium refined the pearlite as well as the mean and maximum graphite flake length. When alloyed at 0.12-0.22 wt\%, eutectic X-Y shaped NbC precipitates formed, which, when combined with the refining effects of $\mathrm{Nb}$, likely resulted in the statistically significant increase in wear resistance. Niobium additions also increased tensile strength, Brinell hardness, and elastic modulus. Niobium was twice as effective as molybdenum at increasing mechanical and wear properties in the 3.97 CE alloys and three-times more effective in the $4.32 \mathrm{CE}$ alloys. 


\section{Reference List}

[1] "The World Foundry Organization." https://www.thewfo.com/census/ (accessed Aug. 07, 2021).

[2] R. B. Gundlach, J. F. Janowak, S. Bechet, and K. Rohrigtt, "On the Problems with Carbide Formation in Gray Cast Iron," MRS Online Proc. Libr. OPL, vol. 34, ed 1984, doi: 10.1557/PROC-34-251.

[3] P. G. Sanders, T. M. Dalka, and R. H. Basch, "A reduced-scale brake dynamometer for friction characterization,” Tribol. Int., vol. 34, no. 9, pp. 609-615, Sep. 2001, doi: 10.1016/S0301-679X(01)00053-6.

[4] Y. Jimbo, T. Mibe, K. Akiyama, H. Matsui, M. Yoshida, and A. Ozawa, "Development of High Thermal Conductivity Cast Iron for Brake Disk Rotors," SAE International, Warrendale, PA, SAE Technical Paper 900002, Feb. 1990. doi: $10.4271 / 900002$.

[5] "Heat checked rotors," EvolutionM - Mitsubishi Lancer and Lancer Evolution Community. https://www.evolutionm.net/forums/motor-sports/424969-heat-checkedrotors.html (accessed Aug. 12, 2021).

[6] Sining Pan, Fanzheng Zeng, Nanguang Su, and Zhaokun Xian, "The effect of niobium addition on the microstructure and properties of cast iron used in cylinder head," J. Mater. Res. Technol., vol. 9, no. 2.

[7] Mohrbacher and Zhai, "Niobium alloying in grey cast iron for vehicle brake discs: Materials Science and Technology (MS\&T)," Process. Microstruct. Prop. Cast Iron Cast Forged Spec. Steels, 2011.

[8] J. Porkert and W. Lotz, "Optimized gray cast iron plate alloy for utility vehicle brake disks," US5894010A, Apr. 13, 1999 Accessed: Aug. 10, 2021. [Online]. Available: https://patents.google.com/patent/US5894010A/en

[9] Z. Wenbin, Z. Hongbo, Z. dengke, Z. Hongxing, H. Qin, and Z. Qijie, "Niobium alloying effect in high carbon equivalent grey cast iron," China Foundry, vol. 8, pp. 36-40, Feb. 2011.

[10] I. Hanna, Mechanical Properties of Niobium Alloyed Gray Iron. 2011. Accessed: Sep. 21, 2020. [Online]. Available: http://urn.kb.se/resolve?urn=urn:nbn:se:kth:diva39691

[11] Gilberto Leal, M. Enloe, M. Meira, and E. Franca, "Wear Evaluation of NiobiumAdded Cast Iron for Brake Disc and Drum Applications," SAE Tech. Pap. 2020-011627, 2020, doi: 10.4271/2020-01-1627.

[12] X.-R. Chen, Q.-J. Zhai, H. Dong, B.-H. Dai, and H. Mohrbacher, "Molybdenum alloying in cast iron and steel," Adv. Manuf., vol. 8, no. 1, pp. 3-14, Mar. 2020, doi: 10.1007/s40436-019-00282-1.

[13] "Constituent Elements in Steel and Cast Iron," Lond. Scand. Metall. Co. Ltd., 1961.

[14] Massalski, "Binary Alloy Phase Diagrams, 2nd edn." ASM International, 1996.

[15] J. Zhou, "Colour Metallography of Cast Iron," China Foundry, vol. 8, pp. 239246, May 2011.

[16] S. A. Brauer et al., "Strain Rate and Stress-State Dependence of Gray Cast Iron," J. Eng. Mater. Technol., vol. 139, no. 2, p. 021013, Apr. 2017, doi:

10.1115/1.4035616. 
[17] M. Song, Y. He, and S. Fang, "Effects of $\mathrm{Zr}$ content on the yield strength of an Al-Sc alloy," J. Mater. Eng. Perform., vol. 20, no. 3, pp. 377-381, Apr. 2011.

[18] A04 Committee, "Test Method for Evaluating the Microstructure of Graphite in Iron Castings," ASTM International. doi: 10.1520/A0247-19.

[19] Doru M. Stefanescu, "Properties and Selection: Irons, Steels, and HighPerformance Alloys," ASM Int., Jan. 1990, Accessed: Jul. 08, 2021. [Online]. Available: https://dl.asminternational.org/handbooks/book/16/chapter/244816/CastIrons

[20] P. Skoglund, J. Elfsberg, N. Ipek, L. Diaconu, M. Larsson, and P. Schmidt, "Thermo-Mechanical Fatigue of Grey Cast Iron for Cylinder Heads - Effect of Niobium, Molybdenum and Solidification Time," Mater. Sci. Forum, vol. 925, pp. 377-384, Jun. 2018, doi: 10.4028/www.scientific.net/MSF.925.377.

[21] R. Gundlach, "ELEVATED-TEMPERATURE PROPERTIES OF ALLOYED GRAY IRONS FOR DIESEL ENGINE COMPONENTS,” 1979, Accessed: Aug. 10, 2021. [Online]. Available: http://pascalfrancis.inist.fr/vibad/index.php?action=getRecordDetail\&idt=PASCAL8300184150

[22] R. L. Hecht, R. B. Dinwiddie, W. D. Porter, and H. Wang, "Thermal Transport Properties of Grey Cast Irons," SAE International, Warrendale, PA, SAE Technical Paper 962126, Oct. 1996. doi: 10.4271/962126.

[23] D. Holmgren, "Review of thermal conductivity of cast iron," Int. J. Cast Met. Res., vol. 18, pp. 331-345, Dec. 2005, doi: 10.1179/136404605225023153.

[24] D. Holmgren and I. L. Svensson, "Thermal conductivity-structure relationships in grey cast iron," Int. J. Cast Met. Res., vol. 18, no. 6, pp. 321-330, Dec. 2005, doi: 10.1179/136404605225023162.

[25] H. T. Angus, Cast Iron: Physical and Engineering Properties. Elsevier, 2013.

[26] J. Helsing and Grimvall, G, Appl. Phys., vol. 70. 1991.

[27] G. Cueva, A. Sinatora, W. L. Guesser, and A. P. Tschiptschin, "Wear resistance of cast irons used in brake disc rotors," Wear, vol. 255, no. 7-12, pp. 1256-1260.

[28] P. W. Leach and D. W. Borland, "The process of severe wear of graphitic cast iron,” Mater. Sci. Eng., vol. 66, no. 2, pp. 167-177, Sep. 1984, doi: 10.1016/00255416(84)90178-2.

[29] S. Slamet, Suyitno, and I. Kusumaningtyas, "Effect of composition and pouring temperature of $\mathrm{Cu}(20-24) \mathrm{wt} . \% \mathrm{Sn}$ by sand casting on fluidity and mechanical properties," pp. 6022-6035, Dec. 2019, doi: 10.15282/jmes.13.4.2019.20.0476.

[30] G. Hızl, M. Salkır, İ. Kalkan, and D. Dispinar, Influence of Melt Quality on the Fluidity of AlSi12Fe. 2018. doi: 10.1007/978-3-030-06034-3_37.

[31] A. Heidarzadeh, M. Emamy, A. Rahimzadeh, R. Soufi, D. S. B. Heidary, and S. Nasibi, "The Effect of Copper Addition on the Fluidity and Viscosity of an Al-Mg-Si Alloy," J. Mater. Eng. Perform., vol. 23, no. 2, pp. 469-476, Feb. 2014, doi: 10.1007/s11665-013-0794-6.

[32] R. G. Huff, A Thermocouple Technique for Measuring Hot-gas-side Wall Temperatures in Rocket Engines. National Aeronautics and Space Administration, 1969.

[33] "ITS-90 Thermocouple Database, Download Files." https://srdata.nist.gov/its90/download/download.html (accessed Jul. 29, 2021). 
[34] D. Bradley and G. Roth, "Adaptive Thresholding using the Integral Image," $J$. Graph. Tools, vol. 12, no. 2, pp. 13-21, Jan. 2007, doi: 10.1080/2151237X.2007.10129236.

[35] ASTM Standard E8, Standard Test Methods for Tension Testing of Metallic Materials. West Conshohocken, PA, 2001: ASM International.

[36] C.-H. Hsu, S.-C. Lee, L. Wang, and X. Dong, "The high strain-rate fracture behaviors of gray iron under compressive loading," Mater. Chem. Phys., vol. 73, no. 2, pp. 174-178, Jan. 2002, doi: 10.1016/S0254-0584(01)00371-6.

[37] G02 Committee, "Test Method for Measuring Abrasion Using the Dry Sand/Rubber Wheel Apparatus," ASTM International. doi: 10.1520/G0065-16E01. [38] E37 Committee, "Test Method for Thermal Diffusivity by the Flash Method," ASTM International. doi: 10.1520/E1461-13.

[39] G. F. Vander Voort and A. Roósz, "Measurement of the interlamellar spacing of pearlite," Metallography, vol. 17, no. 1, pp. 1-17, Feb. 1984, doi: 10.1016/00260800(84)90002-8.

[40] F. M. Smits, "Measurement of Sheet Resistivities with the Four-Point Probe," Bell Syst. Tech. J., vol. 37, no. 3, pp. 711-718, 1958, doi: 10.1002/j.15387305.1958.tb03883.x.

[41] H. Muhmond and H. Fredriksson, "Relationship Between Inoculants and the Morphologies of MnS and Graphite in Gray Cast Iron," Metall. Mater. Trans. B, vol. 44, pp. 283-298, Apr. 2013, doi: 10.1007/s11663-012-9768-6.

[42] M. Bieroński, O. Krasa, M. Koza, D. Ksiąźek, and R. Kuś, "Evaluation of the Mechanical Properties of Gray Cast Iron Using Electrical Resistivity Measurement," Arch. Foundry Eng., vol. 16, no. 4, pp. 29-32, Dec. 2016, doi: 10.1515/afe-20160078. 


\section{Appendices}

\subsection{Appendix A: Charge Chemistries}

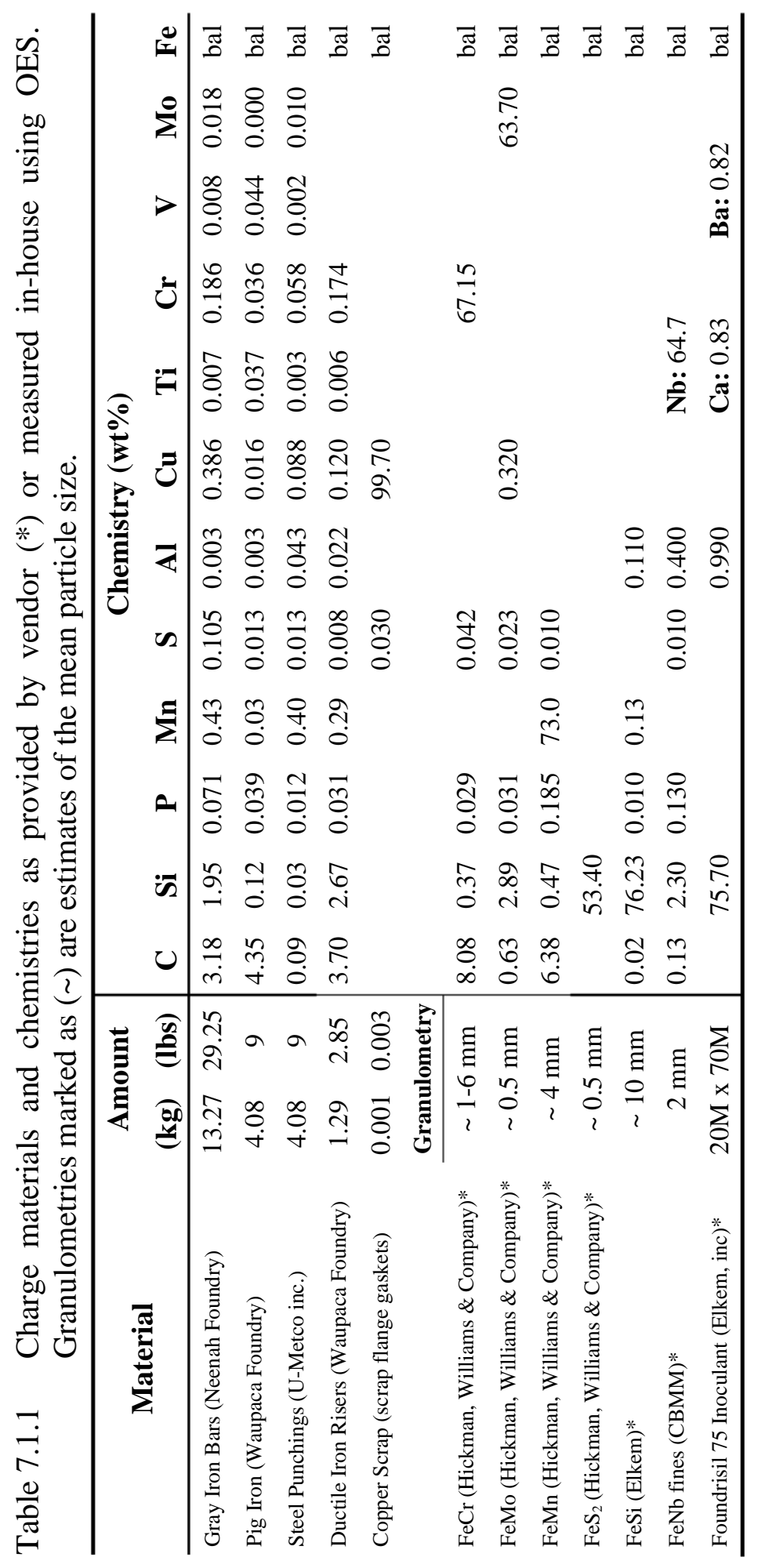




\subsection{Appendix B: Cooling Curves}

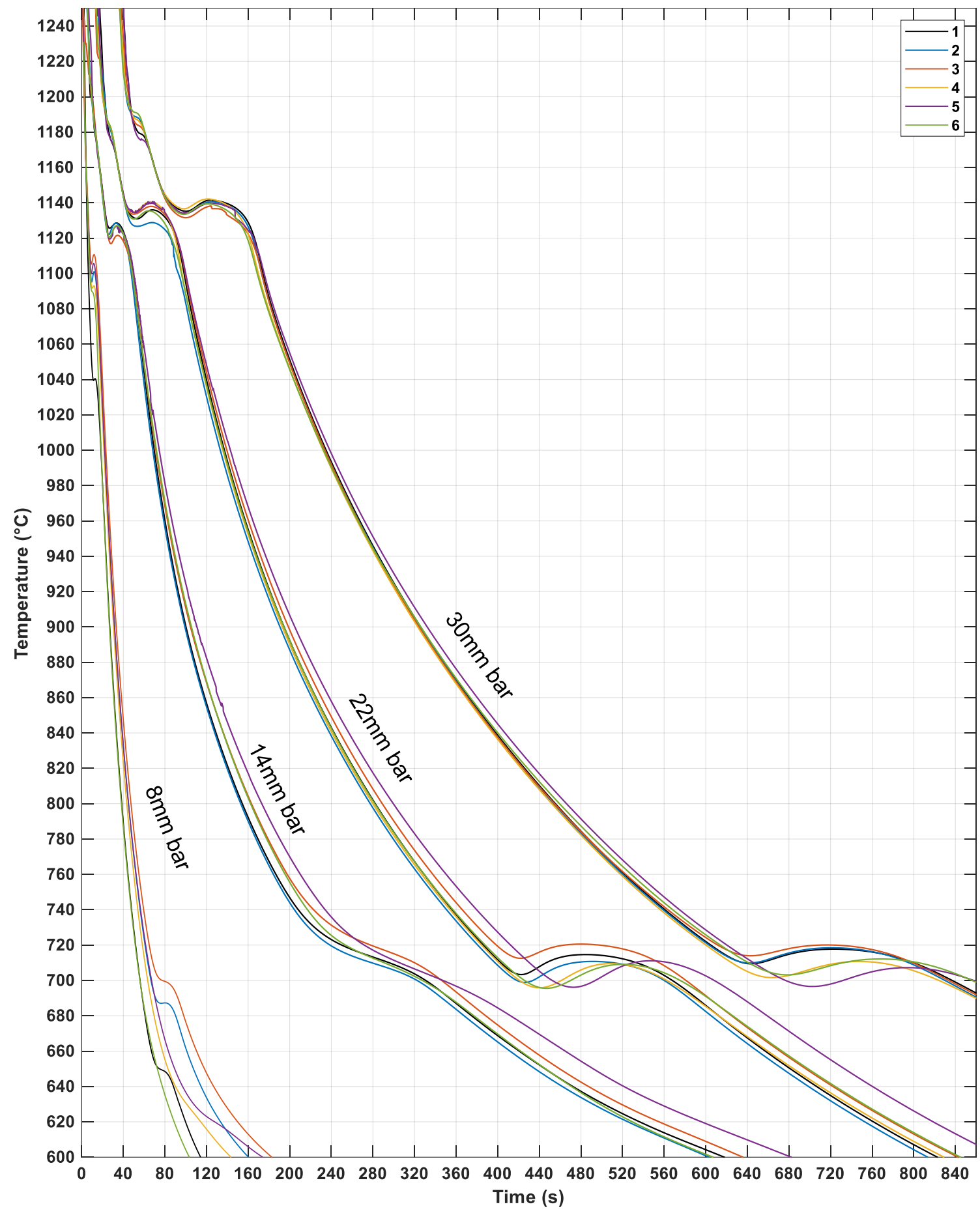

Figure 7.2.1 Cooling curves for the low CE alloys. The time origin for the different section sizes has been offset to observe the eutectic. 


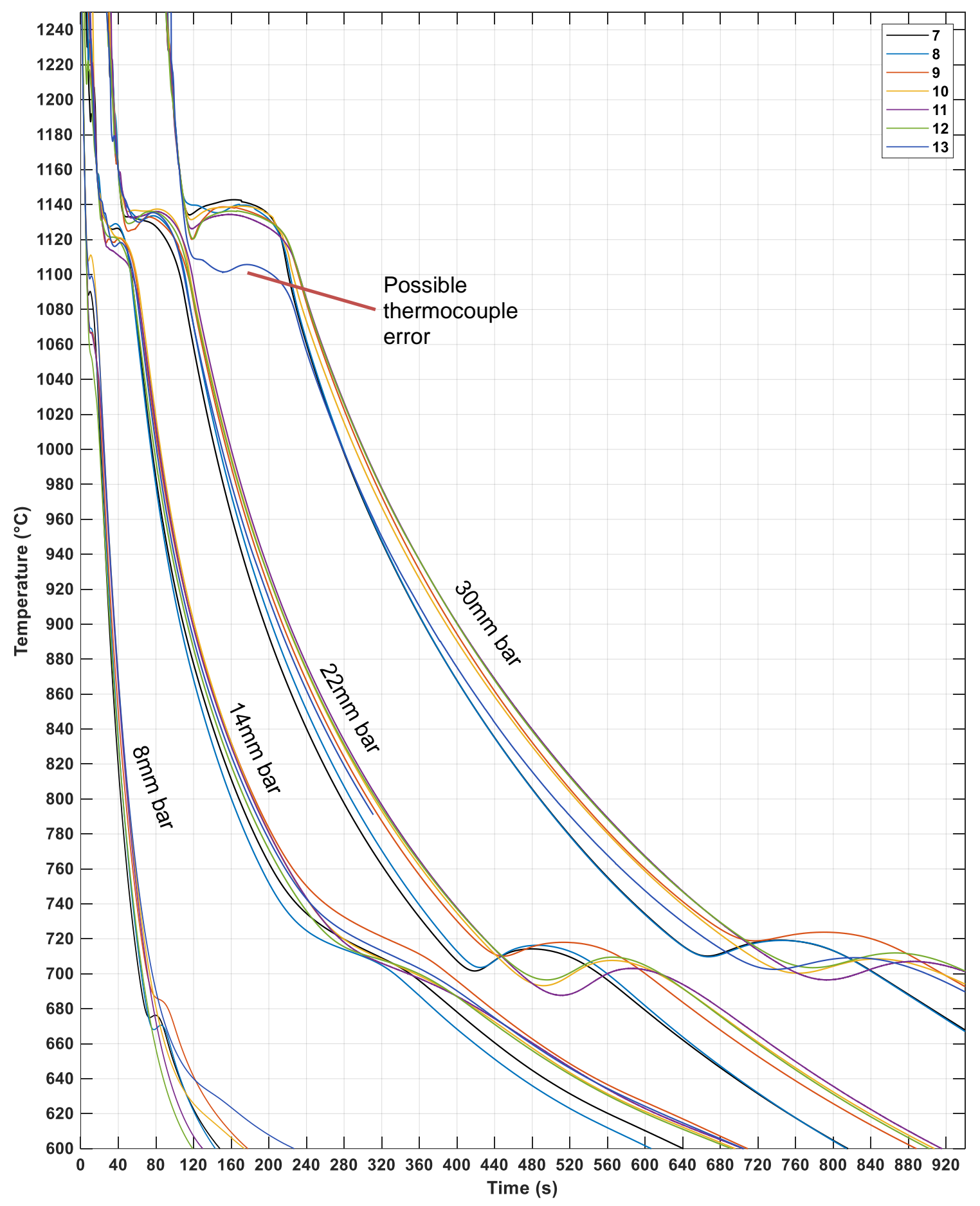

Figure 7.2.2 Cooling curves for the high CE alloys. The time origin for the different section sizes has been offset to observe the eutectic. 


\subsection{Appendix C: Micrographs}

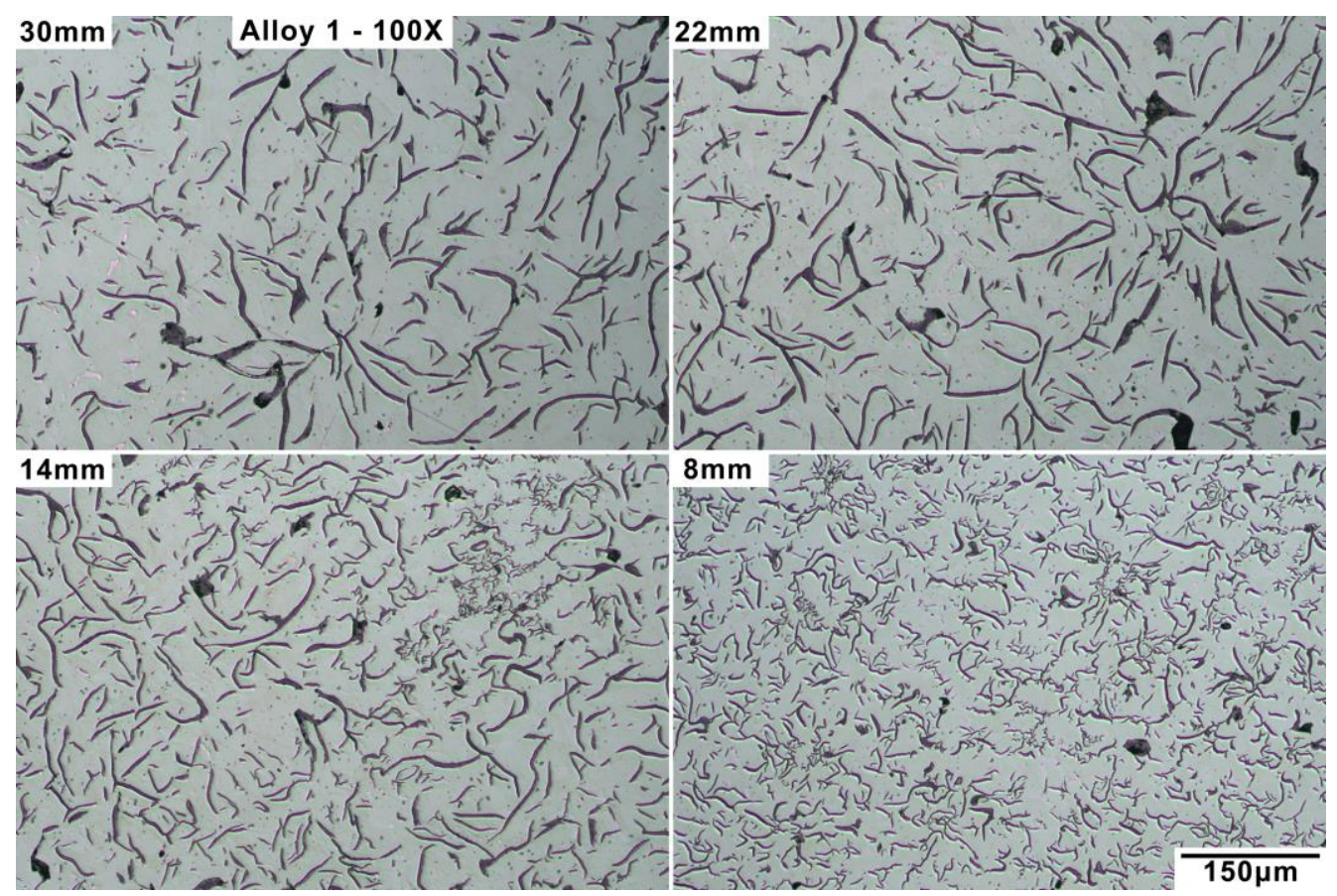

Figure 7.3.1 Representative micrographs of the different section sizes for alloy 1.

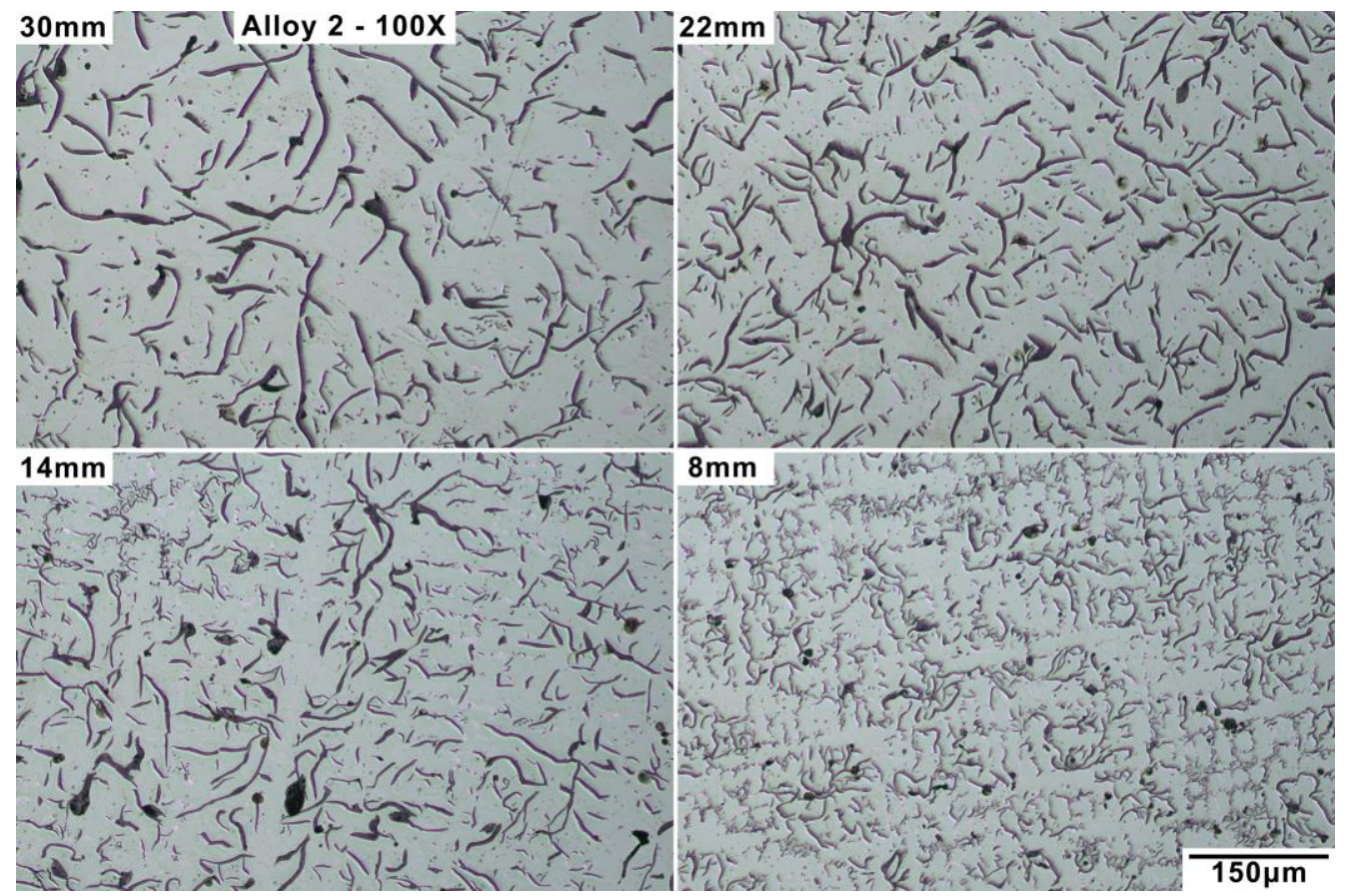

Figure 7.3.2 Representative micrographs of the different section sizes for alloy 2. 


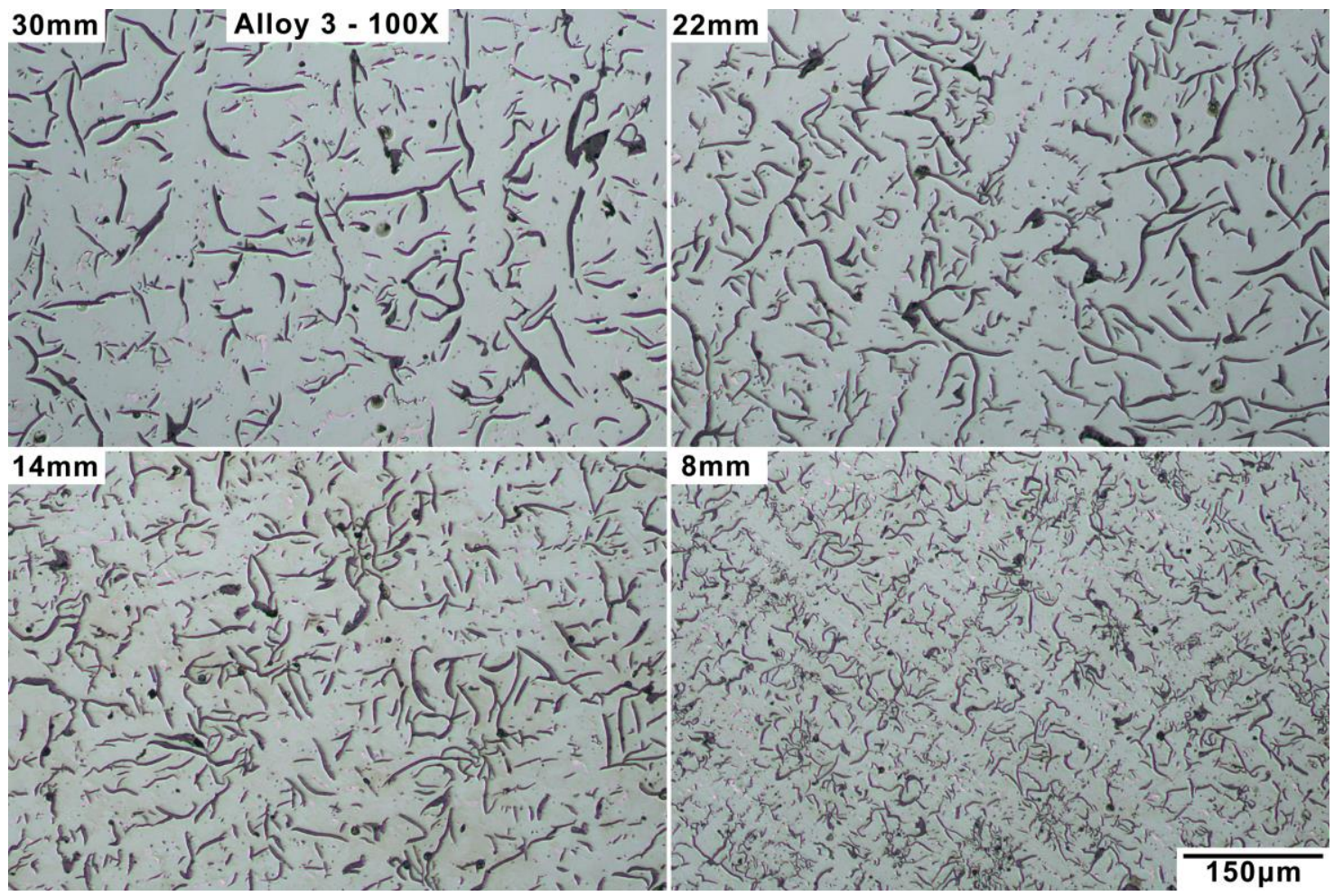

Figure 7.3.3 Representative micrographs of the different section sizes for alloy 3 .

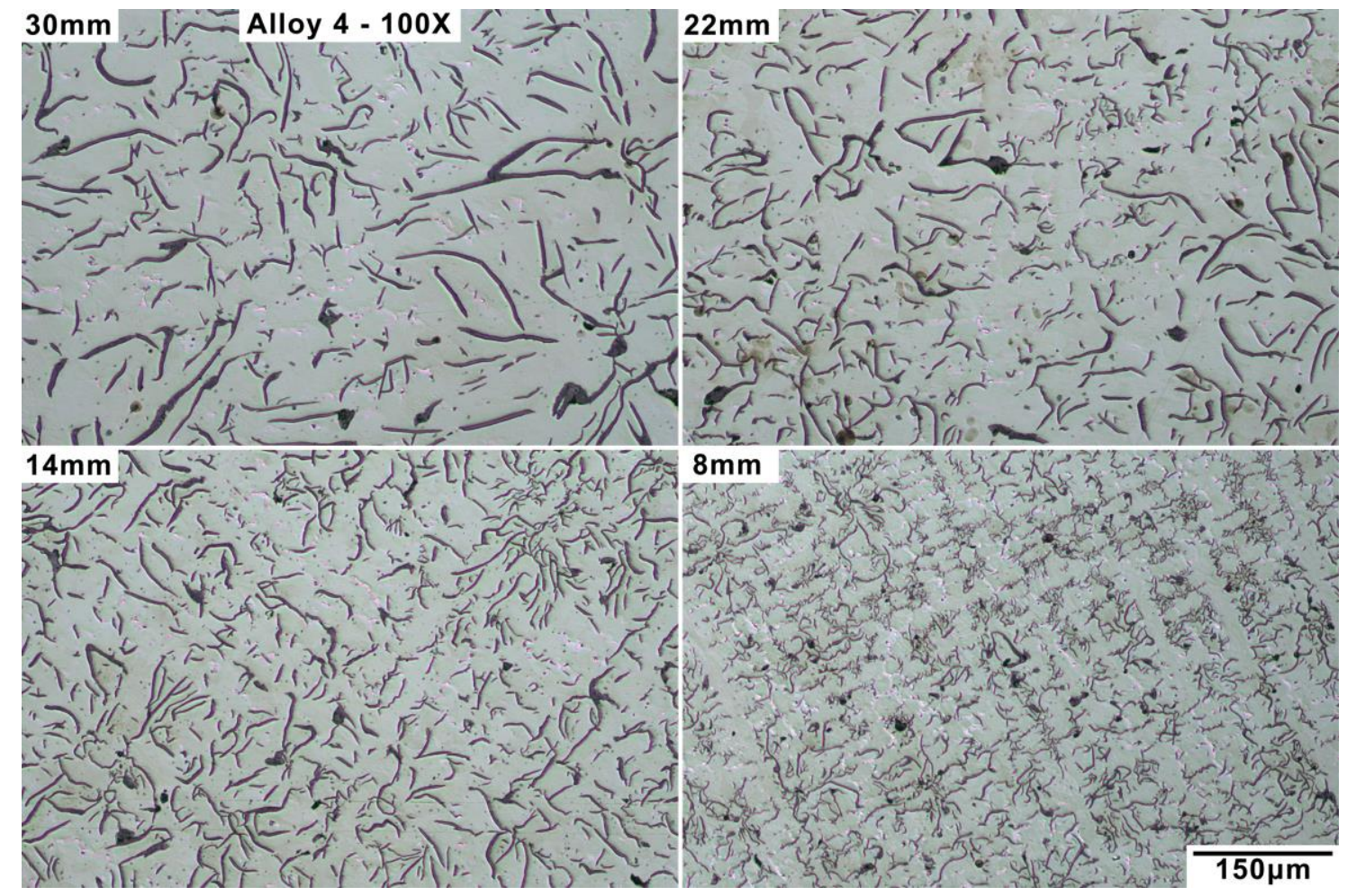

Figure 7.3.4 Representative micrographs of the different section sizes for alloy 4. 


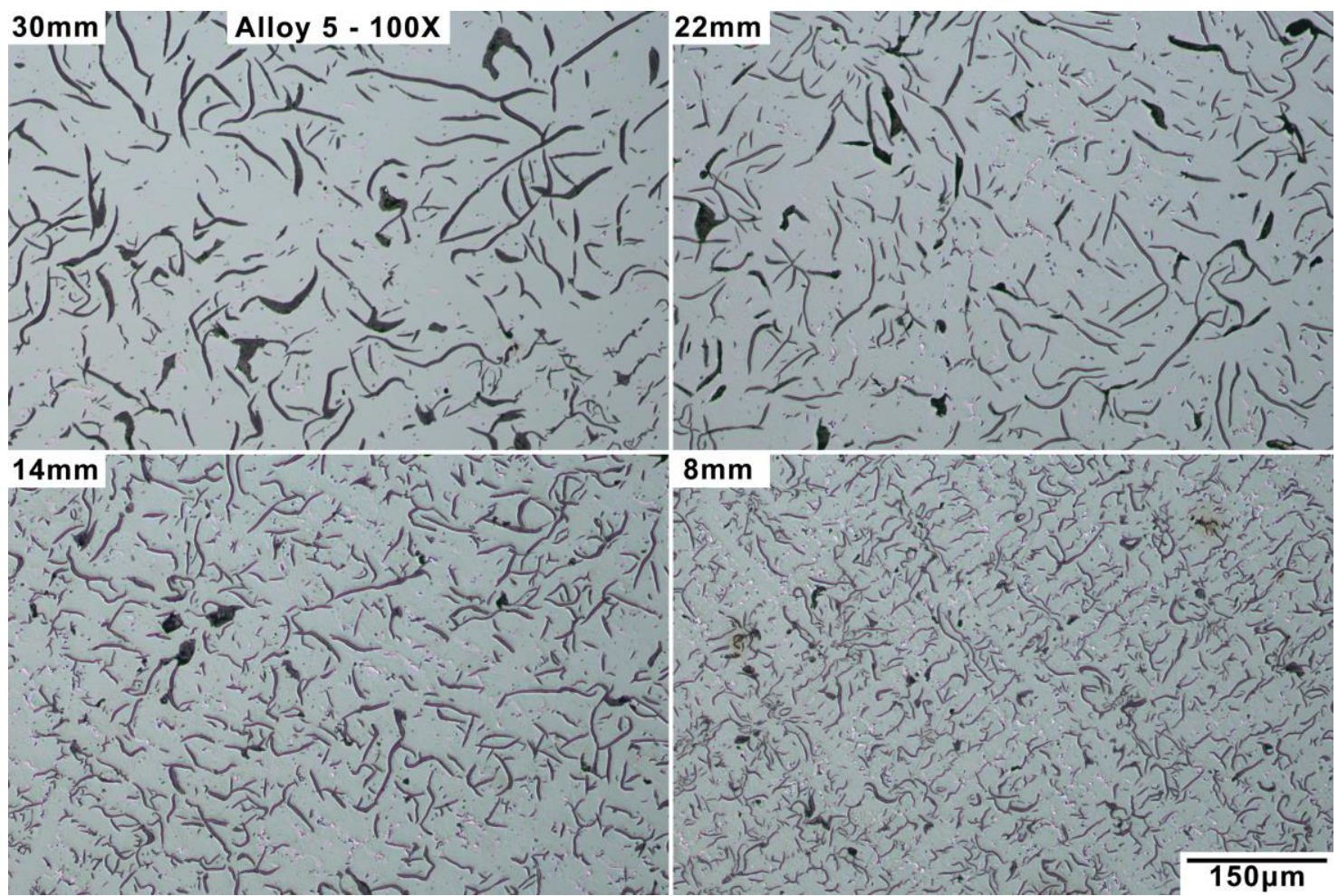

Figure 7.3.5 Representative micrographs of the different section sizes for alloy 5.

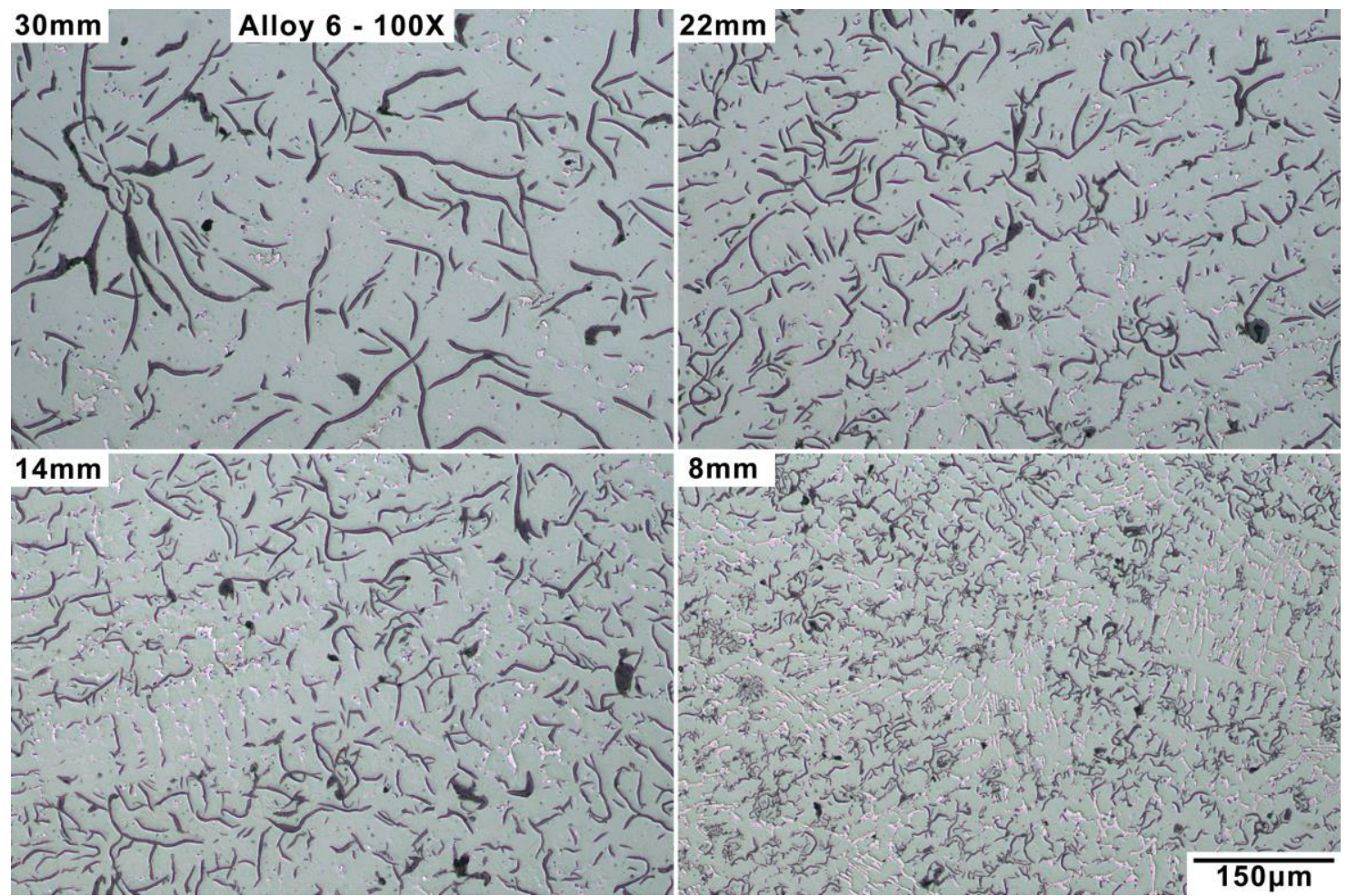

Figure 7.3.6 Representative micrographs of the different section sizes for alloy 6. 


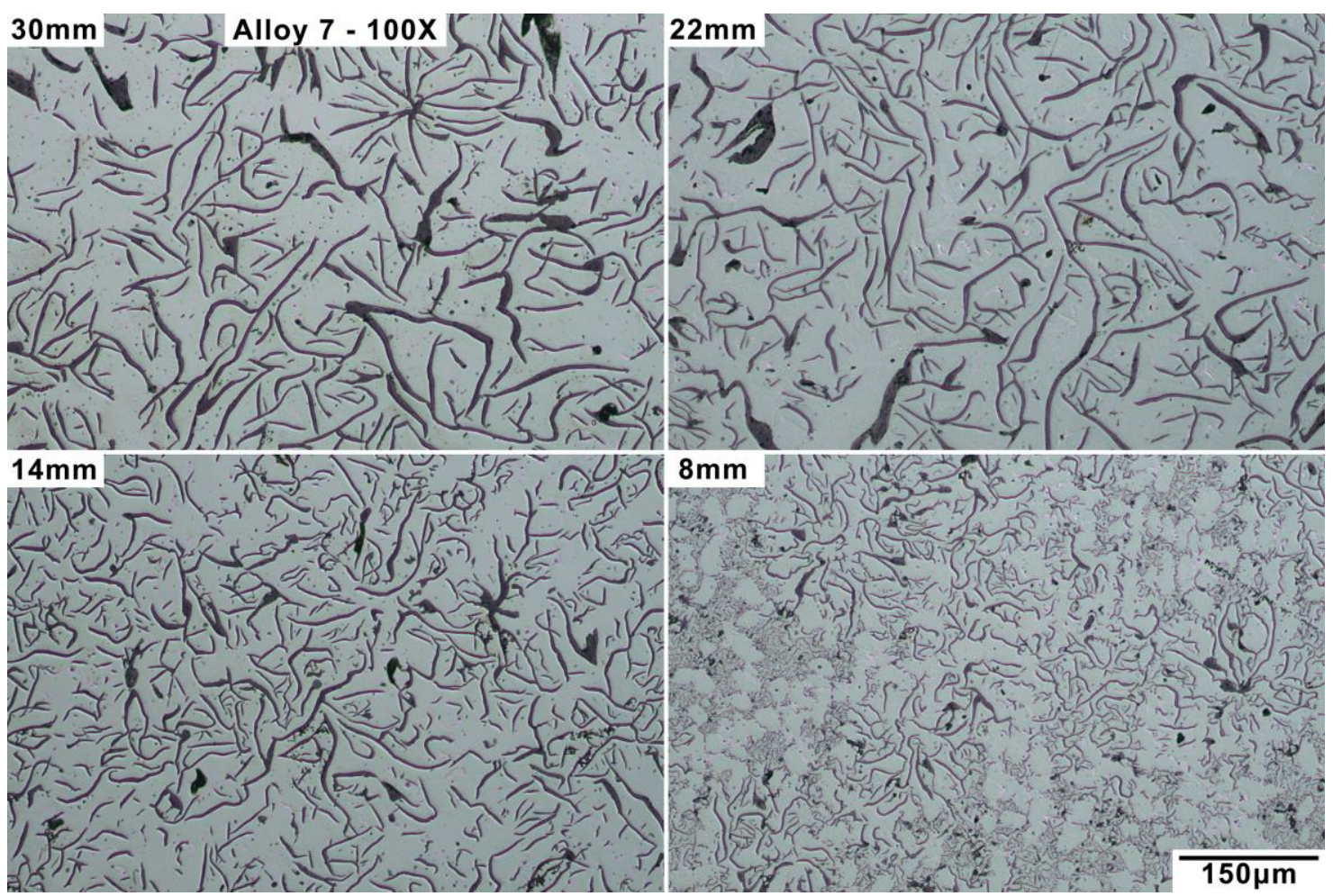

Figure 7.3.7 Representative micrographs of the different section sizes for alloy 7.

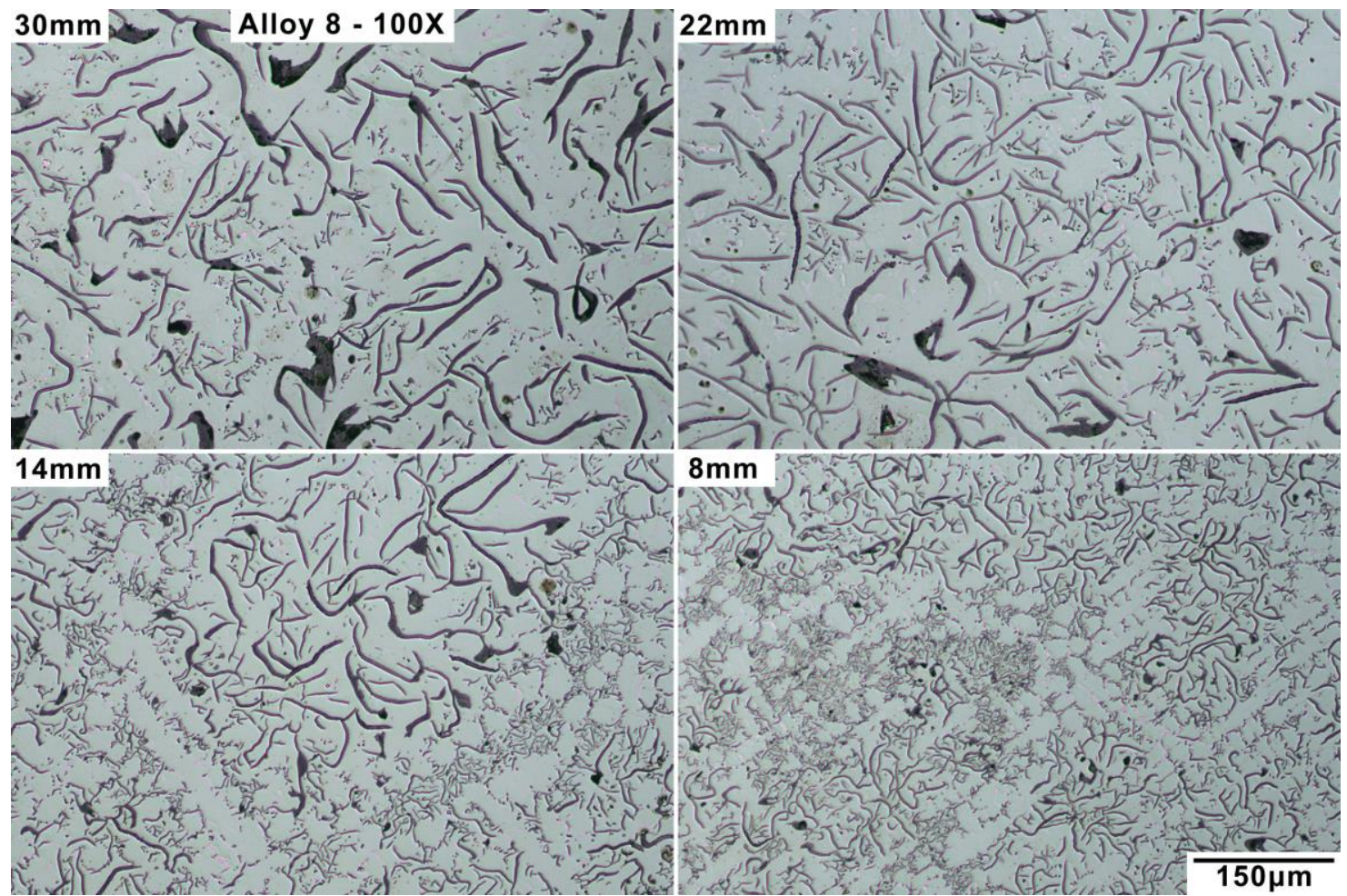

Figure 7.3.8 Representative micrographs of the different section sizes for alloy 8. 


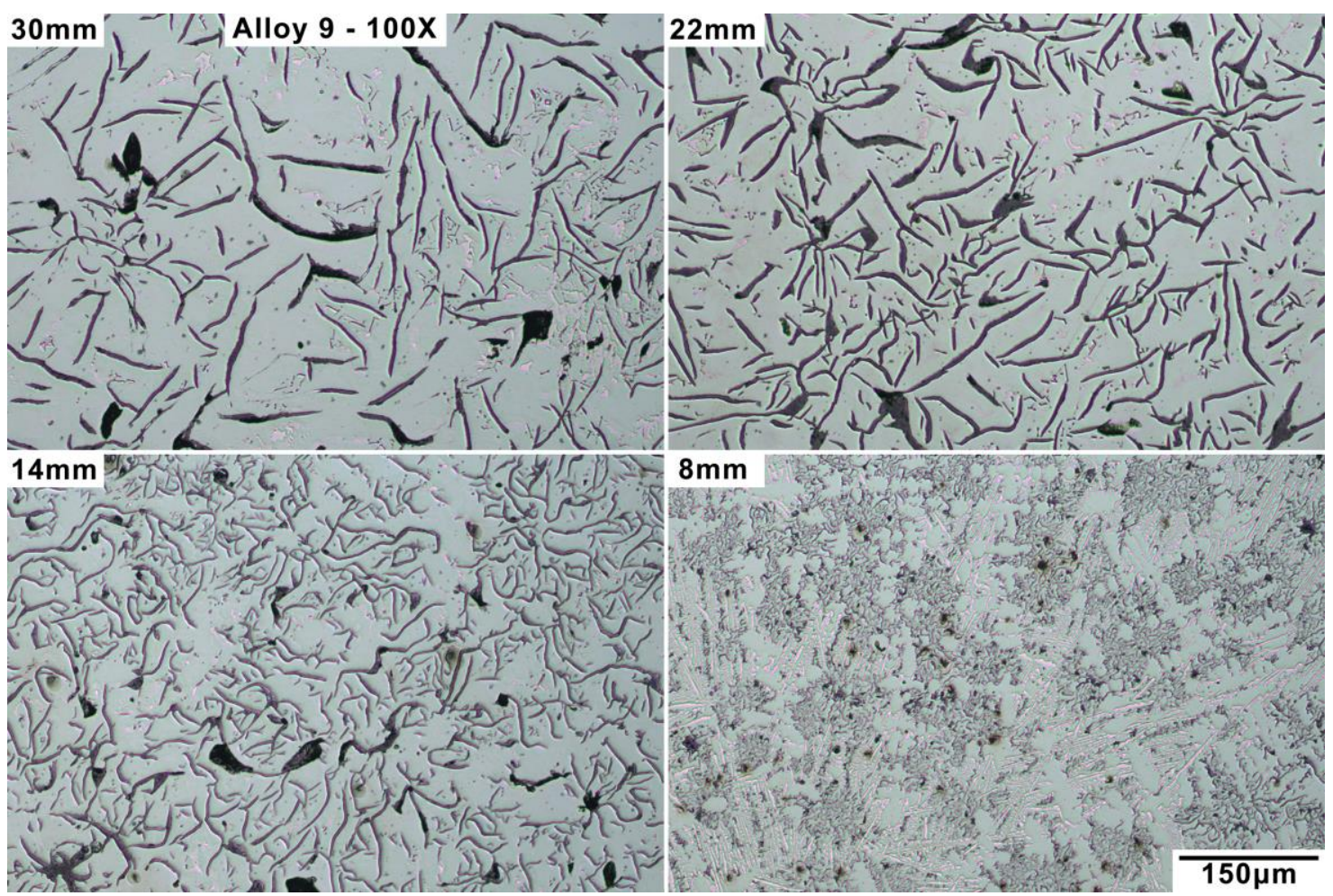

Figure 7.3.9 Representative micrographs of the different section sizes for alloy 9.

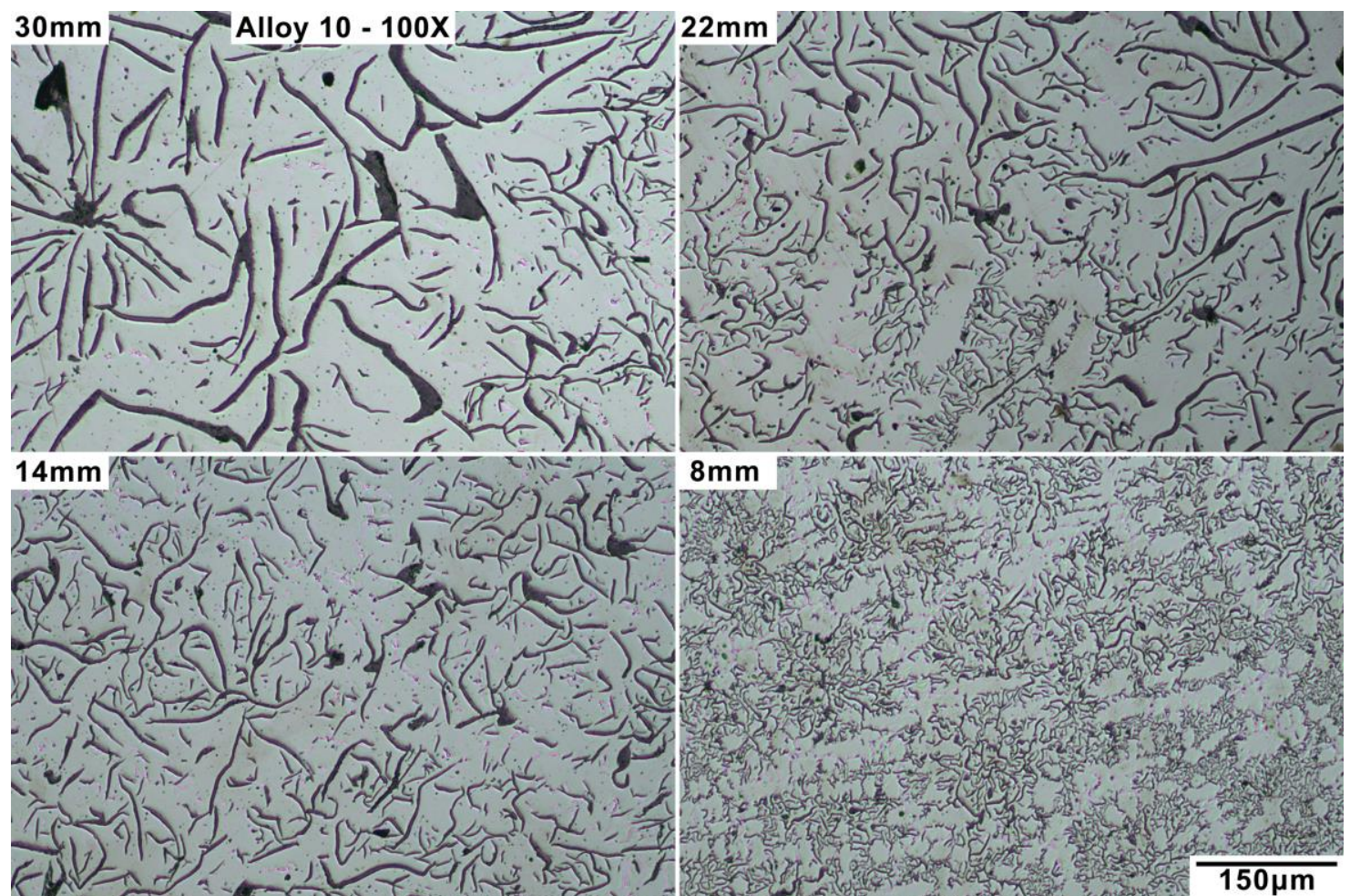

Figure 7.3.10 Representative micrographs of the different section sizes for alloy 10. 


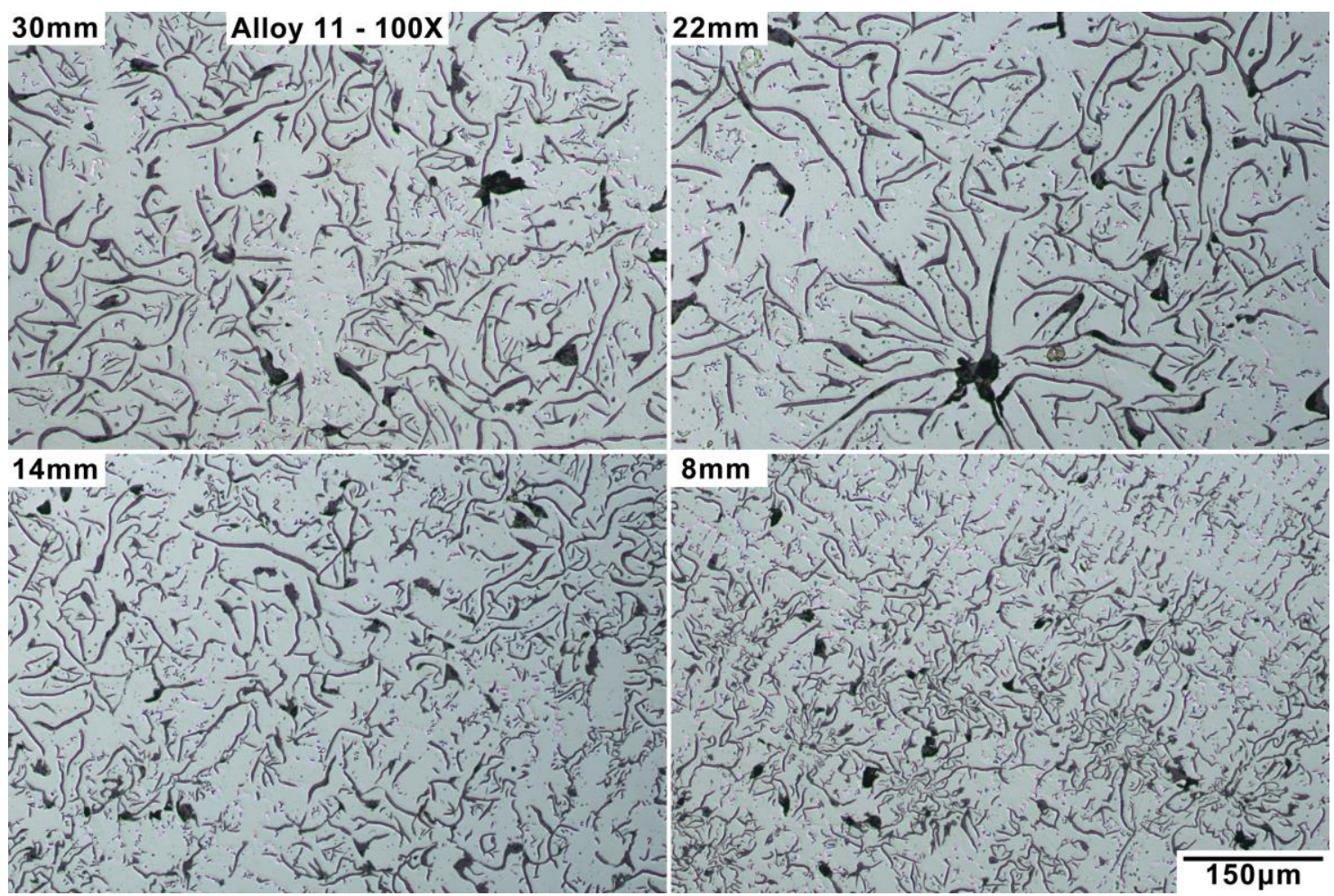

Figure 7.3.11 Representative micrographs of the different section sizes for alloy 11.

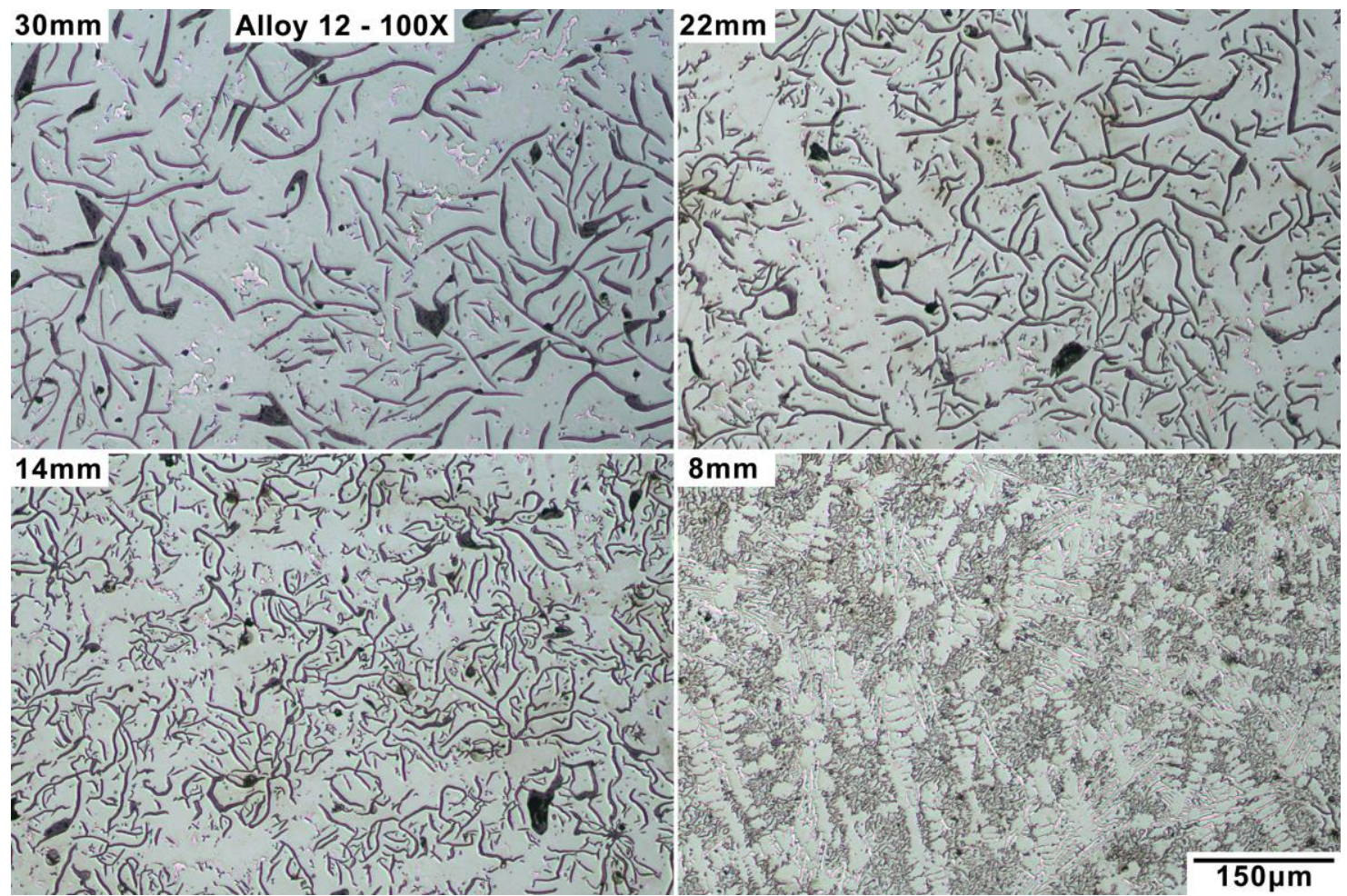

Figure 7.3.12 Representative micrographs of the different section sizes for alloy 12. 


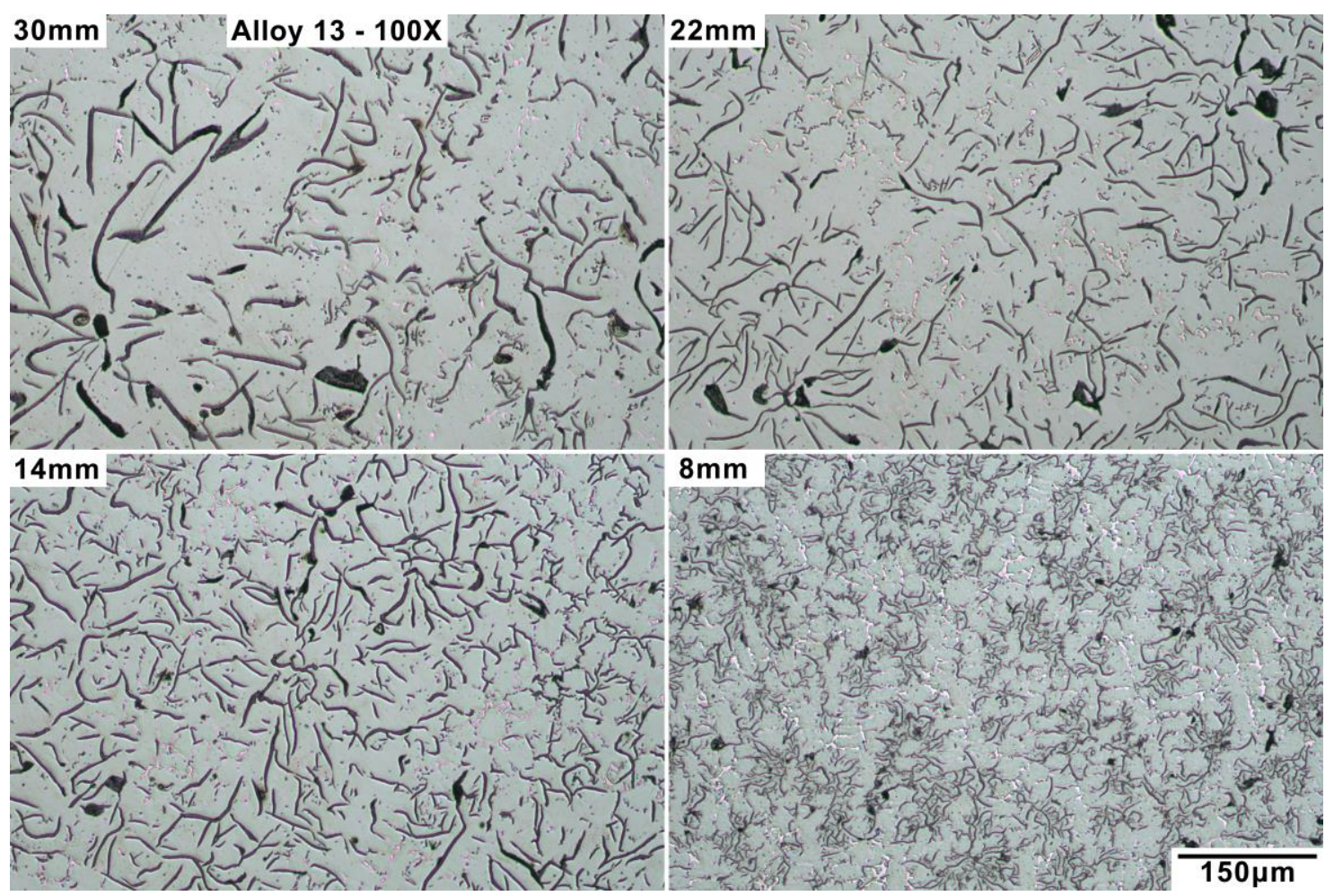

Figure 7.3.13 Representative micrographs of the different section sizes for alloy 13. 


\subsection{Appendix D: High Temperature Tensile Strength}

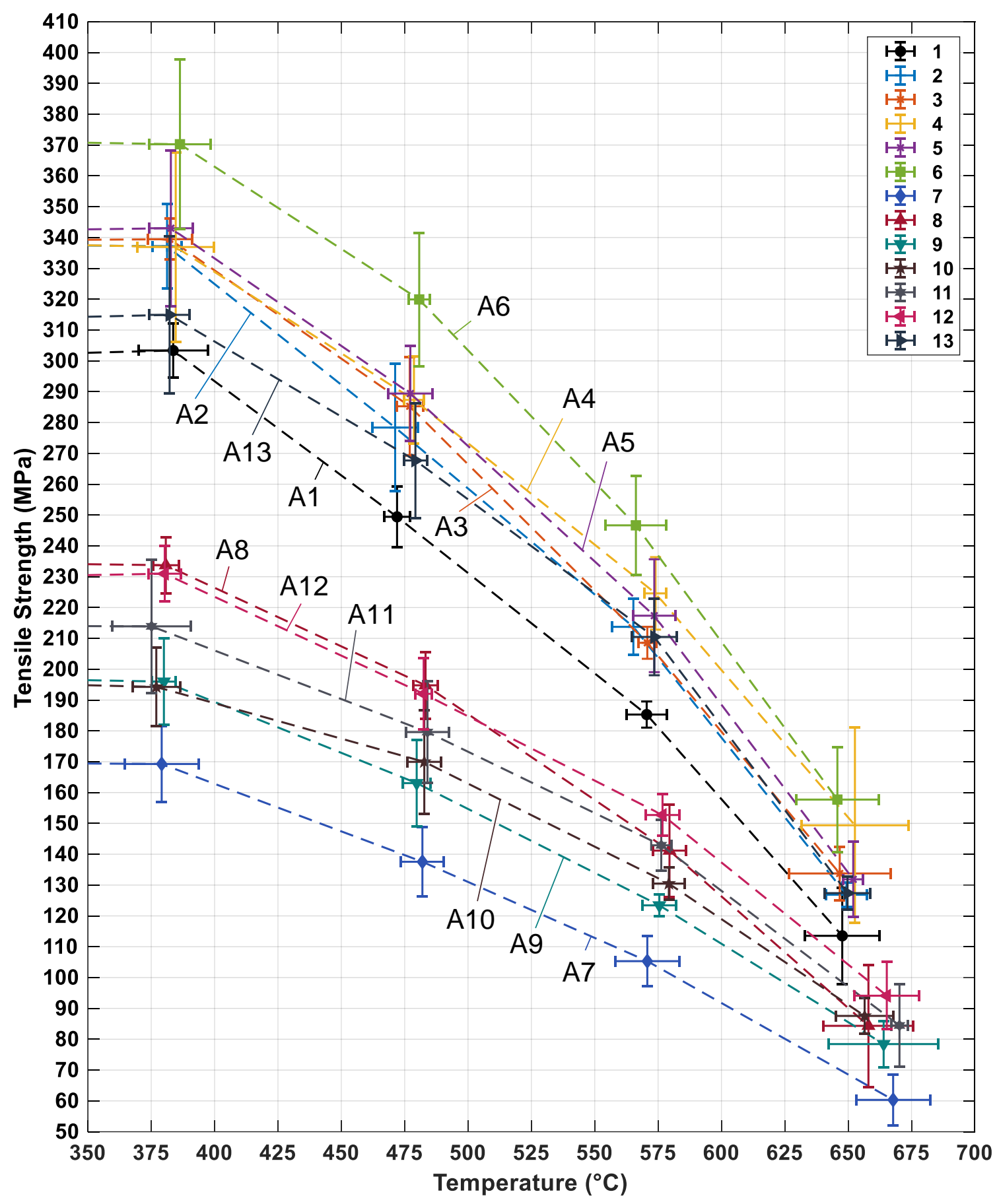

Figure 7.4.1 High temperature ultimate tensile strength for all alloys measured using 0.5 in standard tensile rounds. Error bars represent $95 \%$ standard error from four measurements per datapoint. 